“THEATRE OF SOUND”- A MUSICAL CHALLENGE A. BAKSHI

Putecheva O.A.

Biological sciences

BIOLOGICAL PRODUCTIVITY OF STEPPE PHYTOCENOSES PRICELESSLY THE LOWLANDS OF DAGESTAN

Gadzhimusieva N.T., Asvarova T.A.

\title{
Geographic sciences
}

MUD VOLCANOES OF THE WORLD: CLASSIFICATIONS, ACTIVITIES AND ENVIRONMENTAL HAZARD (INFORMATIONAL-ANALYTICAL REVIEW)

Baloglanov E.E., Abbasov O.R., Akhundov R.V.

\section{Medical sciences}

MORPHOMETRIC PARAMETERS OF THE FACE IN PATIENTS WITH DECOMPENSATED VERTICAL-ANTERIOR FORM OF INCREASED ABRASION OF TEETH

\section{Pedagogical sciences}

IMPROVING THE QUALITY OF THE EDUCATIONAL PROCESS AND NETWORKING

Ivanko A.F., Ivanko M.A., Vinokur A.I., Kulikova E.V.

VALUE CONTEXT OF UPBRINGING AND DEVELOPMENT PROGRAM CONTENT FOR PRESCHOOL-AGE CHILDREN

Yakovlev S.

\section{Philosophy}

LITERAL WORLD PICTURE IN PARADIGM OF SYSTEMATICAL SYNERGETIC APPROACH

Dautova S.B., Ospanova B.R.

\section{Psychological sciences}

UPBRINGING AND EDUCATION: HISTORICAL AND PSYCHOLOGICAL ASPECT

Belova T.A., Britskaya A.L.

\section{Sociology}

CLUSTER APPROACH TO THE FORMATION OF CORPORATE CULTURE OF THE UNIVERSITY

Bondarenko V.P., Ponomarenko E.V., Kozybaev E.Sh, Parmankulova P.Zh

DYNAMICS OF CHANGES IN THE CONFESSIONAL CONSCIOUSNESS

OF THE STUDENTS IN THE CONDITIONS OF EXPERIMENT

Naumenko O.N., Naumenko E.A. 
Technical sciences

WETTABILITY OF SOLID NICKEL BY MELTED CHLORIDES OF ALKALINE AND ALKALINEARTH METALS AND THEIR INTERFACIAL CHARACTERISTICS

Dokhov M.P.

COMPARATIVE ANALYSIS OF DEVELOPING SYSTEM AND FINITE AUTOMAT MODELS

Girlin S.K., Ferenchuk I.I.

MULTIFUNCTIONAL MEMORY CIRCUITS OF MARAKHOVSKY

Marakhovsky L.F.

MULTICRITERIA OPTIMIZATION AND SIMULATION FOR THE DESIGN OF MACHINES

Matusov L.B. 


\title{
“THEATRE OF SOUND" - A MUSICAL CHALLENGE A. BAKSHI
}

Putecheva O.A.

\author{
Kuban state medical university, Krasnodar, e-mail: putecheva.olga@mail.ru
}

The article is devoted to a unique creative model, the so-called "Theater of sound", formed in the work of the Moscow composer A. Bakshi, reflecting not only the author's worldview, but also the direction of the development of musical art of the early XX1 century in Russia. "Theater of sound" represents a decisive transformation of musical material, which incorporates a variety of artistic discoveries in the field of literature, theater, choreography at the intersection and interaction of various trends. This phenomenon is harmoniously integrated into the mainstream of the creative aspirations of the Western masters. The philosophical aspect of the" Theater of sound " is the modeling of a new sound reality and a new sound matter, organically connecting electronic sounds, natural, prepared. The new sound space is recognized as the basis of the transition to the artistic paradigm of synthetic character.

Keyword: "Theater of sound", "instrumental theatre", transformation of sound matter, installation, musical challenge, prepared instruments, performativity

The formation of a new musical phenomenon "Theater of sound" is due to the dynamic cultural shifts of the early XX1 century. Contact with Western musical discoveries leads to the crystallization of domestic innovative techniques, the development of principles, lying at the intersection of arts. The powerful influence of literature, theater and choreographic plastics allowed to expand not only the sphere of musical expression, but also to enrich it with new content.

"Theater Sound" that defines the direction of the composition A. Bakshi, a little mentioned phenomenon, unexplored, requiring a comprehensive study. In this regard, there is a number of relevant aspects to the study of the origins, parallels, analogies of this phenomenon not only on the Russian soil, but also in Western musical culture. This explains the purpose of this article - the formulation of the concept of "Theater of sound", the identification of the characteristic features of the creative method inherent in it. To achieve this goal, a number of tasks are put forward:

a) indicate the origins of " sound Theater";

b) draw Parallels with Western musical works;

c) to present the essential features of the phenomenon.

There is no doubt that in the domestic instrumental music of the twentieth and the beginning of XX1 century was influenced by the experiments of eminent composers-the pioneers, the music systems which go beyond the established patterns in art.

The researchers write about the "Western impulse" [5, p. 201], pointing to the innovative ideas of M. Kagel, J. Cage, K. Stockhausen, J. Kram, M. Monk, who, breaking academic traditions, brought new ideas about the possibilities of musical art. It's a special musical language, which is pure musical possibilities expands to "sound institutions", actively incorporating electronic sounds, naturalistic, manmade.

Innovation is achieved due to the contamination developed related types of art tools, their transformation into new soil, which encourages musical experimentation.

Music and sound matter is recognized and used as a means of transforming reality, and the work is created as a model of alternative existence. The development of a new sound space is a means of movement, a transition to a new artistic paradigm.

It is always a challenge aimed at establishing contact, dialogue with the public, taking the form of political action ("Requiem for Anna Politkovskaya"), the improvisational mindless game of happening ("Listening To Mayakovsky"), the shocking catastrophic recreations of sound explosions of action ("Games in Installations").

Along with the artistic and sound events, the plastic possibilities of the word are used. In a direct appeal to the word, we see a philosophical-hermeneutic tradition: the task of the artist is to listen to the word, syllable and even letter, to stimulate collective consciousness. Starting with J. Cage becomes the material of art life itself in its infinite manifestations, as well as the creative imagination of A. Bakshi, using a variety of material. In his compositions echoes of the experience of F. Glass, La Monte, M. Monk with their minimalist reduction, contamination of spatial effects are heard. This type of works takes different forms-instrumental theater, performance, happening, installation, which are currently crystallized and received theoretical justification in the works of prominent Western and domestic art theorists. Aron Bederson analyzing the work of M. Monk said: "It uses a new vocal dictionary, shouts, screams, sighs, even the language-in new ways, creating your 
own meaningless language and turning it into musical form" [7, p. 76].

American historians and theorists of performance art, Rosley Goldberg, Clare Bishop, Eric Fisher-Lihte and a number of other theorists contributed to the study of this phenomenon. So, K. Bishop devoted her research to the installation, she notes: "instead of making a self-sufficient object, artists began to work in certain places, where all the space was interpreted as a single situation, which includes the viewer... this led to the use of this word for works that used all the space as "installation art" $[8$, p. 10]. The main features of participatory art K. Bishop sees the collectivity, communication, and procedural. "The main motor of the total installation, what it lives by - is the cranking up of the wheel of associations, cultural or everyday analogies, personal memories'. In other words, the installation prompts conscious and unconscious associations in the beholder" [8, p. 16].

Erika Fischer-Lichte has focused on the aesthetics of the performative. The most profound justification of performativity was given by Rosley Goldberg in her work "The Art of performance. From futurism to the present day", in which many pages are devoted to Russian art.

The most musically grounded and studied genre is the instrumental theatre, on the basis of which A. Bakshi's "Sound Theatre" is developing. A significant contribution to the study of the new genre was made by the Russian scientist Petrov V.O., whose work is called "Instrumental theater of the twentieth century". The researcher not only gives a definition of this phenomenon, his attention is focused on the study of the origins, theory and history of the genre, in which "in addition to the musical series that supplies musical information, there are other series associated with the dramatization of the performing process...These elements can be used independently and comprehensively. In the latter case, the performance of the opus is likened to a full-fledged instrumental performance. All the events happening on stage, must be recorded in the score" [4, p. 3].

The legality of the installation of experiments in the" Theater of Sound " with new artistic means, sometimes not previously owned by the artistic sphere, is beyond doubt. The meaning of "Theatre of Sound" in opposition to orderliness, predictability, the old music and the unpredictability, the seeming randomness of experimental music that is by cracking, shocking, inversion transformerait musical matter.
The philosophical aspect of Sound Theater is the modeling of a new sound reality, where the semantic unit is a separate sound. The sounding point as an extremely small value is filled with meaning and weight. Deepening in the reality of the individual sound characteristic of musical pointillism, where the sound is likened to the individual expressive one. But if in pointillism separate components are not connected by a single content and meaning, then in the Theater of Sound from point to point, from sound to sound, a single field of development gives the sound material integrity with consequences and predetermination arising from each state, characterizing the connections and logic of hierarchies.

The ideas of the theater of sound crystallize at the peak of the wave, denoting the movement from the "conventional theater" Meyerhold - Brecht, through the theater of the absurd Beckett, which marked the movement of departure from the verbal beginning. For theater, music is attractive by its propensity for abstract vision, sense of form and structure. For music, action and space taken from the theater are important.

"Instrumental theater or theatre instruments - this is the same phenomenon that is closely associated with healing the need of provocation, which is in our world...Apparently so attractive experiments, hoaxes, and extreme of the action of John Cage and Mauricio Kagel, Franco Donatoni, Silvano Bussotti Wlodzimierz Kotansky, which is entirely directed against most totalitari-European musical systems" [2].

The abrupt transformation of the parameters of all musical dimensions overcomes the evolutionary path of development and leads to the expansion of the musical language, which is like a revolution or revolution in musical thinking.

"Musical speech becomes in itself an infinite transformational and structural discursiveness", - said F.K. Karaev [2]. On the dynamics, mobility and variability indicates R.S. Osminkin, stressing that "in the context of the overall "de-material" turn of the product like things to work as process" [3, p. 122], the role playing and improvisational beginning.

Unlike instrumental theatre, the concept of "Theatre of Sound" has not yet been formulated. If musicologists study the phenomenon of instrumental theater from the point of view of the development of the processes taking place in the works of composers, it should be noted that the objective processes of visualization and dramatization are not accidental, they are also largely associated with counter trends in 
the field of theatrical art, aimed at reducing the role of the verbal beginning and the meanings behind the word.

According to Western researchers, among the key problems of composers who think in terms of avant-garde aesthetics is the search for new relationships between music and words.

The peculiarities of the "Theater of Sound" are related to the fact that it lies at the intersection of two trends - on the one hand - visualization and verbalization of the instrumental performing process, and on the other hand - abstraction and reduction of the verbal beginning (words) in the field of dramatic stage genres. Let us try to present the characteristics of the new phenomenon. A. Bakshi understands "Theatre of Sound" as a field of dialogue between music and theatre. "The Theater of Sound may include and miniatures, and great performances - the size doesn't matter" [1, p.10].

"Sound Theater" is a phenomenon that is included in the field of musical actionism, now widely spread, along with such genres as instrumental theater, happening, performance, action, game structure, art media, multimedia. Visualization and gaming element brings the area of choral theatre, also develop national musical culture.

If in the instrumental theater the works are intended for stage performance, then in the "Theater of Sound" the one-dimensionality of the site is overcome and the playing principle that breaks the conditionality of the scene is enhanced. The "Theater of Sound" is distinguished by the strengthening of theatrical action, the search for Director's decisions and the drama of space. Musical and plastic tendencies are of great importance, increasing attention to tempo-rhythm, sense of structure, plasticity.

It should be noted that this area includes several genre varieties, as the action of the "Theater of Sound" unfolds in different conditions. "Theater of Sound "can be represented as a kind of instrumental music when several soloists-instrumentalists act within the framework of a chamber opus (Trio "Drama", "Shakespeare-concert for violin and orchestra", "He and She. Piece for the violinist and the violinist").

The "Theater of Sound" exists as an integral part within the dramatic performance, in this case other laws come into law - the laws of the stage art of a single synthetic whole. This we see in the performances based on the works of F. M. Dostoevsky "Karamazov and hell", "Double".

Reducing the meaning of the word in the drama theatre makes it necessary to use the mu- sical principle more widely as a means of not only enhancing expressiveness, but also concretizing the content. In this regard, the theatrical works of A. Bakshi are indicative, where the sound works brightly and expressively, which is found in such his performances: "More van Gogh", "Transformation", "Marriage", etc.

The principles of "Theatre Sound" Bakshi can act in great works of mystery in nature, involving the expressive possibilities of the synthesis of many art forms. In this case, the composer refers to the construction of manypart works, such as "Polyphony of the World", "From the Red Book".

"Theatre Sound" there is no literature, no script, libretto, summaries of contents. This, of course, does not mean that there is no plot. But it is presented by musical and plastic means and is not translated into conceptual language. Literature for me is not a field of attraction and a point of repulsion" $[1$, p. 9]. The rejection of the word concretize the idea, demanded to access a method that would set the direction of the movement of thought, having application in the literature and theatre of the grotesque, irony, absurdity, farce, etc. In order to push the semantic boundaries of a literary framework, these methods contribute to superconductivity, volume and symbolic perception of the sound information. An important achievement of musical works is the desire to adequately reproduce the methods that have proven themselves in literature, theater for the approval of new principles of "Theater sound". This is followed by sound experiments.

The "Theater of Sound" moves away from the semantic certainty of the word, verbal expressiveness does not interest him. "The "Theater of Sound" is not connected with the word. This is the main difference from the traditional status genres: opera, operetta, musical. Characters share not replicas, and intonations. Moreover, intonation can be not only playing musical instruments or singing, but any sound - the shuffling feet, coughing, etc. All can be arranged pitch, rhythm and, most importantly, semantic [1, p.10].

Work with literary sources is different, but the main thing is not the literal following of the literature, but any form of generalization, significant abstraction, it can be:

a) use of a plot or an individual plot lines, the individual semantic areas of development actions;

b) reflection of the general sense, the concept of the work;

c) allusions, representation of individual images, states, reflections, sounds of action, 
dreams, somehow reminiscent of the plot, the motives of spiritual vicissitudes.

Features of the Theater of Sound are based on the discoveries of music of the twentieth century: sonoristics, concrete music, electronic music experiments. The sound replaces the text, it is meaningful and, carries a certain musical content. The sound acts as an actor, as a storyline, as a characteristic of the actors, as a state or leitmotif.

In the Theater of Sound there is no rigid hierarchy of subordination: the main character is a secondary role, an episodic role. Each character is important, has a special meaning, even if it is represented only by sound. Sounds can be not only music, but acoustic, naturalistic, and it is better that musical instruments have been issued not the usual classic sounds of the orchestra, and the exotic sounds close to the sounds of concrete music.

Another important feature of the Theater of Sound is that the instrumentalists are not frozen figures, but moving actors, and the actors that break the plane vision of the scene.

Space in the "Theater of Sound" plays an important role, as well as the resulting spatial solutions, volume. "In the volume space of the "Theater of Sound", the performers can be located anywhere in the hall - on the stage, next to the viewer, behind him, above him and even below him. This makes it possible to hear several different music at the same time, which can go at different rates, with different dynamics, etc" $[1$, p. 9].

The "Theatre of Sound" takes a lot from the instrumental theatre, but the actors are characterized not only by traditional musical means and their action on the stage, but also by the sounds of the extra-musical sphere, such as rustles, creaks, knocks, howls, moans, and roars. But if the instrumental theater allows the use of words, speech, the "Theater of Sound" deliberately leaves the conceptual explicitness of words. Words lose their meaning, even if they are present in the "Theater of Sounds".

The words undergo decomposition, transformation, re-arrangement, opening of new sounds, and, consequently, new meanings. In the Theater of Sound, a semantic game with the word and inside the word itself is possible. From a single word grow, swell new meanings. The main task - to escape from the univocity of sense, to get away from the original vision, to give meaning to the kaleidoscopic echo in the game, in combinatorics to open a new and unexplored side of the image, to give a polyphony of meanings when a word, a phrase implying, to leave unsaid the text and forced the thought to flee in several directions. New meanings are accentuated by non-musical sounds. The techniques of "Sound Theater" are adequate to the techniques of stage action-repetition, alternation, transposition, interaction. Thus, the sound is detected, becomes visible and tangible. Connections and relationships are essential, meaningful and can be found in large time intervals or gaming spaces, where the sound does not necessarily arise under the laws of determination flowing into another conditioned, and after significant periods of time as it hangs outside space and time.

The composer is proficient in various techniques of musical writing (aleatorics, sonoristics, concrete and electronic music) and uses them in his works, but comes to the idea of moving deep into the sound matter and the possibility of composing musical primordial principles, that is, composing the sound itself, sound material for each specific product.

A. Bakshi is an artist who has an extremely subtle sense of sound matter, subtle nuances and vibrations, echoes and oscillations; not only timbres, but also their components are important for him. Sound for him is something complex, multi-component, consisting of a variety of colors and sound backgrounds, layers, levels. Those sounds that we imagine noise, he hears as three-dimensional complexes of different sound mixtures. Hence the possibility of choosing for each product its special sound structures.

The theater of Sound is associated with a close attention to a particular sound, the disclosure of its multiple parameters, giving a deepening of the musical idea due to the wealth of means of expression used. It is literature and theatre that give a powerful impetus to the composer's work. He knows literature and has a keen sense of psychological twists and nuances. That is why his works are allusions to well - known subjects of classical works of literature and theater.

It is significant that many composers come to the idea of volume and variety of sound. On the multi-sound writes the German composer N. Tsapf: "for artists of sound or for so - called musical creators today opens a range of musical parameters, which was previously simply unimaginable...these include: time (duration), frequency (pitch) - amplitude (dynamics). As for the parameters that are amenable to comparison and verification, this could include more instrumentation, different techniques of the game and the space (in other words: time, frequency, amplitude, tools, acoustics, interpretation)" [6, p. 20-21]. 
Each parameter can be analyzed and the scope of its application can be traced. In terms of comparing the Theater of Sound with similar phenomena (performance, happening), it is possible to point to the importance of timbre in it, and Bakshi often refuses from the traditional classical sounds of the European orchestra in favor of prepared instruments, performance in a special rarely used way and introducing rare instruments into the score or specially created for this case.

The "Theater of Sound" is a work that is not only musically heard, but also visually provided from the point of view of the Director's plan by the co-authors, so improvisational sections are few and their action is not supposed to involve the viewer. Theatre of Sound-Director's theatre, where the composer designs all levels: 1) micro level (split sound) 2) macro level-drama, interacting lines 3) mega-leveldirecting and the project as a whole.

The "Theater of Sound" is different from the hepening, which is based on the randomness, unpredictability of the game and the actions of the audience. But what is common is the element of absurdity that arises from the clash of reality and virtuality. The model under study is also different from the performance, which has a complete structure, may involve the introduction of elements of randomness, absurdity. All of these genres differ in the degree of improvisation, logic and controlled game behavior.

Summarizing the above, we can say the following: the "Theatre of sound" is the leading creative model of the Moscow composer A. Bakshi and acts as the most adequate means of conveying his vision of the world picture. This creative method is harmoniously integrated into the wide context of the revolutionary transformation of musical matter. It is fully correlated with the creative aspirations of Western musical pioneers at the level of techniques, methods and features of artistic thinking, intersecting with the non-musical phenomena of literary and theatrical spheres. Being the leading artistic model in A. Bakshi's work, "Sound Theater" has absorbed the most significant and highly artistic principles, which expand the possibilities of content in music.

\section{References}

1. Bakshi A. My theater. // Technology of creation: Bakshi Gordon Archive [electronic resource]. URL http://www.academia.edu/35235512/Technologiestichting-Archived (date of appeal 09.06.2018).

2. Karaev F.K. Lecture on the instrumental theater, read at the Moscow Conservatory [electronic resource]. URL http:// www.karaev.net/t_lection_instrumtheater_r.html (date of appeal 09.06.2018).

3. Osminkin R. S. Collective performances: from participation to production of social life. // Historical, philosophical, political and legal Sciences, cultural studies and art history. Theory and practice. Russian Institute of art history. - St. Petersburg, Tambov: Diploma, 2016, № 12 (74) in 3 hours, 3 Hours.

4. Petrov V.O. Instrumental theatre of the XX century: history and theory of the genre. Abstract of the thesis for the degree of doctor of art. - Saratov, 2014.

5. Kholopova V.N. Russian academic music of the last third of the XX-early XXI centuries (genres and styles). - M., 2015.

6. Zapf N. Symmetry - overcoming - balance. Translated by A. Kibanova // Contemporary music: theory, performance, teaching. Collection of materials of the all-Russian scientific and practical conference with international participation. - Perm, 2009.

7. Bederson Aron New York Avant-gard Theatre, Values, Goals And Resonances. The Florida State University 2009

8. Bishop Claire Installation Art. Harry N. Abrams, 2005 144 p. ISBN0415974127. 


\title{
BIOLOGICAL PRODUCTIVITY OF STEPPE PHYTOCENOSES PRICELESSLY THE LOWLANDS OF DAGESTAN
}

\author{
Gadzhimusieva N.T., Asvarova T.A. \\ Caspian Institute of biological resources Dagestan scientific center of RAS, Makhachkala, \\ e-mail: musina.07@gmail.com
}

\begin{abstract}
Investigated biological productivity in natural ecosystems of the Western section Pricelessly the lowlands of Dagestan. The quantitative characteristics of phytocenoses in the "soil - plant" system were obtained by method Titlyanova A. A. The natural and anthropogenic dynamics of the production process in the summer period (20142016 years) was analyzed. The study of species composition and total reserves of above-ground phytomass of steppe phytocenoses was carried out. As a result of observations of indicators of changes in the composition, structure and productivity of plant communities in two sample plots, the dynamics of vegetation cover was revealed. In a comparative perspective shows the topological changes on the meadow and chestnut soils causing changes in plant communities.
\end{abstract}

Keywords: biological productivity, natural cenosis, steppe phytocenosis, meadow soil, chestnut soil

The primary production of ecosystems is its most important characteristic, the assessment of free energy, which ensures the flow of the biological cycle.

Above-ground and underground phytomass is an integral part of the structure of the plant community, reflecting the quantitative ratio of phytocenosis species. Quantitative relations of aboveground and underground phytomass allow to establish the level of loads on the studied communities, to determine the degree of their degradation, to trace the features of the process restoration of steppe vegetation. Changes in the productivity of steppe communities were studied on two key areas in Pricelessly lowland.

Knowledge of this value is necessary both for understanding the functioning of phytocenoses and for assessing their production potential. These data reflect fluctuations and features of production and destruction processes in steppe phytocenoses with different modes of existence, as well as the direction of ecosystem development for the region [2]. Quantitative study of community plants allows to reveal fluctuations and succession of vegetation cover, which is important for background monitoring observations in connection with the problem of restoration of vegetation cover of the Prisulak lowland. Productivity indicators can also be characterized as links in the succession series, each of which represents a particular stage in the change of vegetation cover. Negative climate change and unsustainable use of natural resources cause varying degrees of transformation of ecosystems, degradation of soil and the digression of vegetation cover and, as a consequence, reduction bioproductive and economic potential of agricultural and pastoral lands. This is especially true of regions located in natural areas with arid climate, in particular, such as the steppe ecosystems of Dagestan.

\section{Materials and methods of research}

A comparative analysis of the structure and functioning of cenoses on the basis of comparing the dynamics of stocks and the nature of biomass flows.

Object of study: natural cenosis.

1) Plot Pricelessly lowlands in the vicinities of Makhachkala (the district of the village of Shamkhal). The nature of vegetation mixed Artemisia taurica, elytrígia répens association, soil type-meadow (table 1).

2) Plot Prisulakskoyi lowland in the vicinity of the village Krasnoarmeysky, the nature of vegetation - artemisia vulgaris, elytrígia répensassociation, soil type-chestnut. The vegetation cover is shown in table 1.

The purpose and objective of the study are:

- comparative analysis of the structure and functioning of cenoses on the basis of comparing the dynamics of stocks and the nature of organic matter flows in the "soil-plant" system.

When sampling the soil used the generally accepted by method Arinushkina [1]. We have considered methods for collecting field material Titlyanova A.A. [9-11], Gordeeva T.K. [2]. Underground biomass was determined by the method of monoliths of Shalyt M.S. [12].

Research time 2014-2016 years. Collection of field material, its processing, analysis of samples of fractions of plant matter.

\section{Results of research and their discussion}

Includes data about dynamics of stocks of the substance in blocks (in the case of measuring only reserves) and data on the dynamics of stocks and flows of intensities (in the case of measuring those and others). To build a balance of elements of mineral nutrition, we calculated the value of pure primary products, the intensity of decomposition in different 
fractions of plants. The material was collected monthly during the growing season and was timed to the main phases of development of winter wheat:

1) tillering;
2) pipe-forging;

3) flowering (earing);

4) fruit formation;

5) milk-wax ripeness;

6) full ripeness.

Change of plant community in natural cenoses

\begin{tabular}{|c|l|l|}
\hline Selection time & \multicolumn{1}{|c|}{$\begin{array}{c}\text { Natural coenosis, № 1, } \\
\text { soil-meadow }\end{array}$} & \multicolumn{1}{c|}{$\begin{array}{c}\text { Natural coenosis, № 2, } \\
\text { soil-chestnut }\end{array}$} \\
\hline May & $\begin{array}{l}\text { cardaria draba, hieracium pilosella, } \\
\text { anthemis ruthenica, aégilops cylíndrica, card- } \\
\text { uus acanthoides. }\end{array}$ & $\begin{array}{l}\text { trifóliumcampéstre, anthemis ruthenica, bro- } \\
\text { mus mollis, artemisia taurica, achillea micran- } \\
\text { tha willd, juncus effuses }\end{array}$ \\
\hline June & $\begin{array}{l}\text { euphorbiaceae, ínula británnica, lótus cor- } \\
\text { niculátus, helmin- } \\
\text { thotheca echioides, elytrígia répens (domina- } \\
\text { tum imponere), trifolium repens, potentilla }\end{array}$ & $\begin{array}{l}\text { artemisia taurica willd (dominatum imponere) } \\
\text { seseli tortuosum, alhagi, (dominatum impo- } \\
\text { nere) }\end{array}$ \\
\hline July & elytrígia répens, trifolium repens, potentilla & alhagi, artemisia taurica willd \\
\hline
\end{tabular}

Table 2

Dynamics of plant matter in natural steppe cenosis (site 1 - meadow, site 2 chestnut) $\mathrm{g} / \mathrm{m}^{2}$

\begin{tabular}{|c|c|c|c|c|c|c|c|}
\hline Period & sites & aboveground mass & living roots & mortmass & rags & litter & plant litter \\
\hline \multirow{2}{*}{ April } & 1 & 101,9 & 215,6 & 94,8 & 19,8 & & \\
\cline { 2 - 8 } & 2 & 133,2 & 560,3 & 350,1 & 140,1 & & \\
\hline \multirow{3}{*}{ May } & 1 & 175,4 & 353,8 & 245,6 & 50,1 & 76,1 & \\
\cline { 2 - 8 } & 2 & 207,5 & 700,7 & 601,3 & 59,3 & 76,1 & \\
\hline \multirow{2}{*}{ June } & 1 & 330,0 & 421,9 & 314,1 & 18,4 & & \\
\cline { 2 - 8 } & 2 & 296,4 & 333,1 & 441,4 & 79,9 & & \\
\hline \multirow{2}{*}{ July } & 1 & 640,0 & 229,2 & 52,7 & 8,3 & & \\
\cline { 2 - 8 } & 2 & 365,0 & 219,0 & 56,6 & 105,9 & 11,4 & \\
\hline \multirow{2}{*}{ Septembert } & 1 & 23,6 & 54,9 & 39,8 & 95,3 & 99,3 & 139,8 \\
\cline { 2 - 8 } & 2 & 94,4 & 560,3 & 250,1 & 148,1 & 48,4 & 64,6 \\
\cline { 2 - 8 } & 1 & 169,6 & 429,5 & 102,6 & 85,4 & 18,8 & \\
\hline
\end{tabular}

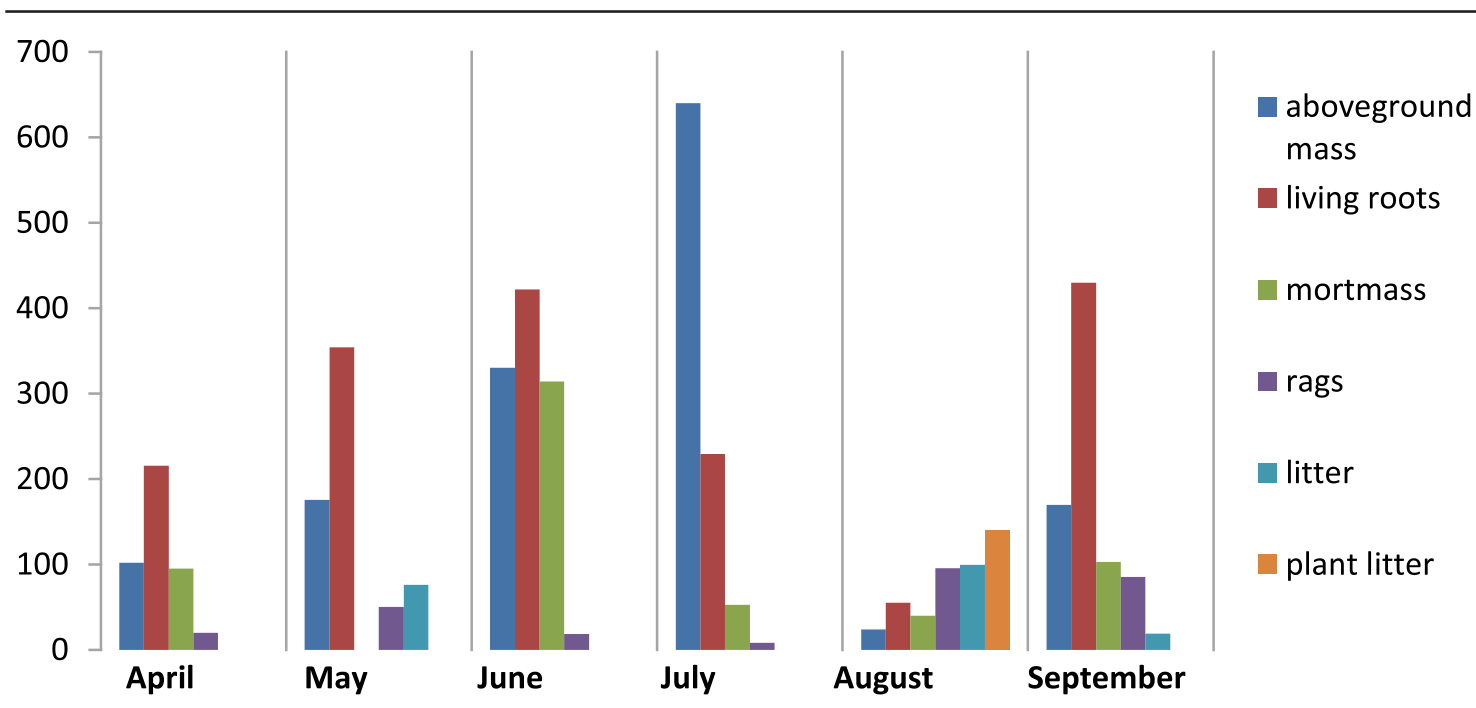

Fig. 1. Site № 1 (meadow soil) $\mathrm{g} / \mathrm{m}^{2}$ 


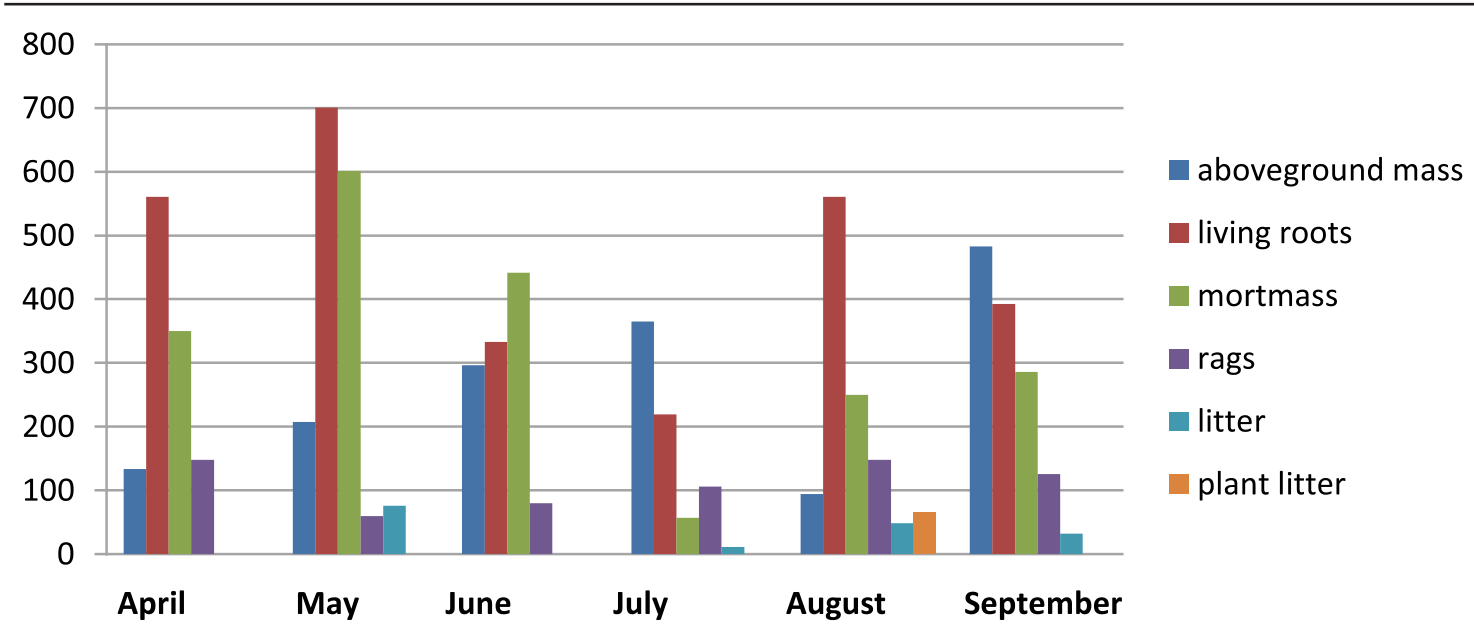

Fig. 2. Site № 2 (chestnut soil) $\mathrm{g} / \mathrm{m}^{2}$

The following fractions of phytomass were distinguished: aboveground: stems, leaves, flowers, grain, living roots, rags (dead, but not yet fallen parts of plants ), trifle and mortmass ( crushed aboveground biomass), undecayed or semi-decayed straw, litter, seeds. Litter was not taken into account separately, as it was found on the soil almost only at the time of harvest. The timing of sampling is conventionally designated (period). The plants were cut to the level with the soil, all the mowing was done at the beginning of the day. Underground biomass was determined by monolith method $[1,4,7]$. The dynamics of plant matter in the steppe cenosis (site 1) on meadow soil and (site 2) on chestnut soil is shown in table 2. Fig. 1. Fig. 2.

The structure and stocks of plant matter reflect both the differences in ecosystems and the relationship to changes in spatial distribution on the landscape profile. Large reserves of phytomass indicate a high intensity of the production process, the accumulation of mortmass (plant litter + litter) - a low rate of destruction.

The quantitative ratio of species and phytomass stock in plant annually accumulating dead remains is determined by the number of undecayed dead remains of previous years, the value of the green part of the above-ground mass, which died by autumn and forms a litter, remaining in the autumn at the root of the green parts of plants that died during the winter and spring of the next year [6].

Allocated in the phytomass of cuts of biography can be considered as elementary structural units in the overall plant mass, which bear a functional load, and the ratio and the weight indicators are markers of the seasonal dynam- ics of production and destruction processes of vegetation cover of the steppes Pricelessly lowland. Productivity indicators can also be characterized as links in the succession series, each of which represents a particular stage in the change of vegetation. These data reflect the fluctuations and features of the production and destruction processes in the steppe phytocenoses with different modes of existence, as well as the direction of ecosystem development for the region. Quantitative study of community plants allows to identify fluctuations and succession of vegetation, which is important for background monitoring observations in connection with the problem of restoration of vegetation cover.

It should be noted that the number of primary products of each phytocenosis depends both on the meteorological conditions of the year and on the biological characteristics of the species that make up this community. Quantitative expressions of the total value of the plant mass of the studied communities and the relationship between its individual components, as well as the course, pace, rhythm of formation and destruction are determined by the biological and morphological features of the components of the vegetation cover [4].

Chestnut soils are the main type of soil in the dry steppe zone. With a humus content of $2.17 \%$. The content of total nitrogen 0,15 $0,20 \%$, hydrolyzed nitrogen 3,0-6,0 mg/100 g of soil; total phosphorus $0,12-0,18 \mathrm{mg}$, mobile phosphorus 2,0-2,5 mg; total potassium 1,2-2. $\mathrm{mg}$, exchangeable potassium $30-70 \mathrm{mg} / 100 \mathrm{~g}$ of soil. The simultaneous manifestation of salinization and weakly expressed intra-soil clay 
formation emphasize the regional specificity of chestnut soils of Dagestan [8].

For the meadow soil typical of clear differentiation of the horizons, a significant humus horizon, carbonate content, well expressed fine lumpy-granular structure, excessive moisture of the lower layers. These soils are characterized by hydrogenic accumulation of carbonates, gypsum, salts and horizontal stratification. Humus content in meadow soils 4-7\%. According to the content of soil nutrients are included in the group of medium-hydrolyzed nitrogen $38.1-39.9 \mathrm{mg} / 100 \mathrm{~g}$ of soil and below the average phosphorus $1.0-2.0 \mathrm{mg} / 100 \mathrm{~g}$ of soil, exchangeable potassium $25-30 \mathrm{mg} / 100 \mathrm{~g}$ of soil $[3,5]$.

Based on the results of the study, the following conclusions can be drawn:

The highest value of plant matter is determined on meadow soil: above-ground biomass in July $-640,0 \mathrm{~g} / \mathrm{m}^{2}$, roots in September - 429,5 $\mathrm{g} / \mathrm{m}^{2}$, mort mass in June $314,1 \mathrm{~g} / \mathrm{m}^{2}$, rags in August $-95,3 \mathrm{~g} / \mathrm{m}^{2}$. The minimum values were determined in Augustbiomass $-23.6 \mathrm{~g} / \mathrm{m}^{2}$, roots $-54.96 \mathrm{~g} / \mathrm{m}^{2}$, mortmassy $-39.8 \mathrm{~g} / \mathrm{m}^{2}$ and rags in July $-8.3 \mathrm{~g} / \mathrm{m}^{2}$.

On chestnut soil (site 2) above-ground biomass reaches its maximum in September $483,0 \mathrm{~g} / \mathrm{m}^{2}$, in May, the roots $700,7 \mathrm{~g} / \mathrm{m}^{2}$, and mortmass - 441,4 g/ $\mathrm{m}^{2}$ and a rag in August $148,1 \mathrm{~g} / \mathrm{m}^{2}$ Minimum value of biomass was determined in August of $94.4 \mathrm{~g} / \mathrm{m}^{2}$, in July, the roots $-219,0 \mathrm{~g} / \mathrm{m}^{2}$ and mortmass $-56.6 \mathrm{~g} / \mathrm{m}^{2}$ and a rag in May of $59.3 \mathrm{~g} / \mathrm{m}^{2}$.

\section{Conclusions}

Comparing the above-ground productivity of communities over the study period

it can be concluded that the restoration of natural vegetation on sites is not always with an increase in productivity communities. During this period, a significant increase can be noted only on one of the sites. The second sites are characterized by significant (to some extent) drop in productivity plant community.

Analysis of the production and destruction process in the studied areas showed that in meadow soil the value of above-ground biomass is greater than in chestnut. The value of the reserves of the root system, mortmass and rags more on chestnut soil than in the meadow.

The primary production of ecosystems is the most important characteristic, the assessment of free energy, which ensures the flow of the biological cycle. Knowledge of this value is necessary both for understanding the functioning of phytocenoses and for assessing their production potential.

Biological circulation of substances or metabolic processes between plants and soil, serve as the basis for the management of biological productivity of natural and agricultural biogeocenoses, preservation of public health, improve soil fertility and animal productivity, environmental quality control.

\section{References}

1. Arinushkina E.V. Manual on chemical analysis of soils. M. Publishing house of Moscow state University. 1970. p. 475.

2. Gordeeva T.K. Biological productivity and circulation of chemical elements in plant communities: Science. 1971. P. 121-126.

3. Zalibekov Z.G. Soils of Dagestan. Publishing House "Science". 2010. p. 57, p. 89.

4. Zalibekov Z.G., Gamzatova H.M. The types of desertification of soils and criteriafor the evaluation of degradation processes. News of universities north-caucasian region. Natural science. 2017. No. 2, p. 51.

5. Kuramagomedov M.K., huseynova Z.A. On the biological productivity of the lung and steppe phytocenosis of the prisulak lower daghestan. Problems of development of the area of the region. Volume: 4Rooms: 4 (32) Year: 2017 P. 86.

6. Rabotnov T.A. Logomedia / T.A. Rabotnov. M.: MGU, 1984. P. 326-347.

7. Rodin L.E., Remezov N.P., Bazilevich N. So. Methodological guidelines for the study of dynamics and biological cycle in phytocenoses. - L.: Nauka.1968. P. 143.

8. Salmanov A.B. Trace elements in soils of the Terek - Sulak lowlands. Sat scientific papers. Makhachkala. 1981. P. 185.

9. Titlyanova A.A. System description of the cycle of substances. Basic concepts in quantitative parameters. Ecology. 1984. No. 1. P. 58-59.

10. Titlyanova A.A., Sambuu A.D. Sukcession In Herbal Ecosystems. - Novosibirsk: Publishing House Sb Ras, 2016. P. 191.

11. Titlyanova A.A. Regimes of biological cycle in aboveground biogeocenose. Soil science 1989. № 6. P. 71-81.

12. Shalyt M.S. Methods of studying the morphology and ecology of the underground part of individual plants and plant communities. Field geobotanica. M.-L.: Science. 1960. P. 87. 


\title{
MUD VOLCANOES OF THE WORLD: CLASSIFICATIONS, ACTIVITIES AND ENVIRONMENTAL HAZARD (INFORMATIONAL-ANALYTICAL REVIEW)
}

\author{
Baloglanov E.E., Abbasov O.R., Akhundov R.V. \\ Institute of Geology and Geophysics of the National Academy of Sciences, Baku, \\ e-mail: elnur1001@mail.ru
}

\begin{abstract}
There are 2508 mud volcanoes and mud volcanic manifestations in 42 geographical regions of the world. The territory of Eastern Azerbaijan and the adjacent water area of the Southern Caspian Basin characterize by the widest spread of mud volcanoes on a global scale. The total number of mud volcanoes and mud volcanic manifestations in Azerbaijan is 353 (154 of them are marine). In comparison with other geographical regions, mud volcanoes of Azerbaijan also distinguish by the number of eruptions and daily gryphon, sopka and salse activity. In addition, Azerbaijan is a unique country, because all types of mud volcanoes were registered here. From this point of view, mud volcanoes of Azerbaijan provide favorable conditions for research of their activity and environmental hazard. Related to the daily activity of mud volcanoes, the composition and quantity of the emitted gases into the atmosphere, as well as mineralization degree and chemical types of waters, and the organic and element composition of the breccias were studied. The zones with high anomalous-radioactive background on the crater area of the volcanoes were revealed and the reasons for their occurrence were explained. It was stablished an associative relationship between the increasing of gamma level and the concentration of uranium for the breccia samples selected from the area has high radioactive background. In connection with the environmental hazard, a comparative analysis was performed on chemical and radioactive indicators of water and breccia samples, respectively, with norms for drinking water and an average concentration of elements for sedimentary rocks.
\end{abstract}

Keywords: mud volcano, distribution area, classification, activity, environment, hazard

Mud volcanoes provide very important and useful information about complex geological and geochemical processes occurring on inaccessible depths for prospecting and exploration wells, and also play an important role in the evaluation of hydrocarbon deposits of great depths $[1-4,6,7,9,11,13-16$, $18,20,22-24,33,34,38,41-46,48,50-52$, 54]. One of the most important areas of the study of mud volcanism is associated with eruptions and daily activity which forms an environmental hazard. Various methods and approaches have been considered by many scientists [26-34, 35, 39, 40, 47, 49, 53] in studying this problem.

\section{Distribution areas of mud volcanoes in the world and their classifications}

There are 2508 mud volcanoes and mud volcanic manifestations within the 42 geographical areas in the world, as well as AlpineHimalayan, Pacific and Central Asian folding zones, in the deep-water zones of the Caspian, Black and Mediterranean seas and on the passive margins of the continents [21] (Fig. 1).

Quantitatively, mud volcanic areas may conditionally be divided into the largest (more than 100 volcanoes), large (50 to 100 volcanoes), moderate (10 to 50 volcanoes), and small ones (less than 10 volcanoes) [21]. Taking it as a basis, the largest mud volcanic areas are: Azerbaijan and western slope of
South Caspian Basin, Eastern Mediterranean (Mediterranean Ridge, Nile delta), Trinidad and its eastern offshore area, China, the USA (Gulf of Mexico and its coast, Barbados and Lesser Antilles Margin; large areas are: Gulf of Cadiz, Italy, Romania, Black sea, Russia (Taman peninsula and Western Kuban), Pakistan, Myanmar, Indonesia, Columbia, Costa Rica; moderate mud volcanic regions are: Western Mediterranean, Turkmenistan and eastern slope of South Caspian, Ukraine (Kerch peninsula), Iran, India, Japan, Malaysia, Georgia, Nigeria, Papua-New Guinea, New Zealand, Nicaragua, Panama, Venezuela; small areas are: Central Mediterranean, Albania, South Sakhalin, Alaska, the Philippines, Namibia, SAR, Canada, Mexico, Ecuador and Peru (Table 1).

The South Caspian Basin a zone of subsidence with a thick sedimentary stratum (more than $30 \mathrm{~km}$ ) and a wide spread of mud volcanism [21]. The largest number of mud volcanoes, including the biggest, most frequently erupting ones and in general, all their known types (Table 2) are located in Eastern Azerbaijan and the adjacent water area of the South Caspian. It is in accordance with these factors that Azerbaijan is considered to be the "Motherland of mud volcanoes". There are 353 mud volcanoes and their manifestations on the territory of the country (Table 3), 199 of which are terrestrial [21]. 


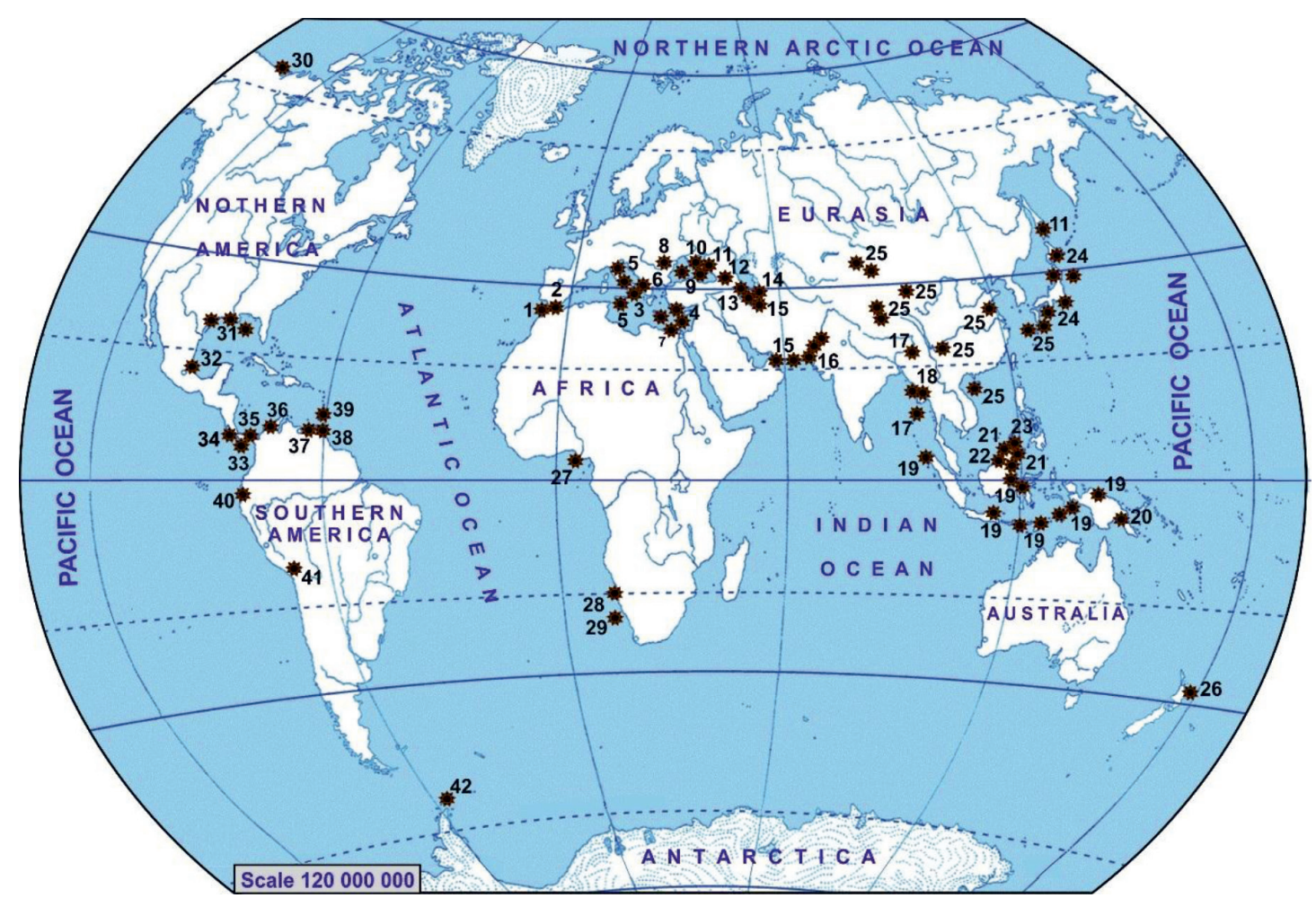

Fig. 1. Geographical location of the areas of mud volcanoes over the world: 1 - Gulf of Cádiz; 2 Western Mediterranean (Alboran Sea); 3 - Central Mediterranean (Calabrian Arc); 4 - Eastern Mediterranean; 5 - Italy; 6 - Albania; 7 - Egypt; 8 - Romania; 9 - Black Sea; 10 - Ukraine; 11 - Russia; 12 - Georgia; 13 - Azerbaijan; 14 - Turkmenistan; 15 - Iran; 16 - Pakistan; 17 India; 18 - Myanmar; 19 - Indonesia; 20 - Papua New Guinea; 21 - Malaysia; 22 - Brunei; 23 Philippines; 24 - Japan; 25 - China; 26 - New Zealand; 27 - Nigeria; 28 - Namibia; 29 - South Africa; 30 - Canada; 31 - USA; 32 - Mexico; 33 - Costa Rica; 34 - Nicaragua; 35 - Panama; 36 Columbia; 37 - Venezuela; 38 - Trinidad and Tobago; 39 - Barbados and Lesser Antilles Margin; 40 - Ecuador; 41 - Peru; 42 - Antractica

\section{Mud volcanic areas and environmental hazard}

The territory of Azerbaijan has a very complex tectonic structure and active seismogeodynamic properties $[5,8,10,12,17,19,21,25$, 27-31]. In this regard, about 5-6 eruptions were recorded in the territory of the republic recent years (Table 4). The eruption of the mud volcano is accompanied by a powerful explosion, deep cracks extending for several kilometers, a 300-350 m high flame (with the predominance of carbon, the eruption occurs without flame) and the release of a large volume of mud volcanic breccia onto the Earth's surface. The amount of organic matter and chemical elements of volcanic products exceeds the average statistical norms for sedimentary rocks, and this factor disrupts the natural balance of the environment. The gryphon and salse activity of mud volcanoes is accompanied by the release of gas, highly mineralized water, mud-water mixture, and in some cases, a large amount of oil. As a result, saline soils, unique volcanic landscapes, as well as oil-impregnated zones form in the mud volcanic and adjoining areas. Such landscapes are rare from the geochemical point of view and have a negative impact on the living organisms that depend on each other [27-32].

Unlike the areas of mud volcanoes spreading around the world, the eastern territory of Azerbaijan is characterized by their widest distribution (Table 1), as well as by the presence of all existing types of mud volcanoes (Table 3 ). This factor creates favorable conditions for the study of mud volcanism and the problems associated with it. From this point of view, Azerbaijan is a unique country for studying the impact of mud volcanoes on the environment. Taking into account the facts mentioned above, the mud volcanoes of Azerbaijan were chosen as an object of study of volcanic activity and environmental hazard. 
The distribution areas of mud volcanoes in the world

\begin{tabular}{|l|c|l|c|}
\hline \multicolumn{1}{|c|}{ Geographical area } & $\begin{array}{c}\text { Number of mud } \\
\text { volcano and mud } \\
\text { volcanic manifestation }\end{array}$ & & \multicolumn{1}{|c|}{$\begin{array}{c}\text { Number of mud } \\
\text { volcano and mud } \\
\text { volcanic manifestation }\end{array}$} \\
\hline Gulf of Cádiz & 50 & Malaysia & 29 \\
\hline Western Mediterranean & 10 & Brunei & 7 \\
\hline Central Mediterranean & 6 & The Philippines & 20 \\
\hline Eastern Mediterranean & 230 & Papua-New Guinea & 12 \\
\hline Italy & 71 & New Zealand & 13 \\
\hline Albania & 3 & Nigeria & 1 \\
\hline Egypt & 160 & Namibia & 8 \\
\hline Romania & 66 & South Africa & 3 \\
\hline Black Sea & 70 & Canada & 139 \\
\hline Ukraine & 43 & The USA & 11 \\
\hline Russia & 46 & Mexico & 59 \\
\hline Georgia & 13 & Nicaragua & 40 \\
\hline Azerbaijan & 353 & Costa-Rica & 50 \\
\hline Turkmenistan & 48 & Panama & 18 \\
\hline Iran & 25 & Columbia & 202 \\
\hline Pakistan & 52 & Venezuela & 250 \\
\hline India & 12 & Trinidad and Tobago & 2 \\
\hline China & 200 & Barbados and Lesser Antillas Margin & \\
\hline Japan & 26 & Ecuador & 5 \\
\hline Myanmar & Peru & \\
\hline Indonesia & Antarctica & \\
\hline & 97 & Total: 2508 & \\
\hline & & Terrestrial: 1107 & \\
\hline & & Marine: 1401 & \\
\hline & & & \\
\hline & & & \\
\hline
\end{tabular}

Classification of mud volcanoes and mud volcanic manifestations

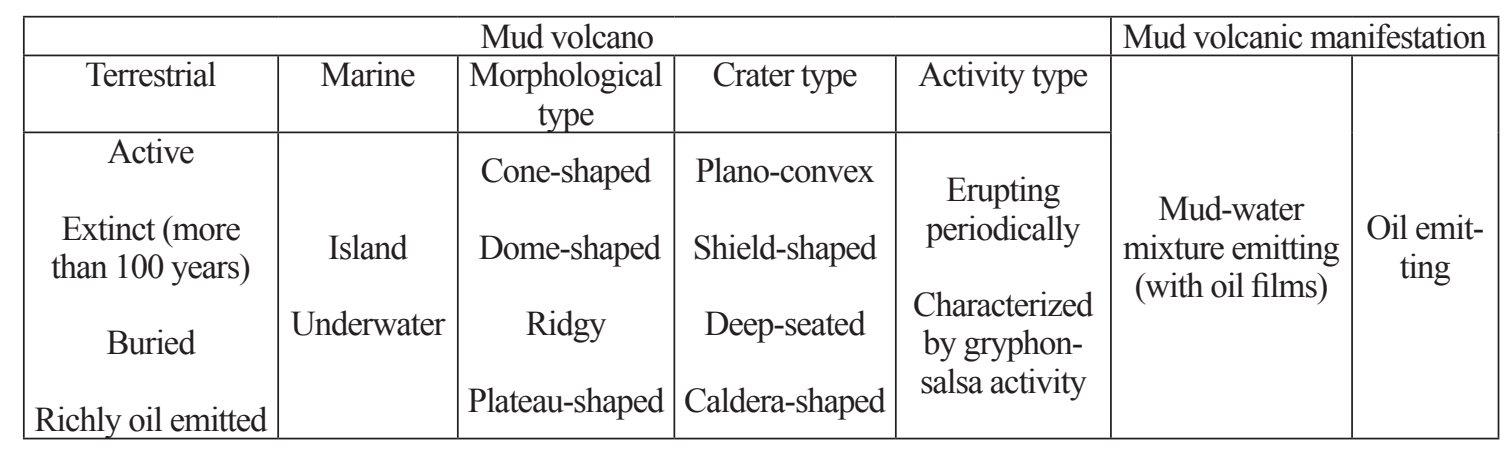

Statistical indicators of mud volcanoes and mud volcanic manifestations

Table 3 in Azerbaijan by geological regions

\begin{tabular}{|l|c|c|c|}
\hline \multicolumn{1}{|c|}{ Geological region } & $\begin{array}{c}\text { Number of mud } \\
\text { volcano }\end{array}$ & $\begin{array}{c}\text { Number of mud volcanic } \\
\text { manifestation }\end{array}$ & Total \\
\hline Pre-Caspian-Guba & 2 & 5 & 7 \\
\hline Shamakhi-Gobustan & 86 & 34 & 120 \\
\hline Absheron & 45 & 24 & 69 \\
\hline Lower Kura & 25 & 8 & 33 \\
\hline Baku archipelago & 85 & 7 & 32 \\
\hline Deep part of the South Caspian & 32 & - & 353 \\
\hline Total & 277 & 76 & 32 \\
\hline
\end{tabular}


Table 4

Mud volcano eruptions recorded within petroleum regions in Azerbaijan (during 1810-2018)

\begin{tabular}{|c|c|c|c|}
\hline Volcano name & \begin{tabular}{|l|} 
Eruption date \\
\end{tabular} & Volcano name & Eruption date \\
\hline \multicolumn{2}{|c|}{ Pre-Caspian-Guba region } & \multicolumn{2}{|c|}{ Lower Kura region } \\
\hline \multirow[t]{2}{*}{ Zarat-deniz } & \multirow[t]{2}{*}{1953} & Kalamaddin & 1872 \\
\hline & & Akhtarmaardy & 1990 \\
\hline \multicolumn{2}{|l|}{ Absheron peninsula } & Akhtarma-Pashaly & $\begin{array}{l}1948,1962,1969,1982 \\
\text { (twice), 1986, 2013, } 2018\end{array}$ \\
\hline Kechaldag & 2000 & Kichik Harami & 1912 \\
\hline Uchtepe & $\begin{array}{l}\text { 1967, 1986, 1992, 1998, 2002, } \\
2004,2005\end{array}$ & Hamamdag & $\begin{array}{l}1938,1947,1967,1984, \\
1996\end{array}$ \\
\hline Beyukdag & 1921,1922 & Agzybir & $1964,1978,2002$ \\
\hline Zikh Pilpilesi & 1993 (twice) & Bendovan & 1932,1989 \\
\hline \multirow[t]{3}{*}{ Keireki } & \multirow{3}{*}{$\begin{array}{l}\text { 1824, 1830, 1865, 1882, 1885, } \\
\text { 1902, 1915, 1952, 1953, 1957, } \\
\text { 1964, 1966, 1968, 1989, 1991, } \\
\text { 2001, 2002, 2014, } 2017\end{array}$} & Kursengi & 1965 \\
\hline & & \begin{tabular}{|l|} 
Durovdag \\
\end{tabular} & 1953 \\
\hline & & Duzdag & 1941 \\
\hline Bozdag-Geokmaly & $1926,1965,2001$ & Oil salse & 1882 \\
\hline Bozdag-Gobu & $\begin{array}{l}1827,1894,1937,1953,1957, \\
1974,1986,1987,1999\end{array}$ & Neftchala Pilpilesi & 1947 (twice) \\
\hline Bozdag-Gyuzdek & $\begin{array}{l}1839,1867,1902,1969,1986, \\
1988,1995,2003,2009\end{array}$ & Dovshandag & 2003 \\
\hline Saryncha & 1936,1976 & \multicolumn{2}{|l|}{ Baku archipelago } \\
\hline Gyzyltepe & 1914 (twice) & Zenbil Island & 1961,1995 \\
\hline Akhtarma-Puta & $1923,1933,1950$ & \multirow{2}{*}{$\begin{array}{l}\text { Khare-Zire } \\
\text { Island }\end{array}$} & \multirow{2}{*}{$\begin{array}{l}1810,1857,1859,1886, \\
1940,1947,1959,1960 \\
1962,1974,1993,1997, \\
2006\end{array}$} \\
\hline Lockbatan & $\begin{array}{l}1829,1864,1887,1890,1900, \\
1904,1915,1918,1923,1926, \\
1933,1935,1938,1941,1954, \\
1959,1964,1972,1977,1980, \\
1990,2001,2010,2012,2017\end{array}$ & & \\
\hline Otmanbozdag & $\begin{array}{l}1854,1904,1922,1951,1965, \\
1985,1994,2004,2017\end{array}$ & Gil Island & $\begin{array}{l}\text { 1810, 1859, 1860, 1895, } \\
\text { 1896, 1913, 1926, 1937, } \\
1960,1962\end{array}$ \\
\hline \multicolumn{2}{|c|}{ Absheron archipelago } & Garasu Island & $\begin{array}{l}1876 \text { (twice), 1923, 1977, } \\
1993\end{array}$ \\
\hline Absheron shoal & 1888 & Balygly shoal & 1868,1913 \\
\hline \multirow[t]{2}{*}{ Buzovna Pilpilesi } & \multirow{2}{*}{$\begin{array}{l}\text { 1892, 1915, 1923, 1950, } 1953 \\
\text { (twice), } 2001\end{array}$} & Chigil Island & 1967 \\
\hline & & Sabail shoal & $1907,1915,1970$ \\
\hline \multirow[t]{2}{*}{ Palchyg Pilpilesi } & \multirow[t]{2}{*}{1935,1950} & $\begin{array}{l}\text { Sengi-Mugan } \\
\text { Island }\end{array}$ & $\begin{array}{l}1903,1923,1932,1933, \\
2002,2008\end{array}$ \\
\hline & & Dashly Island & 1920,1945 \\
\hline Neft Dashlary & $1904,1949,1951,1957$ & \multirow[t]{2}{*}{ Mugan-deniz shoal } & \multirow[t]{2}{*}{1942,1957} \\
\hline Shoal "1906" & 1906 & & \\
\hline Shoal "1908" & 1908 & \multirow[t]{2}{*}{ Chigil-deniz shoal } & \multirow{2}{*}{$\begin{array}{l}\text { 1861,1927 (twice), } \\
\text { 1928, 1939, 1950, 1959, } \\
2001\end{array}$} \\
\hline Shoal "1933" & 1933 & & \\
\hline Shoal "1960" & 1960 & \multirow[t]{3}{*}{ Yanan-Tava shoal } & \multirow[t]{3}{*}{$1813,1825,1843,1868$} \\
\hline Bahar-deniz shoal & $\begin{array}{l}\text { 1876, 1912, 1917, 1921, 1925, } \\
1941,1958,1963,1984\end{array}$ & & \\
\hline Kapaz & 1980 & & \\
\hline
\end{tabular}




\begin{tabular}{|c|c|c|c|}
\hline \multicolumn{4}{|c|}{ Shamakhy-Gobustan region } \\
\hline Damirchi & $1958,1969,1971,2008$ & Agnohur & $\begin{array}{l}1927,1940,1948,1976, \\
1986\end{array}$ \\
\hline Zeiva (Basgal) & 1926 & Cheildag (west) & 1970 \\
\hline Kyurdamich & 1971 & Cheildag (east) & $\begin{array}{l}1870,1957,1968,1970, \\
2004\end{array}$ \\
\hline Gizmeydan & 1987,2001 & Davalidag (east) & 1975 \\
\hline Gasymkend & 1993 & Dashmardan & $\begin{array}{l}\text { 1866, 1954, 1976, 1986, } \\
2011\end{array}$ \\
\hline Jeirly & $1951,1983,2001$ & Shekikhan (west) & $\begin{array}{l}\text { 1988, } 1989 \text { (twice), 2001, } \\
\text { 2004, 2006, 2010, } 2017\end{array}$ \\
\hline Hajily & 1970 & Shekikhan (east) & 1989, 2006 \\
\hline Melikchobanly & 1926, 1967, 1977 & Gotur & $1989,2001,2004,2005$ \\
\hline Gushchu & $\begin{array}{l}\text { 1913, 1917, 1924, 1941, 1952, 1954, } \\
\text { 1958, 1960, 1965, 1968, 1986, 1992, } \\
\text { 2008, } 2018\end{array}$ & Toragay & $\begin{array}{l}1841,1901,1924,1932, \\
\text { 1947, 1950, 1984, 1985, } \\
\text { 1987, 1988, 2018 (twice) } \\
\end{array}$ \\
\hline Kyolany & $1845,1962,1969$ & Beyuk Kyanizadag & 1950,1996 \\
\hline Kichik Maraza & $1848,1970,1986$ & Durandag & $\begin{array}{l}1960,1968,1986,2001, \\
2004\end{array}$ \\
\hline Bozaakhtarma & 1902, 1969, 1970, 1987, 2017 & Agtirme & $\begin{array}{l}\text { 1913, } 1971 \text { (twice), 1985, } \\
1988,1989,1998,2000\end{array}$ \\
\hline Shikhzarli & $\begin{array}{l}1844,1848,1868,1872,1902,1927, \\
1929,1939,1944,1946,1949,1955, \\
1969,1974,1980,1986,1987,1991, \\
1992,1997,2004,2011,2013,2017\end{array}$ & $\begin{array}{l}\text { Garabujag (Hajive- } \\
\text { lieri) }\end{array}$ & $1954,1963,2001$ \\
\hline Jengi & 1851,1873 & Solakhay & 1949, 1989 (twice), 2001 \\
\hline Garyja & 1970, 1987, 2003, 2007, 2011, 2017 & Garakyura & 1928,1951 \\
\hline Shorsulu & 1986 & Oyug & 1988 (twice) \\
\hline Sheytanud & 1975 & Ayrantoken & $\begin{array}{l}1964,1969,1977,1988, \\
1990,2004,2008\end{array}$ \\
\hline Chapylmysh & $\begin{array}{l}\text { 1929, 1933, 1973, 1984, 1989, 2001, } \\
2010\end{array}$ & Goturdag & $\begin{array}{l}\text { 1926, 1959, 1966, 1970, } \\
1977,1987\end{array}$ \\
\hline Ayazakhtarma & $\begin{array}{l}\text { 1926, 1969, } 1973 \text { (twice), 1985, 1989, } \\
\text { 2001, 2005, 2006, 2007 }\end{array}$ & Dilyangyaz & $1902,1912,1951$ \\
\hline Nardaranakhtarma & $1948,1970,1972,1982,1984$ & Dashgil & $1882,1886,1908,1926$ \\
\hline Suleymanakhtarma & $1986,1996,2001,2004$ & & 1958,2001 \\
\hline Bahar & $\begin{array}{l}1853,1859,1885,1886,1911,1926, \\
1967,1992\end{array}$ & $\begin{array}{l}\text { Alat Pilpilesi } \\
\text { (Bala Bahar) }\end{array}$ & $1909,1953,1962$ \\
\hline
\end{tabular}

The Kichik Maraza volcano is located 38 $\mathrm{km}$ south-east of Shamakhi $\left(40^{\circ} 30^{\prime} 36.37 " \mathrm{~N}\right.$, $49^{\circ} 1$ '55.21"E), to the north of Shikhzarli volcano, at the hill summit of $600 \mathrm{~m}$ in absolute height. The hill has steep western and southern slopes and gentle northern and eastern slopes surrounded with shallow gorges and scours. An area covered with breccia is 79 ha. The mentioned volcano is placed at the Miocene sediments and confined to the northwestern pericline of the Mushkemir anticline. An outflow tongues, 40-60 m long and 5-10 m wide, are seen on the slopes. The Kichik Maraza volcano crater field is rather vast, with numer- ous gryphons and $0.5 \mathrm{~m}$ to $14 \mathrm{~m}$ high sopkas. Some of them are distinguished by an abundant emission of gas, water and mud with oil films. The Kichik Maraza volcano first eruption was recorded in 1848, the last one in 1986 (Table 4). The volcano is surrounded by closely adjoining agricultural and cattle breeding areas (Fig. 2 (a) and 2 (b)).

The Duzdag mud volcano is located $600 \mathrm{~m}$ of the Salyan-Neftchala highway $\left(39^{\circ} 22^{\prime} 53.76^{\prime \prime N}, 49^{\circ} 8^{\prime} 46.64 " \mathrm{E}\right), 4 \mathrm{~km}$ of Khylly village. Volcanic cone, $0.6 \mathrm{~km}$ in diameter and $18 \mathrm{~m}$ in relative height, is clearly distinguished over the surrounding flat plain. The volcano is 
situated on the same named anticline composed of upper Pliocene and Quaternary sediments. Mudvolcanic manifestations are confined to the western regional faulting having an amplitude of $400 \mathrm{~m}$ and passing through the southwestern limb of the fold. A several active gryphons and salses emitting gas, muddy water, some with oil, occur on the Duzdag volcano. The last eruption of the mud volcano was recorded in 1941 (Table 4). Currently, the northern, northeastern and southwestern parts of the volcano are surrounded by an artificial lake used for agricultural and fishing purposes (Fig. 3 (a) and 3 (b)). Various phase volcanic products, ejecting from the active gryphons and salses of the mud volcano directly flow to the lake (Fig. 3 (c)).
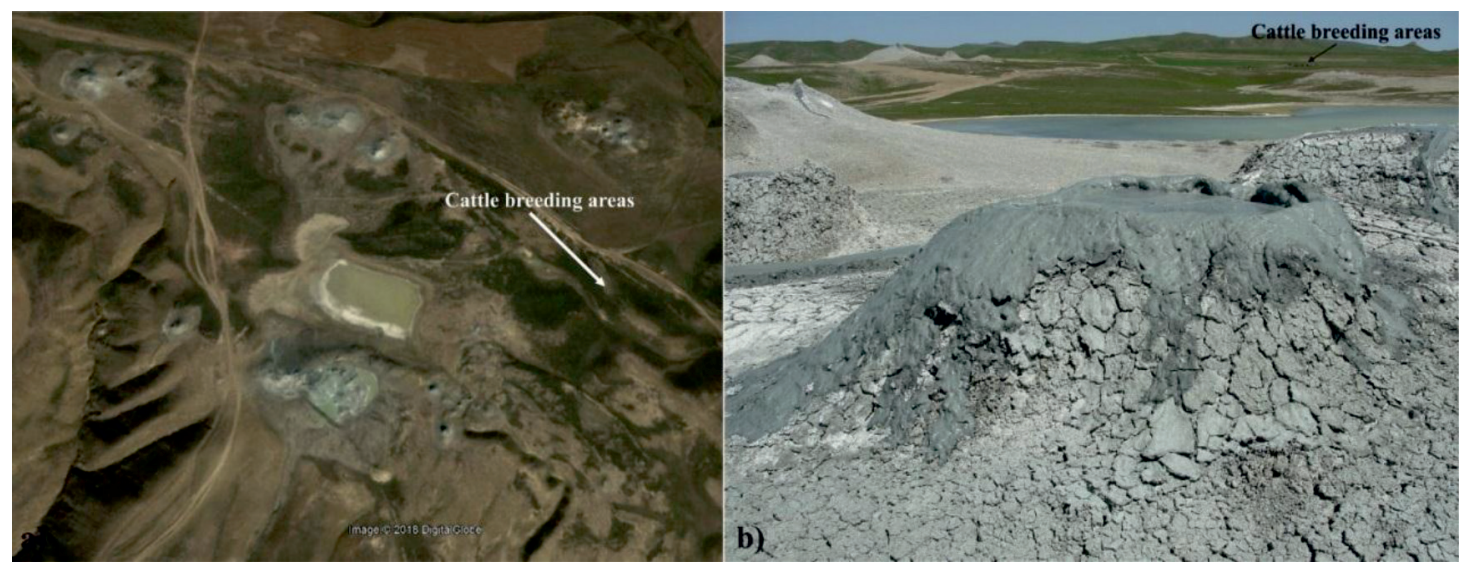

Fig. 2. Satellite image (a) and photo of the crater field (b) of the Kichik Maraza mud volcano
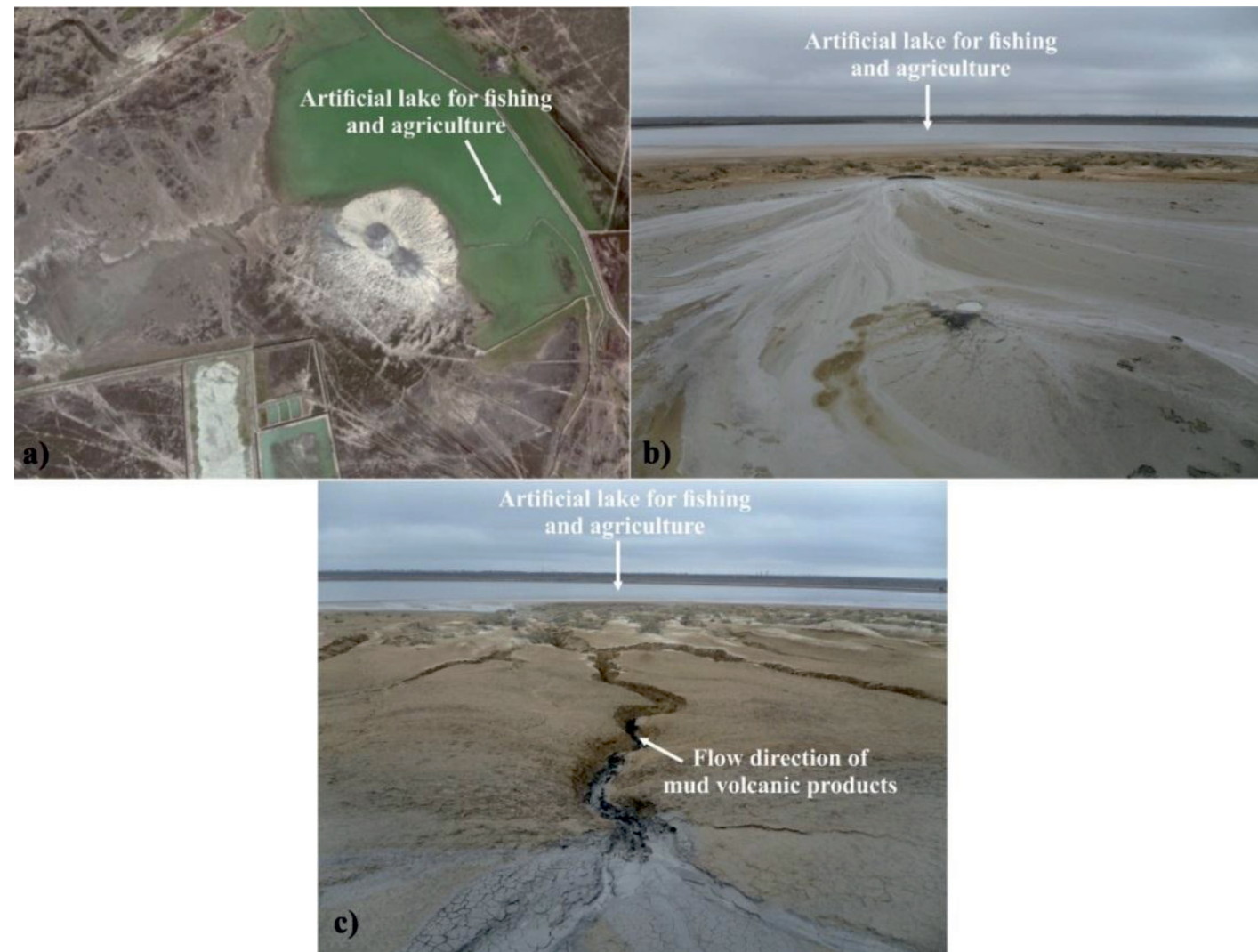

Fig. 3. The Duzdag mud volcano: (a) satellite image, (b) active salse on the crater field, (c) flows of volcanic products (water and mud mixture) towards the lake 


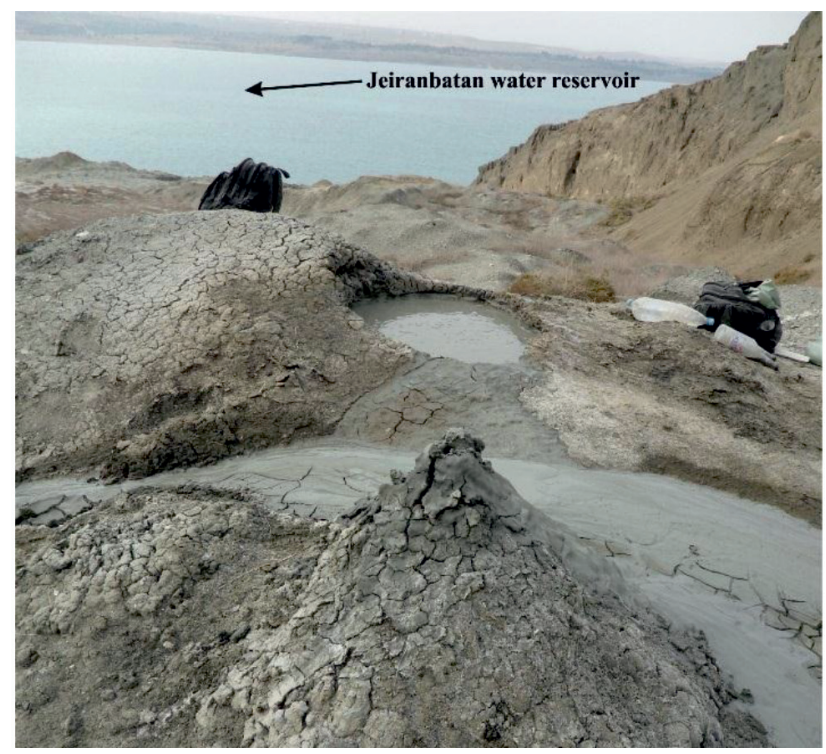

Fig. 4. Active gryphon and salse of the Kechaldag mud volcano located in close proximity to the Jeiranbatan water reservoir

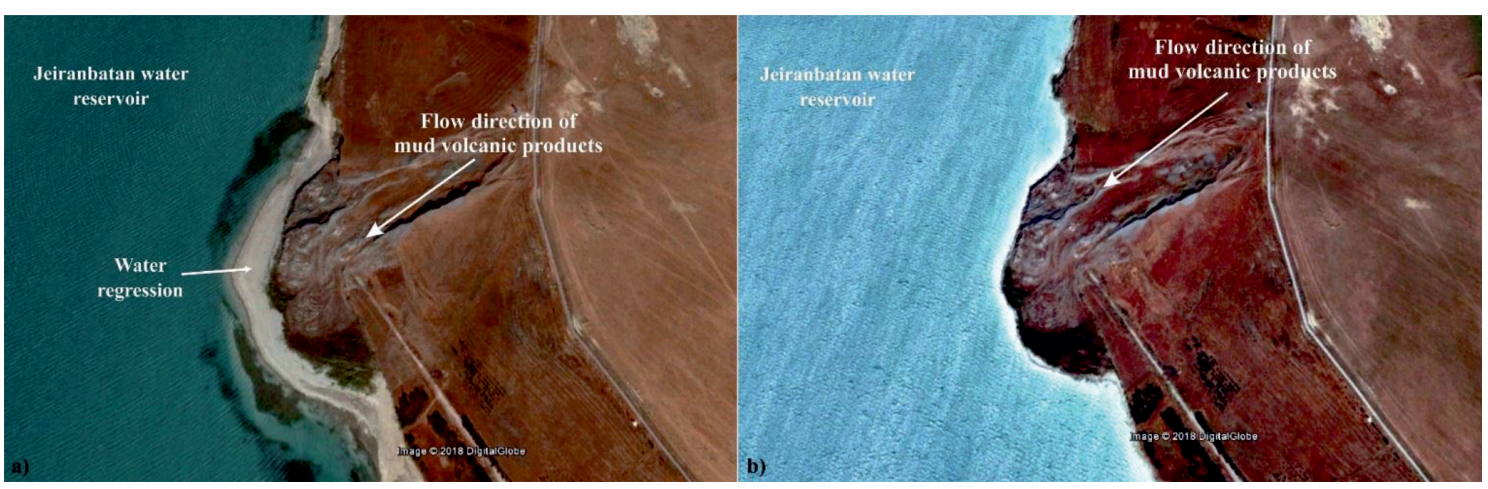

Fig. 5. Satellite image of the Kechaldag mud volcano: (a) - 2016, (b) - 2018

The Kechaldag mud volcano of $114 \mathrm{~m}$ in absolute height, is located $17 \mathrm{~km}$ northwest of Baku $\left(40^{\circ} 29^{\prime} 34.49^{\prime \prime} \mathrm{N}, 49^{\circ} 42^{\prime} 10.66^{\prime \prime} \mathrm{E}\right)$, in southeastern coast of Jeiranbatan reservoir. Fragmental product of the volcano covers an area of $1000 \times 600 \mathrm{~m}$ overlapping the sediments of Middle and Upper Eocene, Oligocene and Miocene which are exposed on the earth surface. Two eruptive centres of the volcano are confined to the most elevated parts of the locality (141.1 and $97.9 \mathrm{~m})$. The largest, southeastern centre, towering to $44 \mathrm{~m}$ above surrounding locality, has 350 long and $250 \mathrm{~m}$ wide crater, bordered with $1.2 \mathrm{~m}$ high rampart (Fig. 4). The second eruptive centre located at a distance of $675 \mathrm{~m}$ northwest from the first centre, has a small crater. The Kechaldag volcano is confined to the northwestern pericline of a large Kechaldag-Zigilpiri anti- cline. The fold is complicated by longitudinal rupture with which a volcano is related. The last registered eruption of the volcano (Table 4) was related to the construction works carried out in 2000 on its slope [21].

Depends on regular changes in the water level in the Jeiranbatan water reservoir, the products of the Kechaldag mud volcano directly contact the water of the reservoir (Fig. 5 (a) and $5(\mathrm{~b})$ ).

The Gaynarja mud volcano is located $8-10 \mathrm{~km}$ southwest of Shabran district (41 $\left.{ }^{\circ} 9^{\prime} 16.31^{\prime \prime} \mathrm{N}, 48^{\circ} 59^{\prime} 2.31^{\prime \prime E}\right)$. Occuring on the Miocenic-Pontian sediments it is expressed as a hill of $60 \mathrm{~m}$ in relative height. A $100 \mathrm{~m}$ diameter crater field has many mud cones and gryphones up to 2-3 $\mathrm{m}$ in height and 1.5$2.0 \mathrm{~m}$ in base diameter, and salses of $3.0-3.5 \mathrm{~m}$ 
in diameter (Fig. 6). Gaynarja volcano is confined to the same name northeasterly trending fold which is the central link of Talabi-Zaratdeniz anticlinal belt. The fold is asymmetric with a steep (55-600) northeastern limb and gently sloping (40-500) southwestern limb. The two longitudinal dislocations of the thrust pattern have been traced on the crest. In recent years there have been no any eruptions of the Gaynarja volcano (Table 4) [29].

The artificial reduction of the minimum distance between the Takhtakorpu water reservoir and the volcano reached a peak (Fig. 7 (a) and 7 (b)). Thus, the boundaries of the reservoir were expanded without taking into account the minimum distance between the mud volcano and the basin of reservoir. Most of the crater field of the volcano, with the exception of the northeastern part, was buried underwater [28] (Fig. 7 (b). As a result, the products of the mud volcano, as in the case of the Kecaldag volcano, directly contact the water of the reservoir.

\section{Materials and methods of research}

The study were conducted on 5 active mud volcanoes (1 - Kichik Maraza, 2 - Duzdag, 3 Kechaldag, 4 - Gaynarja, 5 - Otmanbozdag (Fig. 8)) of Shamakhi-Gobustan, Lower Kura, Absheron and Pre-Caspian-Guba regions. The visual, satellite, geological, geochemical and radioactive surveys, as well as laboratory analyzes were performed. 10 water and sopka breccia samples were collected on each volcano, and their chemical composition was determined at the Institute of Geology and Geophysics using the "S8 TIGER Series 2 WDXRF" spectrometer and the "Agilent 7700 Series ICP-MS" mass spectrometer. The organic properties of rocks (oil shales) found among mud volcanic breccias were determined in the process of two-stage pyrolysis. Radiometric measurements were carried out on multidirectional profiles passing through the crater field using radiometers "СРП-88M" and "Inspektor-1000". A gamma spectrometric analysis of water and breccia samples was conducted to study the anomalous nature of radioactivity. In addition, based on the eruption and daily activity of some volcanoes, an approximate calculation was made to estimate the amount of gases released into the atmosphere [27-29, 3941]. According to the data obtained, the extrapolation was carried out and the annual emission of total gas for the mud volcanoes of Azerbaijan was calculated.

\section{Results of research and their discussion}

The gas composition of the studied mud volcanoes mainly consist of $\mathrm{CH}_{4}, \mathrm{CO}_{2}$ and $\mathrm{N}_{2}$ (Table 5).

\section{Table 5}

Composition and average value of gases emitted from the studied mud volcanoes

\begin{tabular}{|l|c|c|c|}
\hline \multirow{2}{*}{ Mud volcano } & \multicolumn{3}{|c|}{ Emitted gas (\%) } \\
\cline { 2 - 4 } & $\mathrm{CH}_{4}$ & $\mathrm{CO}_{2}$ & $\mathrm{~N}_{2}$ \\
\hline Kichik Maraza & 95.38 & 1.20 & 1.04 \\
\hline Duzdag & 95.73 & 0.53 & 1.74 \\
\hline Kechaldag & 95.31 & 0.64 & 2.3 \\
\hline Gaynarja & 92.73 & 5.64 & 1.08 \\
\hline
\end{tabular}

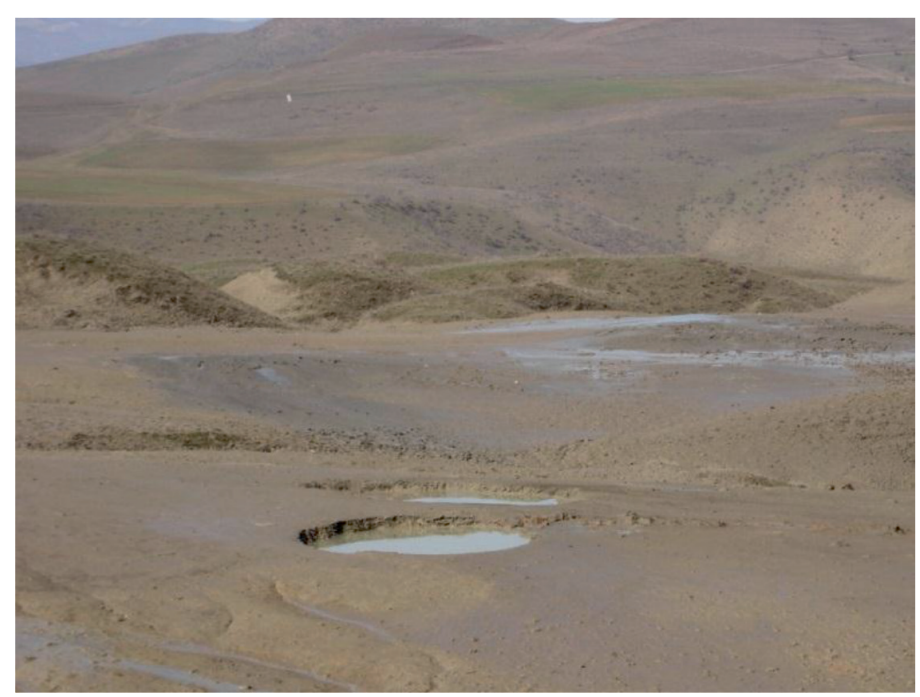

Fig. 6. Active gryphon and salses located on the crater field of the Gaynarja mud volcano 


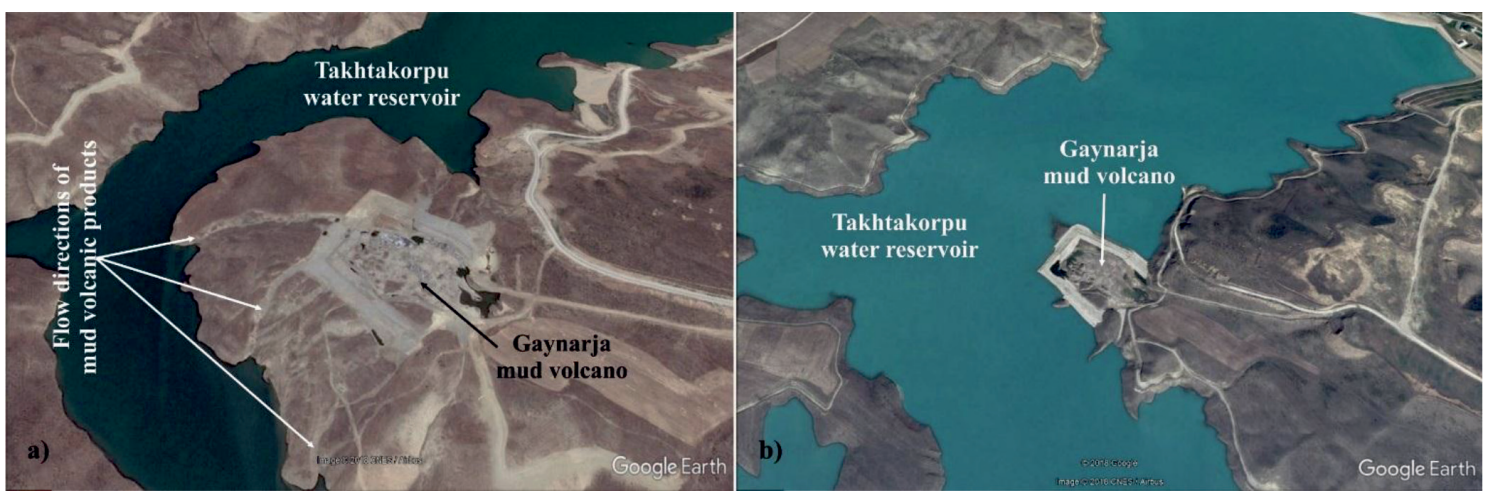

Fig. 7. Satellite image of the Gaynarja mud volcano: (a) - 2013, (b) - 2018

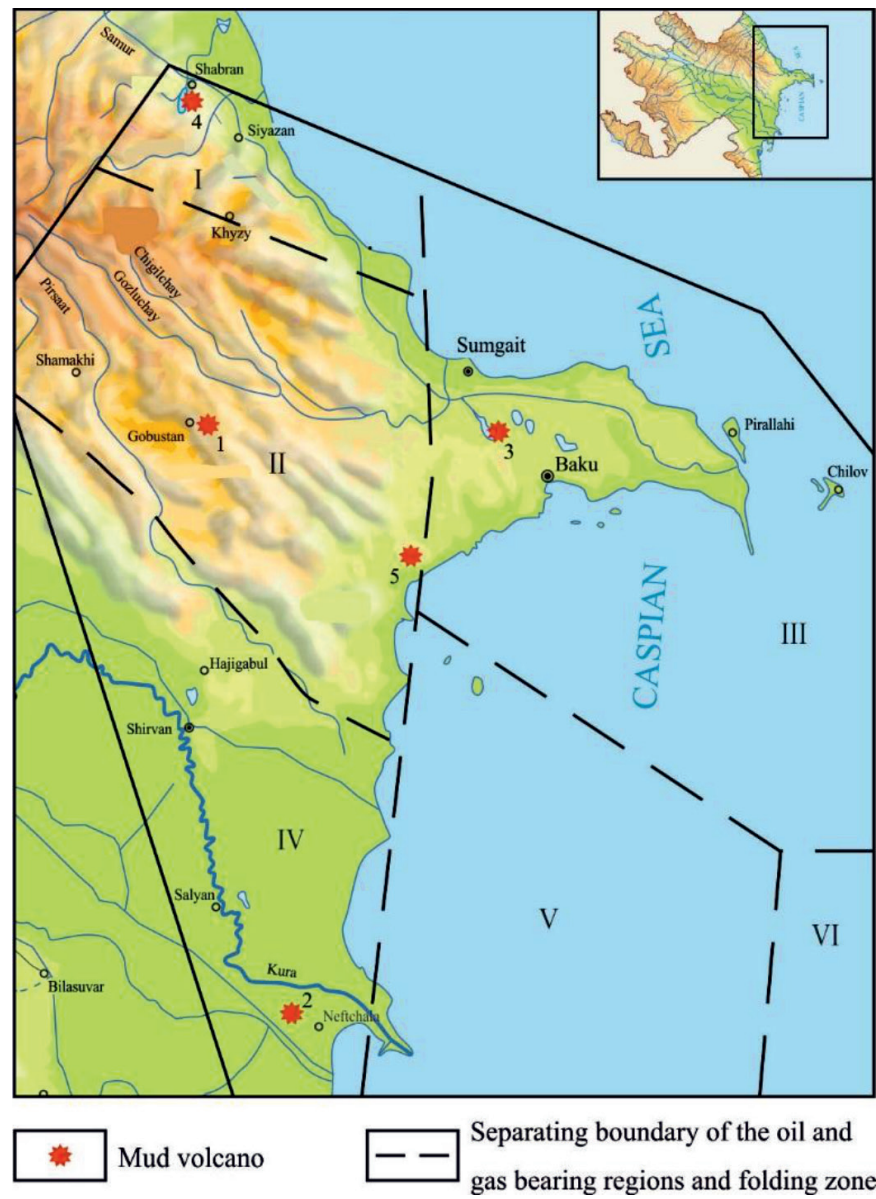

Fig. 8. Location map of the studied mud volcanoes (1 - Kichik Maraza, 2 - Duzdag, 3 - Kechaldag, 4 - Gaynarja, 5 - Otmanbozdag) within the oil and gas bearing regions and folding zone: I - PreCaspian-Guba, II - Shamakhi-Gobustan, III - Absheron, IV - Lower Kura, V - Baku archipelago, VI - folding zone in the deep South Caspian

According to calculations, $69.12 \mathrm{~m}^{3}$ of gas emitted from one active gryphon or salse of mud volcano (an average of 12 in each volcano (Table 4)) into the atmosphere, the total volume of which is $25228.8 \mathrm{~m}^{3}$ per year. Taking into ac- count the fact that the most part (about $70 \%$ ) of total mud volcanoes in Azerbaijan is characterized by active gryphon and salse activity, the annual release of gas into the atmosphere is about $6231513.6 \mathrm{~m}^{3}$. Due to the fact that the volume 
of emitted volcanic gas mainly depends on the seismic events occur in the region [27-32], the annual total amount of gas may increase in proportion to the volcanic activity.

The calculations on the amount of gas burned during the eruption were carried out on the basis of two phases of paroxysmal events (12:20:40 and 14:18:04) that occurred on February 6,2017 on the mud volcano Othmanbozdag (Table 4, 40¹4'25.00"N, 49³0'26.21"E) which the largest and highest mud volcano in the world (relative altitude $404 \mathrm{~m}$ ) (Fig. 9 (a) and (b)) located in the Absheron region of Azerbaijan. Calculations were carried out in accordance with statistical data on recorded eruptions of the mud volcano by the Republican Center of Seismological Service under the National Academy of Sciences of Azerbaijan, according to the following formula:

$$
Q b=\frac{\pi d^{2}}{4} \times h \times \frac{T}{t},
$$

where $\mathrm{h}$ - height of the flame (the first phase is $310 \mathrm{~m}$, the second is $370 \mathrm{~m}), \mathrm{d}$ - diameter of the flame (the first phase is $8.5 \mathrm{~m}$, the second is $12 \mathrm{~m}$ ), $\mathrm{T}$ - duration of flame (the first phase is 3.5 minutes, the second is 5 minutes), $\mathrm{t}$ - time of complete combustion of the flame (according to [36] -0.33 minutes). During the first phase of the paroxysm, the amount of released gas was approximately $186476.2 \mathrm{~m}^{3}$, in the second $-633709.1 \mathrm{~m}^{3}$. Taking into account the fact that at least 5 eruptions are recorded annually in the territory of Azerbaijan, and their above-mentioned parameters correspond to the eruption of Otmanbozdag, it can be concluded like the amount of ejected gas as a result of all these eruptions is $4,100,926.5 \mathrm{~m}^{3}$.

The average amount of the total mineralization of the waters carried to the Earth's surface by mud volcanoes: Kichik Maraza - $10 \mathrm{~g} / \mathrm{l}$; Duzdag - 47.3 g/l, Kechaldag - 9.6 g/l, Gaynarja $-63.8 \mathrm{~g} / \mathrm{l}$. The mineralization of the Gaynarja mud volcano is much higher in comparison with other volcanoes. The estimates allow to conclude that the mineralization value in mud volcanoes of Azerbaijan increases from north to south. Classification types of studied volcanic waters for the Pre-Caspian-Guba and Absheron regions - sodium hydrocarbonate and calcium hypochlorite, Shamakhi-Gobustan region - hydrocarbonate sodium, Lower Kura region - calcium hypochlorite and sodium hydrocarbonate.

$\mathrm{SO}_{4}^{2-}$ and $\mathrm{K}^{+}, \mathrm{Ca}^{2+}, \mathrm{Mg}^{2+}$ in the chemical composition of the water samples taken from the Kehcaldag mud volcano are below the average standards for drinking water, but $\mathrm{Na}^{+}, \mathrm{Cl}^{-}$ and $\mathrm{HCO}_{3}^{-}$are higher. The $\mathrm{Ph}$ values are corresponding to the norm. $\mathrm{Na}^{+}, \mathrm{K}^{+}, \mathrm{Ca}^{2+}, \mathrm{Mg}^{2+}$, $\mathrm{Cl}^{-}, \mathrm{HCO}_{3}^{-}$in the chemical composition of the water samples taken from the Gaynarja mud volcano are significantly exceed the standards, but $\mathrm{SO}_{4}^{2-}$ is below. The $\mathrm{Ph}$ indicators do not exceed the standards (Fig. 10).

The results of a comparative analysis of the microelement composition of breccia samples from the sopkas of the studied mud volcanoes show that $\mathrm{Li}, \mathrm{V}, \mathrm{Zn}, \mathrm{Rb}, \mathrm{La}, \mathrm{Ce}, \mathrm{Nd}, \mathrm{Pb}$, Th in Kichik Maraza, V, Cr, Ni, Sr in Duzdag, Li, $\mathrm{V}, \mathrm{Cr}, \mathrm{Zn}, \mathrm{Sr}, \mathrm{Pb}$ in Kechaldag sharply exceed the norm of the average value for sedimentary rocks [37] (Fig. 11).

The amount of organic matter in the composition of oil shales, found among the solids products of the studied mud volcanoes, ranges from 9.5 to $12.65 \%$. In the process of pyrolysis, it was established that the amount of hydrocarbons (gases) is insignificant in such rocks, and most of the organic matter is in the form of coal (Table 6).

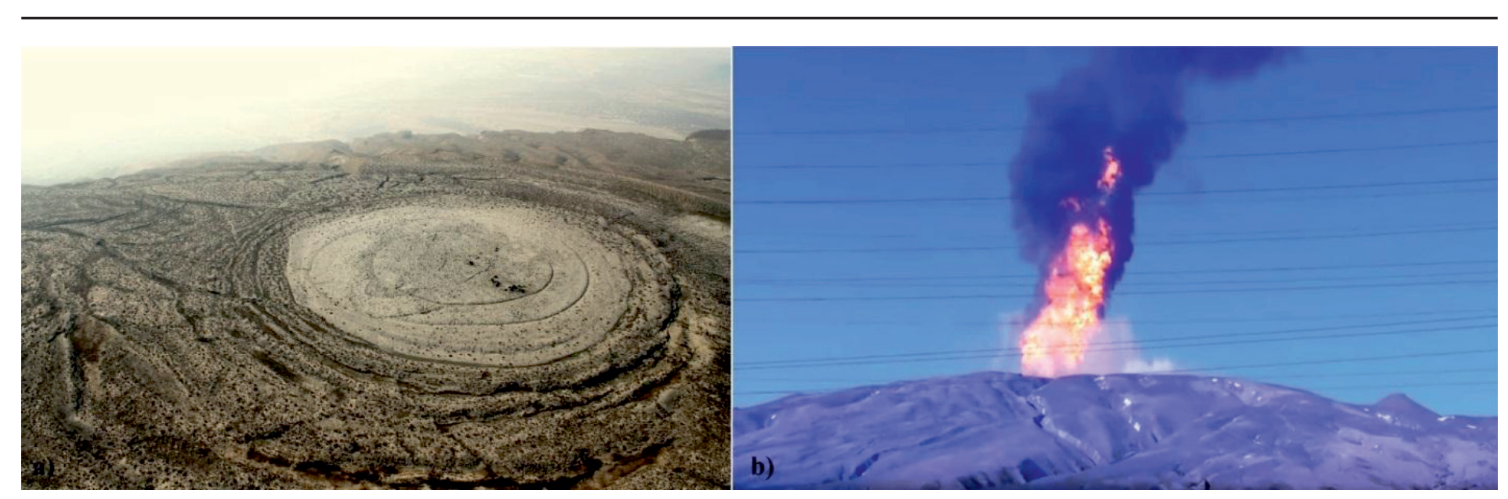

Fig. 9. The Otmanbozdag mud volcano: (a) - image from a helicopter, (b) - eruption recorded on February 6, 2017 

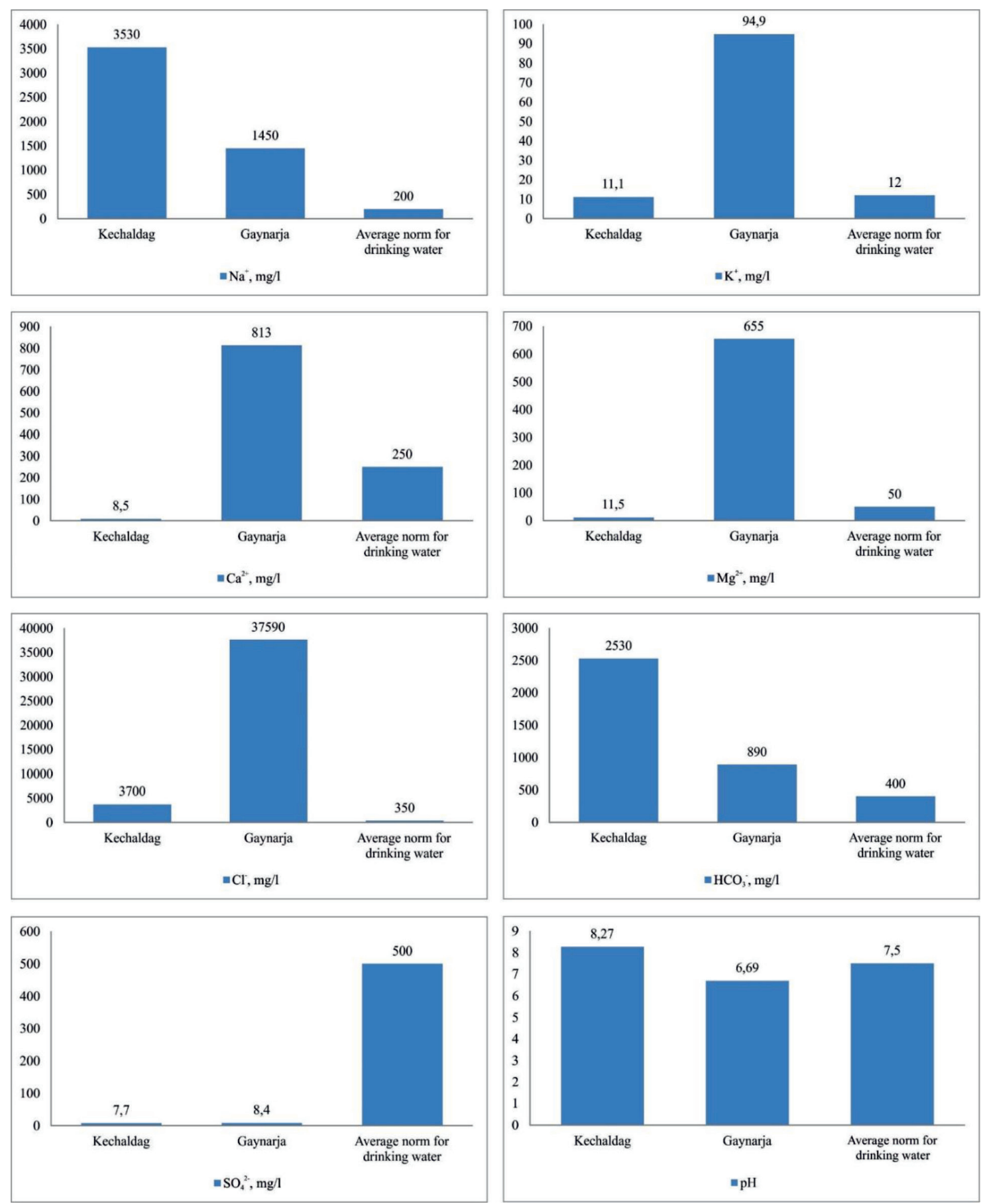

Fig. 10. Comparisons between the chemical composition of water samples taken from the studied mud volcanoes and the average norm for drinking water

Table 6

The results of the two-stage pyrolysis of rock samples taken from the Gaynarja mud volcano

\begin{tabular}{|c|c|c|c|c|c|}
\hline Sample & Organic matter, $\%$ & \multicolumn{2}{|c|}{$500-550^{\circ} \mathrm{C}$} & \multicolumn{2}{c|}{$800-850^{\circ} \mathrm{C}$} \\
\cline { 3 - 6 } & & Oil & Gas & Oil & Gas \\
\hline 1 & 12.2 & - & 2.43 & - & 2.67 \\
\hline 2 & 12.65 & - & 4.99 & - & 1.88 \\
\hline 3 & 9.5 & - & 5.24 & - & 1.20 \\
\hline
\end{tabular}




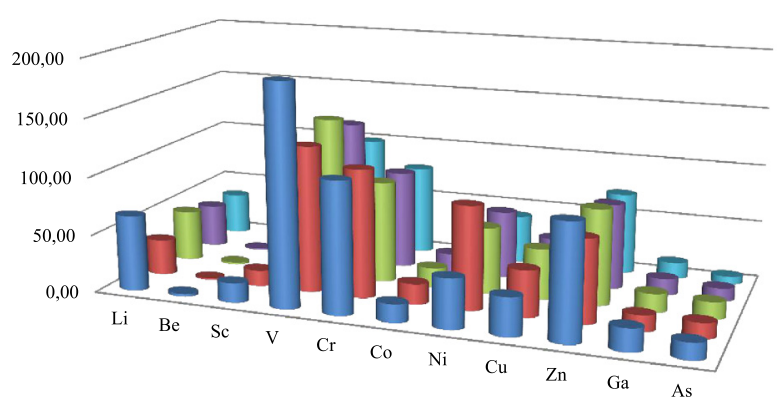

$\square$ Kichik Maraza $\backsim$ Duzdag $₫$ Kechaldag $₫$ Gaynarja $\backsim$ Average value for sedimentary rock

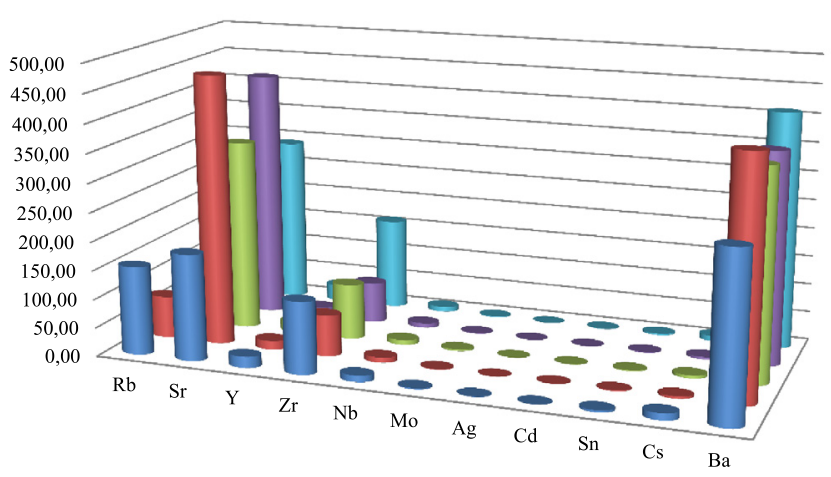

$\square$ Kichik Maraza $₫$ Duzdag $₫$ Kechaldag $₫$ Gaynarja $₫$ Average value for sedimentary rock

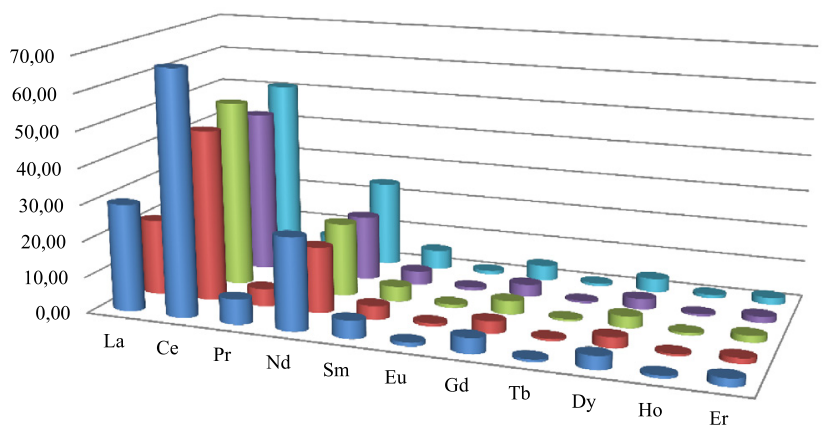

$\varpi$ Kichik Maraza $\square$ Duzdag $₫$ Kechaldag $₫$ Gaynarja $₫$ Average value for sedimentary rock

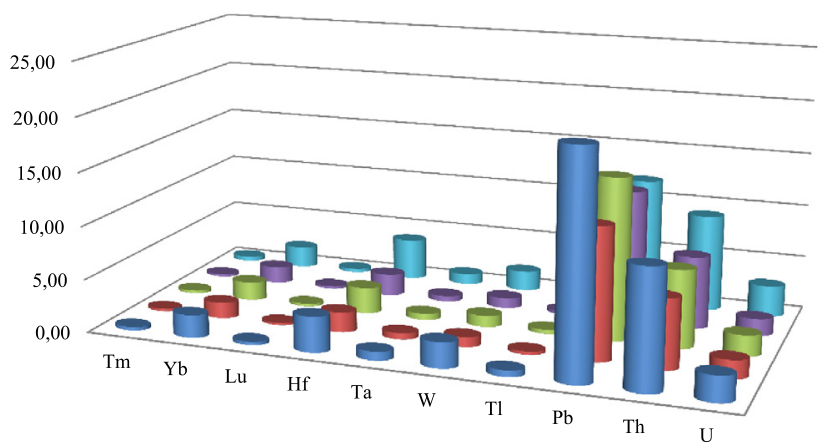

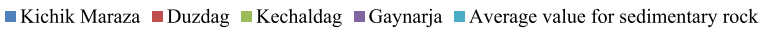

Fig. 11. Comparative analysis between the microelement composition of breccia samples taken from the studied mud volcanoes and average values for sedimentary rock [37] (ppm) 


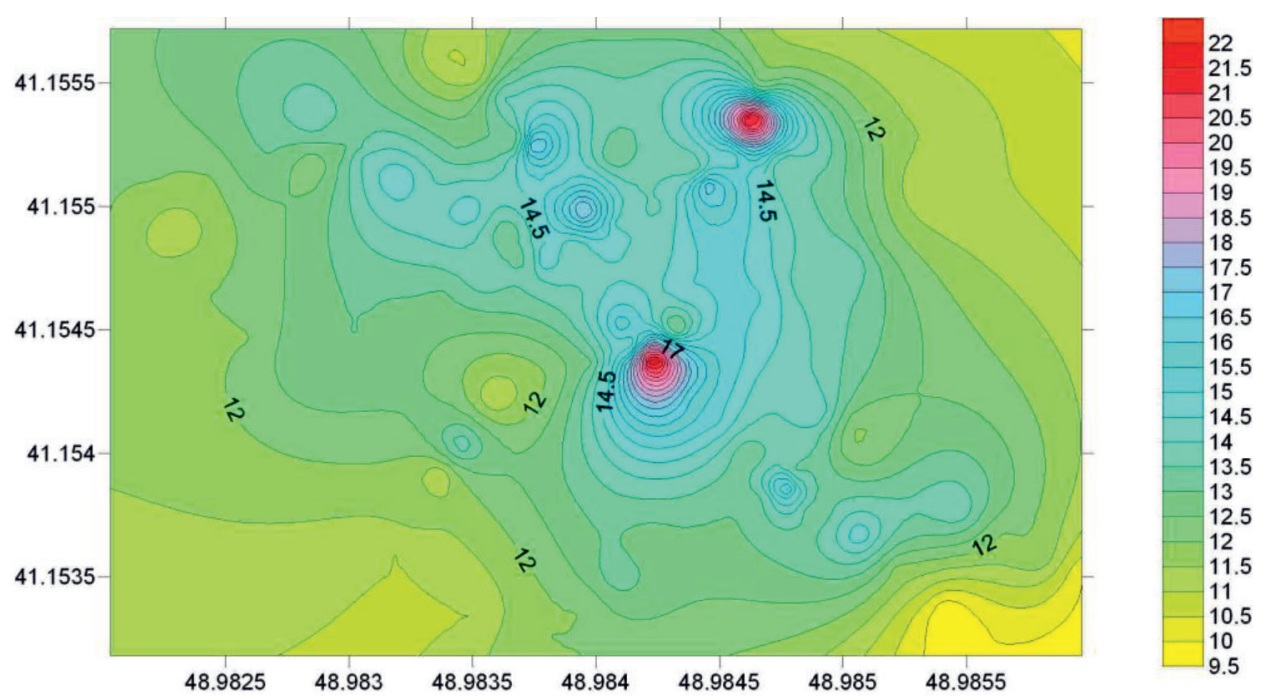

Fig. 12. Distribution map of the radioactivity in the crater field of the Gaynarja mud volcano

Table 7

The content of radionuclides in the water samples from gryphons and salses of the Gaynarja mud volcano

\begin{tabular}{|c|c|c|c|c|}
\hline \multirow{2}{*}{$\begin{array}{c}\text { Radionuclide, } \\
\text { Bk/1 }\end{array}$} & 1 & 2 & $\begin{array}{c}\text { Average concentration } \\
\text { for drinking water Bk/l }\end{array}$ \\
\cline { 2 - 5 } & $25.6 \pm 4.2$ & $15.2 \pm 1.4$ & $16.6 \pm 1.9$ & 22.0 \\
\hline $\mathrm{K} 40$ & $0.228 \pm 0.054$ & $0.154 \pm 0.024$ & $0.126 \pm 0.028$ & 0.5 \\
\hline $\mathrm{Ra} 226$ & $0.138 \pm 0.010$ & $0.324 \pm 0.050$ & $0.644 \pm 0.036$ & 0.2 \\
\hline $\mathrm{Ra} 228$ & $0.20 \pm 0.12$ & $0.18 \pm 0.10$ & $0.10 \pm 0.06$ & 120.0 \\
\hline $\mathrm{Rn} 222$ & $0.0144 \pm 0.0032$ & $0.0064 \pm 0.001$ & $0.0120 \pm 0.0016$ & 3.0 \\
\hline $\mathrm{U} 235$ & $0.312 \pm 0.069$ & $0.139 \pm 0.021$ & $0.261 \pm 0.034$ & 3.1 \\
\hline $\mathrm{U} 238$ & & & & \\
\hline
\end{tabular}

Table 8

Specific activity and content of radionuclides in the breccia samples of the Gaynarja mud volcano

\begin{tabular}{|c|c|c|c|c|c|}
\hline Sample & $\begin{array}{c}\text { Integral radioactivity } \\
\mathrm{mR} / \mathrm{h}\end{array}$ & Activity, Bk/kg & $\mathrm{U}, \mathrm{Bk} / \mathrm{kg}$ & $\mathrm{Th}, \mathrm{Bk} / \mathrm{kg}$ & $\mathrm{K}, \mathrm{Bk} / \mathrm{kg}$ \\
\hline 1 & 23 & 481.56 & 431.81 & - & 634.61 \\
\hline 2 & $14-15$ & 106.4 & 50.19 & 0.45 & 704.87 \\
\hline 3 & $16-17$ & 118.51 & 12.15 & 77.99 & 208.42 \\
\hline 4 & 23 & 515.12 & 480.15 & - & 671.71 \\
\hline
\end{tabular}

The radioactivity of the breccia on the crater field of the Gaynarja mud volcano is 9.5-23 $\mathrm{mR} / \mathrm{h}$. Lower values of radioactivity were recorded in the central, northern and northeastern parts of the volcano (Fig. 12). This can be explained by the presence of tectonic dislocations in these zones.

The amount of radionuclides ( $\mathrm{Ra} 228$ in two samples, K 40 in one sample) in water samples taken from the active gryphons and salses of Gaynarja mud volcano sharply ex- ceeds the average concentration of radionuclides for drinking water. The concentration of radionuclides $\mathrm{Ra} 226, \mathrm{Rn} 222, \mathrm{U} 235$ and $\mathrm{U}$ 238 is much lower than the norms (Table 7).

Radionuclides Ra 228 and $\mathrm{Ra} 222$ were not detected in the breccia samples. Analyzed samples were selected in the zones of both weak and relatively high radioactivity. Thus, the average indicator of radioactivity of rocks ranges between 106.4 and $515.12 \mathrm{Bk} / \mathrm{kg}$ (Table 8). These indicators reflect the overall complex level of 
gamma rays, and depend on the amount of radionuclides in the rock composition. Exceeding the level of gamma rays in two rock samples can be explained by the presence of a uranium element in their composition. The amount of thorium does not exceed the mean value, and potassium is present in all volcanic rocks.

\section{Conclusions}

The content of gases released into the atmosphere as a result of the eruption and daily activity of mud volcanoes in Azerbaijan, mainly consist of $\mathrm{CH}_{4}, \mathrm{~N}_{2}$ and $\mathrm{CO}_{2}$. The total amount of these gases per year is more than $10300000 \mathrm{~m}^{3}$, that $\mathrm{CH}_{4}$ dominates in concentration (more than $90 \%$ ). The obtained results show that volcanic gas emissions have a serious influence on the overall gas budget of the atmosphere.

The total level of mineralization in volcanic waters is high, on average more than 30 $\mathrm{g} / \mathrm{l}$. The classification types of these waters are sodium hydrocarbonate and calcium hypochlorite. $\mathrm{Na}^{+}, \mathrm{K}^{+}, \mathrm{Ca}^{2+}, \mathrm{Mg}^{2+}, \mathrm{Cl}^{-}, \mathrm{HCO}_{3}^{-}$are significantly higher than the average allowable value for drinking water in some samples. The radionuclides $\mathrm{Ra} 228$ and K 40 were found in the water samples that their concentration is also much higher than the norm for drinking water.

Some microelements, such as $\mathrm{Cr}, \mathrm{Ni}, \mathrm{Sr}, \mathrm{Pb}$ and $\mathrm{Th}$ were found in the breccia composition of mud volcanoes, that their concentrations are significantly higher than the average value for sedimentary rocks. The amount of organic matter in the rocks, ejected by mud volcanoes, is more than $9 \%$. The results of pyrolysis show that the yield of hydrocarbons is insignificant, organic matter is most often in the form of coal.

Radioactive backgrounds on the crater field of the mud volcano were often increased, which is explained by tectonic dislocations in the internal structure of the volcano. An increase in the gamma level in some breccia samples selected in areas with a high radioactive background is associated with an increase in the concentration of uranium.

This work was supported by the Science Development Foundation under the President of the Republic of Azerbaijan - Grant № EIF/ GAM-3-2014-6(21)-24/11/2.

\section{References}

1. Abbasov O.R. About Paleogene-Miocene combustible shales of Gobustan // Proceedings of geology institute. 2005. Issue 33 , pp. 10-15.

2. Abbasov O.R. The geochemical characteristic of combustible shales of Paleogene-Miocene in Gobustan // The Second International Scientific Conference of Young Scientists and Students "New directions of investigations in the Earth Sciences". Baku, 2007, pp. 8
3. Abbasov O.R. Geological and geochemical features of combustible slates of Gobustan (Azerbaijan) and their forecast inventories // Bulletin of the Atyrau Institute of oil and gas. 2008. Vol 2, issue 14, pp. 22-29.

4. Abbasov O.R. Regularities of extension combustible schists in Oligocene-Miocene sediments of Gobustan // The National Committee of Geophysicists of Azerbaijan. 2010. Issue $1-2$, pp. $47-49$

5. Abbasov O.R. Possible resources of Gobustan fields and combustible manifestations // Azerbaijan Oil Industry. 2010. Issue 5, pp. 59-62.

6. Abbasov O.R., Baloglanov E.E., Huseynov A.R., Akhundov R.V. Hydrocarbon potential of Baku Archipelago deep deposits by data of mud volcanoes ejects // Proceeding of the 1st International Conference "Ultra deep hydrocarbon potential: future energy resources - reality and predication". Baku, 2012, pp. $137-139$

7. Abbasov O.R., Ibadzadeh A.D., Mammadova A.N. Hydrocarbon generation potential of the deeper sediments of Azerbaijan // Integrated approach for unlocking hydrocarbon resources. Baku, 2012, pp. 48.

8. Abbasov O.R., Mammadova A.N. Evolution of ideas about combustible shales of Azerbaijan and their practical importance // Proceedings the Sciences of Earth, Azerbaijan National Academy of Sciences. 2012. Issue 3, pp. 12-16.

9. Abbasov O.R., Mamedova A.N., Huseynov A.R., Baloglanov E.E. Some new data of geochemical researches of combustible slates of Azerbaijan // Geology, geophysics and development of oil and gas fields. 2013. Issue 2, pp. 32-35.

10. Abbasov O.R., Akhundov R.V. The comparative analysis of mud volcanoes of Azerbaijan and Ukraine (an example of Gobustan region and the Kerch Peninsula) // Proceeding of the 5th International Scientific Conference of Young Scientists and Students "Fundamental and applied geological science: achievements, prospects, problems and ways of their solutions". Baku, November 14-16, 2013, pp. 16-18.

11. Abbasov O.R., Akhundov R.V. Petroleum potential of Paleogene and Miocene deposits in Gobustan based on oil shale products of mud volcanoes // Baku World Forum of Young Scientists. Baku, 2014, pp. 27-28.

12. Abbasov O.R. Oil Shale of Azerbaijan: Geology, Geochemistry and Probable Reserves // IJRSSET - International Journal of Research Studies in Science, Engineering and Technology. 2015. Vol. 2, issue 10, pp. 31-37.

13. Abbasov O.R., Ibadzade A.J., Khasaeva A.B., Guseynov A.R., Akhundov R.V., Baloglanov E.E. Hydrocarbonic potential of the deep-shipped deposits of Gobustan (Azerbaijan) (on the basis of combustible slates and oil-bearing breeds, emissions of mud volcanoes) // Resursovosproizvodyashchy, lowwaste and nature protection technologies of development of a subsoil. Bishkek, Kyrgyzstan, 2015, pp. 342-443.

14. Abbasov O.R., Baloglanov E.E., Akhundov R.V. Geochemical analysis of oil shale and oil-bearing rocks of Gobustan mud volcanoes // 6th International Conference of Young Scientists and Students "Multidisciplinary approach to solving problems of geology and geophysics". Baku, October 12-15, 2015, pp. 118-119.

15. Abbasov O.R., Baloglanov E.E., Akhundov R.V. Organic compounds in ejected rocks of mud volcanoes as geological and geochemical indicators: a study from Shamakhi-Gobustan region (Azerbaijan) // International Multidissiplinar Forum “Academic Science Week-2015". Baku, 2015, pp. 3-4.

16. Abbasov O.R. Geological and geochemical properties of oil shale in Azerbaijan and petroleum potential of deep-seated Eocene-Miocene deposits // European Journal of Natural History. 2016. Issue 2, pp. 31-40.

17. Abbasov O.R. Distribution regularities of oil shale in Azerbaijan // ISJ Theoretical \& Applied Science. 2016. Vol. 3, issue 35, pp. 165-171. Doi: http://dx.doi.org/10.15863/ TAS.2016.03.35.28

18. Abbasov O.R. Genesis and organic geochemistry of oil shale in Eastern Azerbaijan // Proceedings of the VII Youth Scientific Conference "Ideas and Innovations in Geosciences". Kyiv, Ukraine, October 25-27, 2017, pp. 33.

19. Abbasov O.R. Distribution regularities and geochemistry of oil shales in Azerbaijan // Mineral resources of Ukraine. 2017. Issue 2, pp. 22-30.

20. Aliyev Ad.A., Ibadzadeh A.J., Abbasov O.R., Mammadova A.N. The dynamics of genesis of organic substance in oil shales // Azerbaijan Oil Industry. 2014. Issue 07-08, pp. 3-7. 
21. Aliyev Ad.A., Guliyev I.S., Dadashov F.H., Rahmanov R.R. Atlas of world mud volcanoes. Baku: Publishing house "Nafta-Press", "Sandro Teti Editore", 2015, 321 pp.

22. Aliyev Adil, Abbasov Orhan. Organic geochemical characteristics of oil shale in Azerbaijan // The 36th National and the 3rd International Geosciences Congress, Tehran, Iran, February 25-27, 2018, pp. 1-10.

23. Aliyev Ad.A., Abbasov O.R. Mamedova A.N. Geochemistry of oil shale in Azerbaijan // ISJ Theoretical \& Ap plied Science. 2018. Vol. 05, issue 61, pp. 315-322. Doi: https:// dx.doi.org/10.15863/TAS.2018.05.61.52

24. Aslanov B.S., Khuduzadeh A.I. The role of neotectonic processes in the formation of hydrocarbon deposits in the territory of Azerbaijan // STB Karotazhnik. Tver, 2017. Issue 8, pp. 57-66.

25. Babayev F.R., Abbasov O.R., Mamedova A.N., Huseynov A.R. Studying of bitumens of Azerbaijan // Actual problems of humanitarian and natural sciences. 2013. Vol. 7, issue 54, pp. 40-42.

26. Bagirov E., Nadirov R., Lerche I. Earthquakes, mud volcano eruptions, and fracture formation hazards in the South Caspian Basin: statistical inferences from the historical record. Energy Exploration and Exploitation. 1996. Vol. 14, issue 6 , pp. 585-606.

27. Baloglanov E.E., Abbasov O.R., Akhundov R.V. GasHydrochemical Indicators of Mud Volcanism Communication with Seismicity // XXIII International Scientific Conference of Students, Post-Graduates and Young Scientists "Lomonosov-2016". Moscow, Aprel 11-15, 2016, pp. 1.

28. Baloglanov E.E., Abbasov O.R., Akhundov R.V., Nuruyev I.M. Daily gryphon-salse activity of mud volcanoes and geo-ecological risk (based on researches, conducted in Gaynarja mud volcano) // Water resources, hydraulic facilities and environment. Baku, 2017, pp. 512-517.

29. Baloglanov E.E., Abbasov O.R., Akhundov R.V., Huseynov A.R., Abbasov K.A., Nuruyev I.M. Daily activity of mud volcanoes and geoecological risk: a case from Gaynarja mud volcano, Azerbaijan // European Journal of Natural History. 2017. Issue 4, pp. 22-27.

30. Baloglanov E.E., Abbasov O.R., Akhundov R.V., Abbasov K.A., Nuruyev I.M. Impact of seismic activity on fluid (gas and water) and temperature regimes of mud volcanoes in Shamakhi-Gobustan region (Azerbaijan) // Proceedings of the VII Youth Scientific Conference "Ideas and Innovations in Geosciences". Kyiv, Ukraine, October 25-27, 2017, pp. 31.

31. Baloglanov E.E., Abbasov O.R., Akhundov R.V., Hasanov E.H., Abbasov K.A., Nuruyev I.M. Anomalies in gas-hydrogeochemical indicators of mud volcanoes in connection with seismic activity: on the basis of mud volcanoes data in Shamakhi-Gobustan (Azerbaijan) and Sakhalin Island (Russia) // IS. Theoretical \& Applied Science. 2018. Vol. 1, issue 57, pp. 176185. Doi: https://dx.doi.org/10.15863/TAS.2018.01.57.32

32. Baloglanov E.E., Abbasov O.R., Akhundov R.V. Hydrochemical changes in mud volcanoes: a precursor of earthquakes // XXV International Scientific Conference of Students, Post-Graduates and Young Scientists "Lomonosov-2018". Moscow, Aprel 9-13, 2018, pp. 1.

33. Bashirov O.Kh. The mineralogical investigation of the materials of the Keyreki mud volcano // Azerbaijan Geologist. 2016. Issue 20, pp. 87-90.

34. Bashirov O.Kh. Some new data of mineralogy of Shikzarli mud volcano // Proceedings of the VII Youth Scientific Conference "Ideas and Innovations in Geosciences". Kyiv, Ukraine, October 25-27, 2017, pp. 47.

35. Cothray J.E., Aliyev Ad.A. Delineation of Mud Volcano Complex, Sacrificial Mudflows, Slump Blocks, and Shallow Gas Reservoirs Offshore Azerbaijan. Offshore Technology Conference. Houston, Texas, USA, May 1-4, 2000, pp. 28

36. Dadashev F.G. Hydrocarbon gases of mud volcanoes in Azerbaijan. Baku: Azerneshr, 1963. 65 pp.

37. Grigoryev N.A. Distribution of chemical elements in the upper part of the continental crust. Ekaterinburg: UrO RAN. 2009. $382 \mathrm{pp}$.

38. Fuad Nabiyev and Orhan Abbasov. Geochemical study of ejected rocks (oil shale and oil-bearing rocks) of mud volcanoes in Shamakhi-Gobustan region (Azerbaijan) as indicator of hydrocarbon generation and accumulation // European Geosciences Union General Assembly 2018, Geophysical Research Abstracts. Vol. 20, EGU2018-12244. Vienna, Austria, April 8-13, 2018.
39. Hasanov E.H. Characteristics of the choice of favorable engineering and geological conditions for fulfilling of the prospecting and exploration surveys // Young Researcher. Baku, 2016. Volume II, issue 2, pp. 73-77.

40. Hasanov E.H., Yolchiyev M.R. Report on prospecting and engineering and surveys of the Garabakh field // Integrated Engineering Exploration Production. 2017. 218 pp.

41. Hasanov E.H., Khuduzadeh A.I. Assessment of perspective areas in the north Absheron uplift zone of the South Caspian basin and geological and geochemical features of the upper part of the sections: a study from the Garabakh field // ISJ Theoretical \& Applied Science. 2018. Vol. 04, issue 60, pp. 5057. Doi: https://dx.doi.org/10.15863/TAS.2018.04.60.12

42. Ibadzadeh A.J., Abbasov O.R. Geochemistry of combustible shales in Gobustan and use of their pyrolysis products // Proceedings of Geology Institute. 2008. Issue 36, pp. 58-67.

43. Khuduzadeh A.I., Akhundov Sh.Kh., Mustafaev Y.R., Gurbanov M.F. Lithological-facies and paleotectonic criterias in the formation of hydrocarbon deposits of the Paleogene complex sediments in the oil and gas bearing region Kura and Gabirri interfluves // Azerbaijan Oil Industry. Baku, 2015. Issue 12, pp. 6-12.

44. Khuduzadeh A.I. Formation and oil-gas content of thrust type structures in north-west part of Absheron archipelago // Azerbaijan Oil Industry. Baku, 2016. Issue 4, pp. 13-18.

45. Khuduzadeh A.I., Akhundov Sh.Kh., Askerov I.N., Akhundov S.Sh. Lithophatic features, structural and paleotectonic analysis of Upper Cretaceous sediments in the middle Kura basin based on new data (on the example of the Kura and Gabirri interfluves) // Proceedings of the Azerbaijan National Academy of Sciences, Earth Sciences. Baku, 2017. Issue 1-2, pp. 37-44.

46. Matthieu Dupuis, Francis Odonne, Orxan Abbasov, Teymur Fiqarov, Anthony Dofal, Patrice Imbert, Bruno C. Vendeville. The Ayaz-Akhtarma mud volcano: an actively growing mud pie in the foothills of the Greater Caucasus, Azerbaijan // 13th International Conference on Gas in Marine Sediments. Tromsø, Norway, 2016.

47. Mellors R, Kilb D, Aliyev A, Gasanov A, Yetirmishli G. Correlations between earthquakes and large mud volcano eruptions // Journal of Geophysical Research. 2007. Vol. 112. B04304. doi:10.1029/2006JB004489. pp. 1-11.

48. Milkov A.V., Sassen R., Apanasovich T.V., Dadashev F.G. Global gas flux from mud volcanoes: a significant source of fossil methane in the atmosphere and the ocean. Geophysical Research Letters. 2003. Vol. 30, issue 2, pp. 1037.

49. Newton R.S., Cunningham R.C., Schubert C.E. Mud volcanoes and pockmarks: seafloor engineering hazards or geologic curiosities? Proceedings - Annual Offshore Technology Conference. Houston, USA, May 5-8, 1980, vol. 1, pp. 425-435.

50. Orhan Rafael Abbasov. Oil shale of Azerbaijan: geology, geochemistry and probable reserves // International Journal of Research Studies in Science, Engineering and Technology. 2015. Vol. 2, issue 9, pp. 31-37.

51. Orhan R and Abbasov. Organic compounds in ejected rocks of mud volcanoes as geological and geochemical indicators of source rock: a study of oil shale in Shamakhi-Gobustan region (Azerbaijan) // International Journal of Current Advanced Research. 2016. Vol. 5, issue 7, pp. 1042-1046.

52. Orhan Abbasov and Adil Aliyev. Geodynamic stresses and eruption paroxysm of mud volcanoes // European Geosciences Union General Assembly 2018, Geophysical Research Abstracts. Vol. 20, EGU2018-6467. Vienna, Austria, April 8-13, 2018 .

53. Venikova A.L., Obzhirov A.I., Abbasov O.R., Baloglanov E.E., Akhundov R.V. Mud volcanism and seismicity (based on a comparative analysis of geochemical data of mud volcanoes located on Sakhalin Island of the Russian Federation and Shamakhi-Gobustan District of Azerbaijan) // 1st International Scientific Conference of Young Scientists and Specialists "The role of multidisciplinary approach in solution of actual problems of fundamental and applied sciences (Earth, technical and chemical)". Baku, October 15-16, 2014, pp. 5-8.

54. Yershov V.V., Nikitenko O.A., Perstneva Y.A., Baloglanov E.E., Abbasov O.R. Geochemical studies of products related to the activity of mud volcanoes in Azerbaijan // V AllRussian youth geological conference "Geology, geoecology and resource potential of the Urals and adjacent territories". Ufa, September 25-30, 2017, pp. 117-123. 


\title{
MORPHOMETRIC PARAMETERS OF THE FACE IN PATIENTS WITH DECOMPENSATED VERTICAL-ANTERIOR FORM OF INCREASED ABRASION OF TEETH
}

\author{
${ }^{1}$ Subbotin R.S., ${ }^{1}$ Puzdyreva M.N., ${ }^{1}$ Fishchev S.B., ${ }^{2}$ Lepilin A.V., ${ }^{1}$ Orlova I.V., ${ }^{1}$ Sevastyanov A.V. \\ ${ }^{1}$ St. Petersburg State Pediatric Medical University of the Ministry of Healthcare of the Russian \\ Federation, St.Petersburg, e-mail: roma.seregin.92@mail.ru; \\ ${ }^{2}$ Federal State budgetary Educational Institution of Higher Education "Saratov State Medical University \\ named after V.I. Razumovsky" of the Ministry of Healthcare of the Russian Federation, Saratov

\begin{abstract}
The paper presents an analysis of the morphometric parameters of the face in patients with increased abrasion of the teeth with a decrease in the height of the gnathic part. Morphometric parameters of the face in the decompensated vertical-mesial form of increased teeth abrasion were compared with the norm. The obtained data can be used to determine the tactics of orthodontic and orthopedic treatment of patients with increased abrasion. Increased abrasion of the teeth (IAT) is a common nosological form in dentistry. Iordanishvili A.K. (2015) Notes that adult IAT occurs in 3,5-35,4\% cases. IAT is less often within younger people $(6,3 \%)$ than within middle-aged $(32,7 \%)$ and also within elderly $(11,8-20,6 \%)$. A ranking place in dentistry goes to patients with increased abrasion of the teeth (IAT), this pathology occurs in $11,8 \%$ to $42,6 \%$ of cases $(2,4,5,8,9,10,11,12)$. The reasons of IAT could be hard tooth tissues inferiority, functional congestion of teeth, chemical activation, occupational hazards, muscles of mastication tonus and other factors $(2,6,7,8,12)$.
\end{abstract}

Keywords: orthodontia, orthopedics, increased dental abrasion

Current increased abrasion classifications fail to meet the systematization of clinical aspects of this pathology $[3,5,10,11]$. The horizontal form of abrasion is diagnosed accurately, but vertical, mixed and other forms are hardly differentiated. That's why besides horizontal form we distinguish vertical-distal and vertical-mesial, depending on occlusion and position of temporomandibular joints elements. Gnathic part of the face is the variable structure of the craniofacial complex. Vertical parameters are most prone to changes, due to anatomical and physiological features of head growth and development (dental changes, occlusion abnormalities, loss of teeth, increased tooth abrasion, etc.). The interalveolar height increase can lead to a bigger muscles of mastication tonus, and cause dysfunction of the temporomandibular joints and structural changes in the jaw bone $[4,5,8,10,11]$.

There are decompensated and compensated IAT. Decompensated is accompanied by a decrease in the gnathic part of the face height, and in case of compensated IAT the gnathic part of the face height does not decrease or its height change is insignificant. This is due to vacant (false, compensative) hypertrophy of the alveolar crests bony structures $[3,4,8,9,10,11]$.

The decrease in the gnathic part of the face height is affected not only by the abrasion of the teeth degree, the anomaly of occlusion in various directions, but also by changes in the maxillofacial region that occur with increased abrasion of hard tooth tissues, loss of antagonists and other associated pathological conditions $[6,8,9]$. At the same time, there is no clear distinction between the forms of lower- ing the gnathic part of the face height within patients with increased teeth abrasion. The basic morphometric parameters of patients with a reduced gnathic part of the face are not shown.

\section{Goal of research}

Determination of the basic face morphometric parameters within patients with decompensated vertical-mesial form of increased teeth abrasion.

\section{Matherial and methods of research}

Morphometric examination of parameters was carried out within 30 patients (12 men and 18 women) with decompensated vertical-mesial form of increased abrasion of teeth.

The comparison group consisted of 64 people (27 men and 37 women) with physiological occlusion and intact dentition.

Kefalometric measurements were carried out with reference to the instructions of J.J. Roginsky (1968), F.J. Horoshilkina (1991), and in accordance with the requirements of anthropometry, which provide the definition of the distance between conventional points. A standard caliper with a fission rate of $0.01 \mathrm{~mm}$ was used as a tool.

10 parameters of the brain and facial region of the head were included to the statistical processing. Morphometric parameters were measured when the head was placed in the oculoauricular (Frankfurt) horizontal.

Following measuring points were used during cephalometry to determine the main parameters of the head and face in different directions (Fig. 1). 


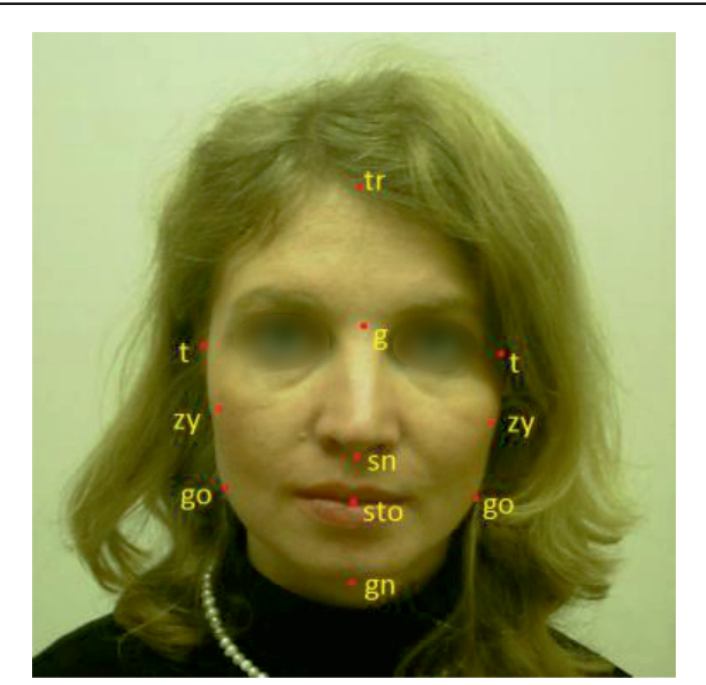

Fig. 1. A photograph of a person with dotted cephalometric points (frontal plane)

Glabella - glabella $(g)$ - the most protruding forward point on the midline between the eyebrows;

Trichion - trichion (tr) - the upper point of the median line of the forehead on the border of the scalp;

Chin - gnathion $(g n)$ - a point located on the middle line on the lower edge of the chin;

Upper nasal - nasal $(n)$ - a point located above the root of the nose at the level of the nasophilic suture;

Subnasal - subnasale $(s n)$ - a point located at the intersection of the nasal septum with the upper lip;

Oral - stomion (sto) - the point of intersection of the line of closure of the lips with the mid sagittal plane;
Zygomatic - zygion $(z y)$ - the most prominent point outside the zygomatic arch;

Goat - tragion $(t)$ - the point located on the upper edge of the tragus of the ear;

Mandibular-gonion ( $\mathrm{go}$ ) is the most outward point on the corner of the lower jaw;

Pogonion - pogonion ( $p g$ ) - the most protruding point on the chin.

Distances between individual cephalometric points made it possible to determine the size of the head and face in different directions and to evaluate the parameters of the gnathic part of the face with physiological occlusion of permanent teeth. Measurements on the head and face were carried out in three mutually perpendicular directions.

In the sagittal direction, the length of the head (g-ops), the distance from the tragus of the ear to the nasal points and points on the lower jaw (t-n; t-sn; t-pog; t-gn). The depth of the face was calculated with the formula using distances between points $(t-t)$ and $(t-n)$.

\section{Results of the research and their discussion}

Law of the relation between the shape of the head and various morphometric parameters of the face is established within the examined control group.

We have determined the morphological features of the head structure and its separate parts (face, gnatical part of the face, intergnatic distance, lower jaw). Morphometric parameters are considered in accordance with sexual dimorphism. The sizes of the head and face were studied. The relation between individual morphometric parameters of the head and face in men and women were determined.

The study results of the morphometric parameters of the head with comparison group are presented in the table 1 .

Morphometric parameters of the head and face

\begin{tabular}{|l|c|c|}
\hline \multicolumn{1}{|c|}{ Morphometric parameters } & \multicolumn{2}{c|}{ Face size (mm) } \\
\cline { 2 - 3 } & males & females \\
\hline n-me (face height) & $125,64 \pm 6,3$ & $111,87 \pm 2,26$ \\
\hline gl-me & $136,75 \pm 3,29$ & $122,34 \pm 2,34$ \\
\hline n-inc (height of nasomaxillar complex) & $81,47 \pm 3,52$ & $73,45 \pm 2,24$ \\
\hline sn-inc (height of dental alveolar part of upper jaw) & $21,82 \pm 1,17$ & $20,07 \pm 1,24$ \\
\hline n-sn & $61,19 \pm 2,7$ & $58,57 \pm 2,29$ \\
\hline sn-spm (intergnathic height) & $55,84 \pm 4,5$ & $53,16 \pm 1,54$ \\
\hline gn - me & $6,52 \pm 1,29$ & $6,02 \pm 1,19$ \\
\hline inc - spm (height of dental alveolar part of lower jaw) & $21,96 \pm 1,89$ & $21,14 \pm 1,27$ \\
\hline zy - zy & $143,57 \pm 5,1$ & $138,41 \pm 3,72$ \\
\hline sn - gn & $65,46 \pm 1,43$ & $63,28 \pm 2,16$ \\
\hline
\end{tabular}


Table 2

Morphometric parameters of the facial skeleton measurement within patients with decompensated vertical-mesial form with increased abrasion of teeth

\begin{tabular}{|l|c|c|}
\hline \multirow{2}{*}{ Morphometric parameters } & \multicolumn{2}{c|}{ Face size (mm) } \\
\cline { 2 - 3 } & males & males \\
\hline n-me (face height) & $108,6 \pm 3,11$ & $105,26 \pm 2,53$ \\
\hline gl - me & $118,3 \pm 3,29$ & $115,24 \pm 2,33$ \\
\hline n-inc (height of nasomaxillar complex) & $71,53 \pm 2,56$ & $69,45 \pm 2,34$ \\
\hline sn-inc (height of dental alveolar part of upper jaw) & $12,36 \pm 2,37$ & $11,6 \pm 1,62$ \\
\hline n-sn & $52,18 \pm 3,26$ & $52,44 \pm 3,54$ \\
\hline sn-spm (intergnathic height) & $36,68 \pm 2,32$ & $34,71 \pm 1,47$ \\
\hline gn - me & $43,31 \pm 3,65$ & $42,51 \pm 2,84$ \\
\hline inc-spm (height of dental alveolar part of lower jaw) & $14,96 \pm 1,79$ & $13,54 \pm 1,37$ \\
\hline zy - zy & $133,27 \pm 6,35$ & $131,471 \pm 6,73$ \\
\hline sn - gn & $54,37 \pm 2,16$ & $52,56 \pm 1,56$ \\
\hline
\end{tabular}

Thus most of the morphometric parameters of the head and face within male patients were larger than within females and were significantly different.

In general, the morphological height of the face and the height of the nasal part within males were larger than within females. At the same time, the height of the gnathic part was not significantly different in men and women.

The height of the lower jaw (inc- me) was mostly twice the size of the dental alveolar part of both the upper and lower jaws. The joint height of the dental alveolar parts of the upper and lower jaws corresponded to the dimensions of the lower jaw height, and according to these signs of sexual dimorphism was not identified. The height of dental alveolar part of the upper jaw (sn - inc) corresponded to the dental alveolar part of the lower jaw (inc - spm) both in males $(21,82+1,17$ and $21,96+1,89$ respectively) and females $(20,07+1,24$ and $21,14+1,27$ respectively).

The results of the facial skeleton measurement within patients with decompensated vertical-mesial form with increased abrasion of teeth are shown in the table 2.

The results of the study showed that the height of the face nasal part (n-sn) corresponded to the lower part of the face (sn-gn) and the difference in these parameters was about 1-2 $\mathrm{mm}$. It should be noted that the height of the dental alveolar part of the upper jaw (sn - inc) was about three times smaller than the height of the nasal part of the face and did not correspond to the dental alveolar part of the lower jaw (inc-spm). The height of the intergnathic part (sn-spm) was reduced by $9-13 \mathrm{~mm}$. Thus, the height decrease of the gnathic part of the face, especially the height of the lower jaw and intergnathic distance, was evident within patients. The interocclusion gap within the patients of this group was between 4-10 mm.

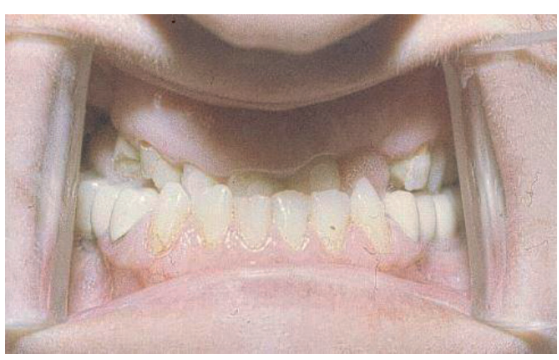

Fig. 2. Oral cavity of the patient Sh. 54 years. The presence of vertical-mesial facets of abrasion of teeth

During the oral cavity examination within patients of this group, there were objected a decrease in the interalveolar height, the presence of defects in the dentition, dental alveolar deformation of the dentition, the facet of abrasion in the vertical-mesial direction (Fig. 2).

\section{References}

1. Berdin V.V., Sevastyanov A.V., Fishchev S.B., Dmitriyenko D.S., Lepilin A.V. To a question of determination of the sizes of tooth arches in the sagittalny and transverzalny directions // Stomatology of children's age and prevention. - 2013. T. XII - No. 3(46). P. 43-45.

2. Iordanishvili A.K. Age-related changes in the masticatory-speech apparatus. Publishing House "Man", St. Petersburg, 2015. - P. 13.

3. Ramanovsky A.P. Antropometrichesky method of an assessment of harmony of the person // Problems, achievements and prospects of development of medicobiological sciences and practical health care. - Works KGMU. - 2002. - Vol. 138, p. 1. - P. 167-170. 
4. Sevastyanov S.B. Fishchev I.V. Orlov, etc. specifying the location of permanent teeth, depending on the size of orthopantomogram. / .. A. // Pediatric Dentistry and prevention. - 2014. T. XIII. - № 4 (51). - P. 48-50.

5. Fishchev S.B., Sevastyanov A.V., Dmitriyenko D.S. Berdin V.V., Lepilin A.V. The key linear parameters the zubochelyustnykh of arches at a normodontizm of second teeth // Stomatology of children's age and prevention. - 2012. - T. XI No. 3(42). P. 38-42.

6. Fishchev S.B., Sevastyanov A.V., Orlova I.V., Korolev A.I., T.S. Bagamaev the efficiency of the computer simulation results of treatment of patients with defects of dentition in combination with a distal occlusion. // Pediatric dentistry and prevention. - 2015. - T. XIV. - № 1 (52). - P. 23-28.

7. Bolton W.A. The clinical application of a tooth-size analysis. // Am. J. Orthod., 1962, - № 48. - P. 504-529.
8. Gesch D., Kirbschus A., Gedrange T. Do bivariate and multivariate cephalometric analyses lead to different results concerning the skeletal cause of postnormal occlusion? //Funct Orthod. 2005 Summer-Fall;22(2):6-8, 10, P. 12-13.

9. Poosti M., Jalali T. Tooth size and arch dimension in uncrowded versus crowded Class I malocclusions // J. Contemp. Dent. Pract. - 2007. 8(3). - P. 45-52.

10. Potter R.H., Nance W.E. A twin study on dental dimension. I, Discordance, asymmetry and mirror imagery // Am. J. Phys. Antropol. - № 44. - 1976. - P. 391-395.

11. Potter R.H., Nance W.E. A twin study on dental dimension. II, Independent genetic determinants // Am. J. Phys. Antropol. - № 44. - 1976. - P. 397-412.

12. Tanaka M.M., Johnson L.E. The prediction of the size of unerupted canins and premolars in a contemporary orthodontic population. JADA 88: 798-801. - 1974. 


\title{
IMPROVING THE QUALITY OF THE EDUCATIONAL PROCESS AND NETWORKING
}

\author{
Ivanko A.F., Ivanko M.A., Vinokur A.I., Kulikova E.V. \\ Moscow Polytechnic Institute, Moscow, e-mail: alekfed@mail.ru
}

One of the most urgent problems of the development of the educational process is the formation of educational networks. The modern goal of the state policy of education is, first of all, increasing the accessibility of quality education, corresponding to the current needs of society and every citizen, in the concept of long-term socio-economic development of the Russian Federation for the period until 2020. On the basis of this, let us outline the following principles for the implementation of network interaction: Information technology, which will allow higher education institutions to develop more rapidly. Partnership and cooperation, allowing the exchange of developments and new materials. Development and implementation of joint programs. Networks in the educational process can be represented: as a set of interacting educational institutions, and technology for communication between teachers of various levels of training. To date, only a few higher education institutions have joint training programs for bachelors, specialists and masters. There are several problems in the implementation of network interaction, which are discussed in the article: A small work experience of teachers in the field of information technology; Lack of knowledge on the use of Internet resources in the educational process; Insufficient formation of professional competencies. The article examines examples of network interaction between teachers of higher educational (VO) institutions, as well as problems of networked pedagogical interaction

Keywords: computer networks, network interaction, higher education (VO), information technologies, educational process

Pedagogical interaction is a universal characteristic of the pedagogical process. Even without experience in the pedagogical sphere, you can clearly see several forms of pedagogical interaction: "student-student", "studentcollective", "student-teacher", "students - the object of assimilation", etc. The main thing in this diversity is the relationship "pedagogical activity - student activities". But ultimately determining is the attitude of "student - the object of assimilation". This is the very specific nature of pedagogical tasks.

The pedagogical process expresses the interaction of two subjects, mediated by the object of assimilation, i.e. content of education.

From the scientific point of view, we distinguish such types of pedagogical interaction as: pedagogical (the relations of teachers and students); mutual (relations with teachers, peers, juniors); subject (the relationship of students with objects of material culture); relations to oneself.

Pedagogical interactions can differ among themselves. For example, direct and indirect effects. No less diverse and the response to these effects. For example, ignoring, ecstasy, indifference, acceptance of information, processing, memorization, action, etc.

\section{Network pedagogical interaction}

Informatization, widespread use of information technology in everyday life has an impact on education in the Russian Federation. These criteria became a condition for fulfilling the state order for the development of education.

GEF 4 th generation forms a request for the renewal of the information and educational environment of higher education and for the qualitative use of its resources, which is unrealistic without the development of the professionalism of VET teachers.

What is network interaction?

The teacher's network interaction is a technology that makes it possible to realize the opportunities for developing the teacher's competence through the activation of his personal characteristics, interests and opportunities.

What are the goals of networking between teachers?

They are quite understandable to any person, because in the age of information technology, every third qualified employee deals with a computer.

The objectives of networking are: to increase the level of professional knowledge of teachers, the practical development of innovative methods and technologies of the educational process, and, consequently, to improve the effectiveness of the pedagogical process.

Of course, the teacher can not be immediately ready for network interaction. This process goes through several stages:

1. Introduction and study of network services (software that handle different types of information).

2. Introduction of network technologies in the educational process (the introduction of projectors, electronic diaries, performance matrix, etc.).

3. Use of networks as an environment for the exchange of information between teachers.

4. Formation of own network service (teacher's website).

5. Use of personal information space (transfer of experience in network groups). 
One can note the advantages of network interaction between teachers.

First, networked pedagogical interaction does not limit or establish a temporary, territorial framework for participants in the process. Teachers of different regions, and different countries, without obstacles can "cross" thousands of kilometers in just 1 second. And most importantly, it's availability! Secondly, networked pedagogical interaction is focused on the individual needs of each teacher. This can be the transfer and acquisition of experience, participation in scientific webinars, online training, etc.

Thirdly, it is economy. Reducing the cost of transportation costs for going to the training centers.

Thus, network communities or teacher associations are a new form of professional activity organization available in a computer network. But, unfortunately, it was this effective innovation that was not sufficiently developed adequately among university professors. It is professional network associations that can give teachers the opportunity to communicate with each other, solve pedagogical issues, realize themselves and improve their professional level.

\section{Network communities as a method of development of the educational process}

An excellent option for continuous professional development, constant communication and exchange of knowledge with colleagues, presentation of their own experience are - network professional communities of teachers.

Teachers who participate in online communities acquire the skills to post information on the Internet, and also transmit and receive invaluable experience of their colleagues. All together, teachers create a semblance of an archive of methodological and didactic materials, which is necessary for the next generation of teachers and methodologists.

These groups have great advantages: space for information exchange between teachers, professional growth, incentive for creative development.

\section{Examples of network pedagogical communities}

So let's start with websites where university teachers can officially publish their works, articles, etc.

The first of such sites can be called the AllRussian site "For the Teacher" (https://dlyapedagoga.ru/). This is a web-based publication designed to publish author's developments of educators, teachers, teachers, as well as organizing and holding all-Russian competitions, quizzes and olympiads. The publication of the material on the website "For the teacher" is confirmed by the issuance of an electronic certificate, participation in an all-Russian event an electronic diploma [1].

All-Russian site "For Teacher" allows teachers:

participate in express competitions; publish articles; participate in conferences; publish reports; to pass distance learning; participate in webinars; create your own personal sites.

Also, the site divides all publications into preschool, primary, basic general, secondary (full), secondary (professional), higher and additional education. Such a structure allows teachers of any category to easily determine the direction of their activities, their potential competitors, etc.

The electronic educational journal "Teacher" (https://zhurnalpedagog.ru/) also has a number of advantages [2]. At first glance, this magazine in its structure is very similar to the All-Russian site "For the Teacher", but he also has differences.

Consider the differences:

1. The structure of the site also includes publications on pre-school, primary, basic general, secondary (full), secondary (professional), higher and additional education. But here one more item has been added - All-Russian conferences.

2. In the journal can be tested not only teachers, but also students with the curator.

3 . If necessary, you can get a review of the work of the teacher.

4. The teacher can check the issued document on the website of the magazine "Teacher" on the series and number.

5. All the teachers who posted the publication on the website of the publication, or who participated in one of the events of the site, can download a letter of gratitude from the editorial staff. Is free!

6 . The teacher can also take part in the expert activity.

All-Russian educational "Portal of the teacher" (https://portalpedagoga.ru/)[3].

This portal is also similar and almost exactly copies the previous one. Here teachers can also publish their articles, participate in online conferences, go through distance learning and refresher courses.

We examined three electronic platforms for VO teachers. Already now we can say that the All-Russian site "For the Teacher", and the Electronic Educational Journal "Teacher", 
and the All-Russian Educational "Portal of the Teacher" have only paid publications.

Consider, as an example, several free sites for communication between teachers.

One of these sites is the Sotsobraz network community (http://wiki.iot.ru/index.php/) [4].

Networked social and pedagogical community created within the project "Creation and development of social and pedagogical communities in the Internet (teachers, methodologists, social educators, psychologists, specialists in additional education and parents). Here teachers can participate in consultations, in training, in educational developments, write an article. "SotsObraz" is an interactive platform for the exchange of experience of teachers, methodologists, social educators, class teachers, teachers of additional education, school psychologists, and the network community where parents can receive counseling and necessary recommendations on the issues of education, upbringing and development of schoolchildren.

Of course, there is no section for teachers of higher education institutions, but to raise their level of knowledge of pedagogical psychology, social pedagogy will not hurt the teacher of the university.

A professional community of teachers "Methodist.ru" (http://metodisty.ru/m/groups/ home//5] will really help to feel the network pedagogical communication. It is designed to meet the needs of teachers precisely in the exchange of information, communication and self-realization. The site has a forum, the teacher can create a group, blog, chat. There is a library of teachers' works, where you can contribute your work. The community contains more than 30 groups (different subjects and directions - administration, class leaders, subject matter, etc.). Presentations, programs, development of lessons within each group. Everything can be downloaded! Each development contains an author's comment with a description. There is an opportunity to discuss work within the group, evaluate it or communicate with the author. Many audio and video files are freely available. You can publish your own materials, and even create a group. The advantage of this pedagogical community is that you do not have to register for downloading the material. In fact, even a student of a pedagogical higher educational institution can find a lot of useful information for himself.

Faculty "Education Reform" of the educational portal "My University". Club of teachers (http://edu-reforma.ru/index/0-23)[6]. Provides a platform for communication and exchange of experience, as well as extensive opportunities for all those who are engaged and interested in teaching children and reforming education. There is a dedicated subject (thematic focus) - for the experts of the contest "Active teaching methods".

A member of the Club can be any person who has fulfilled the conditions of joining the Club, which deals with teaching students or reforming education.

Conditions for joining the Club as a member:

1. It is necessary to accept the conditions of participation in the Club.

2. Follow the Club Rules

3. Fill in the application form for joining the Club

Opportunities for Club members:

1 . The possibility of communication among professionals, involvement in the professional community.

2. The possibility of obtaining useful information on educational reform and pedagogy.

3 . The possibility of finding partners for the development and implementation of their educational projects, the acquisition of useful links.

4. Help, professional advice of colleagues.

These are just a few examples of e-portals for teachers. That's just missing a highly specialized site for university teachers in a certain area.

Thus, in the Internet space there is a sufficient number of sites for communication and exchange of experience between teachers. Another question is whether university professors are ready to participate in the activities of these sites?

\section{Peculiarities of network interaction of higher educational institutions}

The development of the economy of the Russian Federation assumes the introduction of new organizational forms of interaction between domestic and foreign educational institutions, in particular, higher education institutions.

Not only network pedagogical communities, but also networked communities of higher educational institutions should undergo modernization.

It is not necessary to concentrate in education all attention on the vertical system of VO (bachelor's-master's degree-postgraduate study, specialty-postgraduate study). In the 21 st century, it is necessary to provide an opportunity to expand the range of professional opportunities for students at the undergraduate or specialist level (horizontal system). Now there are very few examples of a horizontal system for training future professionals. One such example is the USU project - joint programs for the preparation of bachelors 
in economics of the State University - Higher School of Economics (SU-HSE) and Ural State University (USU). Thus, students receive two diplomas of a bachelor's degree - a native university and a diploma of SU-HSE. This project is set up as an experiment, the inter-university agreement is the normative basis, which sets the conditions for the selection of students of the USU for simultaneous training at SU-HSE, as well as the mode, terms, and cost of training.

This example proves that now, in the everchanging conditions of the Russian vocational education system, the trainee can be given opportunities to increase the mobility of his education.

But not only the student wins on the basis of a networked university association. The teacher also has the opportunity to upgrade his skills and expand his professional experience, through communication and consultation with other university teachers and staff.

The only drawback of the USU program is that the competences of graduates do not increase.

The solution to this shortcoming was the joint educational program for the preparation of bachelors of the Academy of National Economy under the Government of the Russian Federation (ANE) and the Moscow Institute of Physics and Technology (MIPT). Here the program is designed in such a way that students study the full course on economics at the Academy of National Economy and on one of the directions at MIPT. Among these directions, MIPT presented applied mathematics and physics, as well as systems analysis and management. At the exit, graduates receive two diplomas from MIPT and ANE.

As for the specific networked pedagogical interaction within several higher educational institutions, a striking example is the network association - "Pedagogical Staff of Russia". This association of educational institutions is created with the purpose of raising both pedagogical quality of teaching and increasing the activity of teaching staff in different regions of Russia.

It should be noted that this is the largest network of universities in Russia. This includes more than 19 state educational institutions of higher education of the Russian Federation. And almost all of them are located in different cities and regions of our country. The main objectives of the network association "Pedagogical cadres of Russia" include: providing a higher quality of professional training of teachers; joint preparation and implementation by teachers of different institutions of programs of higher, secondary and postgraduate education; creation of a clear system of training and re- training of qualified professional teaching staff; creation of a unified database of information resources of teachers; analysis and forecasting of the development of the modern market of pedagogical work (including for graduates); creation and development of interuniversity mobility of students and teachers; creation of a common educational space for higher educational institutions through the implementation of joint educational programs (exchange of teachers in different regions); organization of international cooperation; exchange of technology and teaching methods, etc.

\section{Conclusions}

On the basis of the conducted research it is evident that the network interaction of $\mathrm{VO}$ teachers is undoubtedly a positive factor in influencing the quality of the educational process. On how often the teacher will "update" his knowledge depends on the relevance of the knowledge of students currently.

In the 21 st century, with constantly changing economic conditions, with an ever-changing information environment, first of all, it is necessary to understand the teacher of VO in this environment. After all, it is the quality of knowledge, the reliability of information transmitted to learners that will determine the future of not only graduates, but also of Russia as a whole. The general welfare of our country depends on the degree of qualification of the employee.

Computer networks, especially the Internet - the main source of information now! From this point of view, the teacher simply needs to have network communication with other educators.

The network interaction of teachers solves, perhaps, the most important problem of our country - the fast transfer of information over long distances. And since Russia occupies more than 17 million ???? the need for network communication is unambiguous.

\section{References}

1. Petrushkevich A.V. Network interaction as a factor in the development of an educational institution: article / A.V. Petrushkevich, L.V. Voronina. - Moscow: GBOU SPO Polytechnic College №2, 2011 .

2. Yakovleva A.V. Development of network interaction between universities: article / A.V. Yakovlev, I. Bondyreva. - SPb.: NIU, 2015.

3. Shultz O.N. Prospects for the introduction of network interaction in the professional pedagogical university: article. Ekaterinburg: the Russian State Pedagogical University, 2015.

4. International educational journal "Teacher". - Electronic source. - https://zhurnalpedagog.ru.

5. All-Russian educational publication "For Teachers". Electronic resource. - https://dlyapedagoga.ru.

6. All-Russian educational "Portal of the teacher". - Electronic resource. - https://portalpedagoga.ru.

7. The Internet source. - https://megalektsii.ru/s25909t10.html. 


\title{
VALUE CONTEXT OF UPBRINGING AND DEVELOPMENT PROGRAM CONTENT FOR PRESCHOOL-AGE CHILDREN
}

\author{
Yakovlev S.V.
}

Federal State Budgetary Scientific Institution "The Institute for the study of childhood, family and upbringing of the Russian Academy of education”, Moscow, e-mail: yakov27lev@yandex.ru

\begin{abstract}
In this article there is considered a value approach to define the upbringing content for preschool-age children. On the basis of the revealed structure components for the value system of a person the author is offering a method of integration of various directions of preschool-age children upbringing into their development program. The author considers the values of harmony and security, freedom and autonomy of an individual, actions, laws and rules, personality traits, life position as a category of values, profession, transfer of experience to the structural components of the system of personal values. In the program, the structural components of the value system are invariant. As the personality of the preschooler develops, they are filled with new cultural content.
\end{abstract}

Keywords: value, upbringing content, program, person, preschool-age child

At the present time there is more and more actualized the search for a value foundation for upbringing and education of coming generation and for a substantive filling of it which has a paramount importance for preparation of children for worthy and successful life under the conditions of competitive society becoming more and more complicated. It is a common knowledge that the activity of children in their life, their successfulness, a completeness of their vital interests, satisfaction with the results of their doings are in many aspects depending thereon what value priorities shall be laid down in the basis of education content for the preschool-age children and how they shall be taken into account in the programs of their development which are to be elaborated.

\section{Methodology and research methods}

For the revelation purposes concerning the value priorities for a preschool education this work contains an axiological analysis of the upbringing content for the preschool-age children. As a basis it has been taken the wellknown program which is used in the preschool educational institutions and has been elaborated by a team of authors under the scientific editorship of M.A. Vasilyeva, V.V. Gerbova, T.S. Komarova [3].

This program is directed at an all-round development of psychical and physical qualities of children in the age range from the birth and up to 7 years by taking into account peculiarities of their age-related and individual development. The axiological analysis of upbringing priorities of the program conducted by us shows that in its main content it is directed at the following:

- upbringing of the sense of involvement in the life of a preschool institution, native city or settlement and the entire country [3, p. 84]; careful attitude towards nature through a teach- ing for an aesthetic perception of it [3, p. 85]; explanation about the importance of a peaceful coexistence with all nations of the world, respect for their cultures, traditions and customs [3, p. 195];

- encouragement of an active participation of the preschool-age children in artistic-creative activities on their own free will [3, p. 209]; performance of the role of host / hostess in playing activities [3, p. 140]; stimulation of desire to get without any assistance the knowledge about the outside world, to be engaged in a self-education [3, p. 222];

- formation of moral ideas concerning good and bad deeds [3, p. 85], and among them on the basis of examples of literary characters [3, p. 90]; mastering of table manners [3, p. 89]; teaching to cultivate careful attitude towards animate beings [3, p. 90];

- training of children to keep proper hours of day regimen [3, p. 41]; observance of playing rules $[3$, pp.42, 138], rules of the road $[3$, p. 84], order in a group [3, p. 89]; teaching to correctly build the phrases, pronounce words, use grammatical forms [3, p. 44];

- development of moral properties (honesty, benevolence, responsiveness, empathy, and so on) $[3$, p. 221];

- adoption of moral positions through the teaching to live in unity, including through joint playing activities [3, p. 89]; formation of interest to read books [3, p. 90]; development of curiosity [3, p. 118]; upbringing on the way of benevolent character interrelations between the children, development of ability to take into account the interests of comrades [3, p. 139], and the interests of their relatives [3, p. 194]; formation of the skill to substantiate their aesthetic choice, to assess aesthetically the environment [3, p. 209]; stimulation of the development of the aesthetic taste and the ability to understand pieces of art [3, p. 221]; 
- formation of a positive attitude towards the labor of adults [3, pp.76, 84]; development of interest concerning occupations of parents [3, p. 194];

- acquisition of knowledge through the adoption of elders' experience, for instance, through the observance how the elders are looking after the plants and animals in a pet s' corner [3, p. 85].

\section{Results of research and their discussion}

In the framework of analysis concerning the main directions of the preschool-age children upbringing which have been traditionally taken into account in the process of the upbringing activities in the preschool educational institutions we are finding a confirmation for a correctness of our point of view about the appropriateness of systematization of main upbringing priorities according to the following value groups: the values of freedom and independence; the values of life, which are manifested in a harmony and security; the values of development of positive qualities of a person; the values manifesting the common laws and rules of a person's behavior; the values of particular actions as ways of behavior of human being in specific life situations; stand in life as a value category; the values of occupational activity and professional competence of a specialist; translation of a vital and occupational experience as a value [4]. The validity of our allocation of these value groups is confirmed by other researchers: [1], [2], [5].

As can be seen from the above, the value groups singled out by us can be considered as elements of the value system of a person which are manifesting themselves as a certain sequence of new formations subjectively actualized on the corresponding stages of an agerelated development. Herewith, the personal value system does have a dynamic structure and is to be modernized in the process of an ontogenetical development of the human being. As the striking illustrations hereof it can be considered the revaluations of the values occurring once and again on the various agerelated stages. It must be also stressed that in each of the value groups revealed by us there are reflected the values manifesting different upbringing directions and allowing to integrate the different directions of its content on an unified axiological basis which is equally meaningful for many stages of historical development of society and its culture.

So, the values of development of positive qualities of a person of a preschool-age child are expressed in the following: formation of the interest concerning the knowledge of objective world, abilities to research and construction activities, punctuality, politeness, discipline, skills to self-service; development of social abilities, skills to collective interaction with comrades; formation of patriotism as a love of Fatherland; upbringing on the way of a moral responsibility for realization of rights and duties of a team member, of a sense of conscience, justice, responsibility for own behavior; development of abilities to an aesthetic perception of natural phenomena, works of visual art and children's literature; development of artistic abilities concerning various arts of creative activity; one's own health promotion, development of main motional abilities (powers of endurance, flexibility, coordination of movements, rhythmics, and so on).

As the values of trust of a preschool-age child to the outside world, which are manifested in a harmony and security, we consider the following: understanding of interrelations of the human being, society and nature, their integrity and unity of development; elucidation by the preschool-age child of the importance of a careful attitude towards nature as a condition for a preservation of a proper environment status, necessity to look permanently after order and cleanness at home, in the streets, in a group of a preschool educational institution; love for nature of native shore; well-wishing and respectful interrelations in a team of children, careful and tactful attitude towards a friendship; skills of sanitary and hygienic culture.

The values of freedom and independence are manifested in the following: need and ability of the preschool-age children to display initiative, cognitive and creative activity, originality in description and explanation of social realm phenomena; ability to arrange playing activities independently; responsible and diligent attitude towards learning, fulfillment of lessons, self-testing concerning observance of accuracy, completeness and exactness by their fulfillment; drive for a positive self-development; manifestation of a voluntary discipline and behavior culture; conscious attitude towards a civil duty; unity of words and deeds; ability to display independence.

To the values manifesting the common laws and rules of behavior of the preschoolage child are belonging the following ones: knowledge of rules of decorum and rules of community life; understanding of moral sense of a conscious discipline of human being, of responsibility and response to orders by the observance of rules of cultural behavior and communication, recognition of moral norms 
accepted in a family and society; understanding of the essence of friendship and unity of nations belonging to Russia, importance of humane interrelations in society; recognition of a moral and legal duty in relation to a natural environment, of responsibility for its status, of concern about its protection against destruction and pollution; need to be guided by the aesthetic principles in the framework of playing activities and everyday life, by the contacts with nature; harmonization of the inside and outside cultures; sanitary and hygienic knowledge; need for observance of the regimen and order of the day.

The values of particular actions as ways of behavior of the preschool-age child in specific life situations can be presented in the following way: faithful fulfillment of the child's own duties and orders of teachers; desire to be honest, ability to admit own errors and to act in accordance with civil norms and requirements; respect for elders, love for parents and other members of the child's family, and for a native nature; active participation in collective forms of cognitive activities, responsible and diligent attitude to a learning, careful attitude to textbooks and training facilities, to state, private and personal property, to nature, to representatives of animal and vegetable world; manifestation of readiness to socially useful activities; providing compliance with moral norms and collectivism principle, manifestation of initiative and independence, readiness to create the atmosphere of a genuine comradeship and friendship in a group; manifestation of a humane attitude to animals and plants; ability to display resoluteness and to overcome the difficulties with a due persistence; observance of the behavior norms in everyday life and in public places, norms of communication (politeness and modesty, attentiveness and courtesy, tactfulness and delicacy, and so on), culture of speech and appearance; reasonable compliance with fashion; active and regular participation in physical culture and health-improving events.

The stand in life of the preschool-age child as a value category is manifested in the following: his / her creative activity by a mastering of knowledge, ability on the basis of a well-reasoned position to manifest a personal attitude towards events to be observed; compliance with moral principles in playing and in everyday life, conviction in preference of a healthy way of living; active stand in life, conscious attitude towards a civil duty; observance of rules of community life, respect for authorities and persons preserving peace and order in society, understanding of a moral sense of combat and labor traditions of our people, respect for the person's honor and dignity, drive to an ideal of a moral behavior and interrelations between people, well-wishing attitude towards people, understanding of necessity concerning respectful relations between boys and girls, irreconcilability concerning immorality, amoral acts, violations of norms and rules of behavior in society and in the open country; responsible attitude towards execution of his / her duties, unity of words and deeds, respect for working men creating material and spiritual values, condemnatory attitude towards violation of discipline, irresponsibility and negligence, parasitism, plunderer and waste of natural resources; condemnatory attitude towards superstitious beliefs and narrow-mindedness; careful attitude towards cultural artefacts and folk art memorials; drive to a healthy way of living, a critical attitude towards underestimation of importance of physical exercises, sport, tourism, violations of norms of personal and public hygiene, towards the acts destructing the natural environment.

As the values of occupational activity and professional competence to be adopted in a preschool-age we can consider the following ones: drive to knowledge, expansion of ideas concerning occupations, perfection of brain work culture; recognition of public value of education for a preparation of a child for life and labor in interest of society, human being and state; understanding of importance of material production for development of society and interdependence of occupations, understanding of moral sense of labor traditions; aesthetic perception of labor activities of specialists to be observed in various production fields, understanding of necessity to improve the abilities and skills of occupational activity; rendering support to a teacher on the basis of a proper behavior and obedience for a fulfillment of teacher's occupational activities, observance of safety regulations as well as sanitary and hygiene standards.

Translation of a vital and occupational experience as a value is displayed in the understanding by the preschool-age children of the connection of science and practice under conditions of technological progress; their understanding of social role of learning activity for a preparation for life and labor; rendering of support concerning knowledge mastering; attentive attitude towards the experience of the elders.

\section{Conclusion}

As can be seen from the above we can state that the different upbringing directions do have united value content. For instance, in the group 
of values of development of positive qualities of a person there are present the content elements practically of all known directions: moral, aesthetic, physical, labor, ecological, patriotic upbringing, and so on. We can also predict an emergence of new upbringing directions which can be present in the future in connection with development of the society culture. It is quite difficult to predict the upbringing targets of a distant future but in the framework of the system of personal values offered in this study the future upbringing targets are presented implicitly. Such an approach makes it possible to present the unity of upbringing directions targeted at the development of an integral personality of a preschool-age child.

The article was prepared within the framework of the state task of the federal state budgetary institution "Institute for the Study of Childhood, Family and Education of the Rus- sian Academy of Education" for 2018 (No. 27. 9397. 2017 / BC) "Modern paradigms and practices of spiritual and moral education of children in the general education system".

\section{References}

1. Galynsky V.M., Kissel N.K., Poznyak Yu.V., Samokhval V.V., Sirenko S.N., Shvarova G.G. Foundations of personal development in the system of continuous education: a structurallogical scheme // Modern Higher School. № 4. 2007. p. 40-16.

2. Lotova I. Education of the moral culture of the individual in the system of general education // Journal of Pedagogical Research. Limited Liability Company "Scientific Publishing Center INFRA-M". 2016. Vol. 1. No. 6. P. 9. DOI: 10.12737 / 22969.

3. The program of education and training in kindergarten / Ed. M.A. Vasilyeva, V.V. Gerbovoy, TS Komarova. Moscow, 2007.

4. Yakovlev S.V. The dynamic structure of the personal value system // Questions of the humanities. No. 4 (19). 2005. P. 218-227.

5. Yarulov A.A. On the development of the axiological concept of education of moral culture // Journal of Philosophical Studies. Limited Liability Company "Scientific Publishing Center INFRA-M". 2016. T. 2. No. 5. P. 2. 


\title{
LITERAL WORLD PICTURE IN PARADIGM OF SYSTEMATICAL SYNERGETIC APPROACH
}

\author{
Dautova S.B., Ospanova B.R. \\ Kazakh National Pedagogical Universitynamed after Abai, Almaty, e-mail: baian_80@mail.ru
}

\begin{abstract}
Significance and reliability of the state of the art is the subject of the national culture of determinant coding culture, the Kazakh literature, reflecting on the universal tradition of tradition, translating universal spiritual values. The Kazakh literary formulates the cultural expressions, having the status of commonwealth. And it is a global cultural heritage. It is a means of preserving the natural humanitarian and social-historical climate, providing a positive image and investment inclusion. The artistic and physical picture of the world is a philological phenomenon characterized by purity, invariance, polylinece, and historicity. Theory and methodology of studying the artistic and the picture of the world are moving in the stadium forming. Aktwalnımï voprosamï otrasley yazıkoznanïya and lïteratwrovedenïya yavlyayutsya problems reprezentaciï xwdojestvennoy and Linguistic pictures from the World lïteratwrnom proïzvedeniï, xwdojestvennıe Tools realïzaciii, interpretation xwdojestvennıx and yazıkovix modeley peace, vıyavlenïe razlïçïy and sootnoşenïya category "xwdojestvennaya picture of the World”, "yazıkovaya picture of the World," "yazıkovaya picture xwdojestvennaya the world".
\end{abstract}

Keywords: production, language, literature, culture, horrific concept, author's interpretation, spiritual values, morality principles

Modern philological science, being a part of humanitarian knowledge, is characterized by dynamics and by usage of new approaches. Modern science is developing researching tools taking into consideration interdisciplinary links in paradigm of humanitarian knowledge. Historical understanding of concept "world picture" approves these changes as the scientific reality cognition.

The research paper has actuality as studying linguistic and literal world picture is one of the most important problems of modern humanitarian sciences. Observed problem has significant value in forming spiritual values of youths. The theory of linguistic world picture and literal world picture is based on methodology and cognitive theory which are under reformations in modern science. This reformation started at XX century when the cognitive standards became dependent on cognitive process, awareness of cognizer and on the type of cognizing objects. The methodology is being based on social historic, anthropical, individual, cultural changes. Modern methodology studies dynamics of cognitive problems, cultural historic issues of cognitive tools, changeability of categories and concepts, formation of new cognitive orientations. The task of modern methodology is clarification, formation and transformation of mechanisms which integrated in individual daily experience. So the relevant studies are aimed on anthropocentrism which means that the study of language and its functions closely connected with human nature and human is a center of existence. Making researches in the sphere of linguistics or literature and their functions in human life it is possible to find out such linguistic functions which have not been investigated before or it is necessary to continue the researches in this direction. Linguo-anthropocentrical approach which is used in this research defines language as cognitive source for human and human activity as the source for language and its functions studying. Introducing anthropocentrical approach in linguistics allowed investigating the language function in new level which made possible to connect language activity in its functioning with human activity in society.

The concept "world picture" was introduced in physics at the end of XIX century and at the beginning of XX century. G. Gerts was the first scholar who used it refer to physical world picture. He introduced the term as a combination of internal representations of objectives logically using which it is possible to get behavior characteristics about these objects. According to $\mathrm{G}$. Gerts internal representations or symbols of objectives, created by researches, has to be such that the "logically necessary consequences of these representations in their turn were natural representations of these objects" $[1,152]$. Created representations should be logical and represent natural proportions of the objects including all details. According to G. Gerts the way our brain creates representations determines the ways of their representations. The scientist tried to characterize simple thing picture in sensible world and processes in it, including to this picture the main principles of mechanics using which it is possible to introduce total mechanics without references to experience. He considered if we interpret differently the mechanical principles depending on its basic statements, "we get different world pictures" $[1,154]$. M. Planck also used concept 
"world picture" introducing physical view of actual nature regularities. In his view the content of this representation, based on principals of energy conservation and transformation, as on increasing entropy principles, enriches releasing anthropomorphic elements during the physics development $[2,19]$. A. Einstein also used this term in his works.

Therefore, the first usage of this concept connected with scientific world picture. According to A.A. Melnikov "the status of this concept remains indefinite in the modern methodology and philosophy". Determine concept "world picture" through scientific and general scientific point of view, it has several interpretations which locate between science and world view as well as between science and philosophy: world picture is observed as world view which include in itself type of social practice; world picture is a type of philosophical reflection (neonatural concept of scientific world picture); world picture is a type of scientific knowledge $[3,124]$. Then the term "world picture" started to use in culture and linguosemiotic studies.

World viewing as a part of world picture was studied in cultural aspect. Firstly scientists investigated collective consciousness basing on materials of myths and folk literature through reconstruction of its structure. Scientists observed the term as primary and secondary modeling systems in semiotic direction of study. They considered the model in cybernetic meaning so the world was described as "passive automotive memory". Then concept "world picture" changed under the influence of gnoseological and general scientific meaning to an image of modeling object. According to A. Gurevich "every civilization, social system could be characterized by the way how they interpret the world. Accepting the main conceptual and spiritual categories as universal, we meant the fact that they are natural for a person at any stage of his life but their meanings change during the time $[4,7]$. In recent years many scientists, who are making researches in this sphere, have come to conclusion that "world picture" of each ethnic group should be studied separately. Accepting the concept "world picture" as "world view" is the main factor for researching linguistic world picture and literal world picture. Generation of the concept is closely connected with language and determined by language. It is called as linguistic world picture which reflects national world picture and found in linguistic units of different levels. Taking into consideration definite world picture of individual we can say that it is based on conceptual world picture forming it in its turn as any human-being can understand the world and himself only through language. Language includes general and national social historic experience so we can say that enrichment happens in two directions: 1) life conditions and welfare determine people's behavior and consciousness which reflect on language, especially in its grammar and semantics; 2) person understands the world through native language which determines his behavior and cognition [5, 204].

It is necessary to note that the term "world picture" is metaphorical as "specific uniqueness of national language, which includes specific historic experience of definite nation, does not creates different world picture, it creates "national world picture" based on unique attitude to some things, events, processes showing uniqueness of specific national culture" [5, 204]. E.D. Suleimenova emphasized "the linguistic world picture cannot be equated to world picture as we cannot equate language to cognition". So the distinction of the world picture and the linguistic world picture is definite as the distinction between the terms: language and cognition. However linguistic world picture as a term unit originated due to interaction of reality and language (without cognition) [6, 89]. Linguistic world picture includes specific language figures: culture-specific concepts, categorical division of the world - the composition of categories and paradigms, quantization of semantic continuum, standard type of estimation, etc. The world picture is expressed in two ways: on the one hand, by language units (grammatical categories, morphemes, stable word combinations, phrasemes), on the other - by the way of their formation, syntactic constructions" $[5,87]$. Each ethnos language describes the world by its own way of conceptualization which means that it creates its own world picture model. According to the Humboldt's view, different languages are different worldviews and specificity of each particular language determines "linguistic consciousness of this nation" $[7,15]$. According to the functional aspect the concept "consciousness" can be divided into conceptual, linguistic and coordinative one" $[8,2]$. Linguists who study the problem of linguistic consciousness, national linguistic consciousness, operate with such terms as mentalistic language, mentality, cognition. The work of V. Humboldt, A. Potebni, I. Baudouin de Courtenay contributed to formation of these concepts which are closely connected to the concepts of world picture, linguistic world picture, literal world picture. 
Theorists of literature study literal semantic and literal figures in ethno-ethic features. Among recent researches it is necessary to mention: dissertation of Z. Gassanova "Caucasian mentality in the image of Russian literature of the nineteenth century", T. Belyaeva "Poetics of symbolic images in Mari drama", L. Cheltygmasheva "Ethno-poetic originality of Khakass prose of 1930-1990 period", among domestic researches: monograph of A. Tumanova "Contaminated linguistic world picture in literal discourse of bilingual writer", article of A. Karkanova "Reproduction of national world picture based on culture-specific concepts of the epic novel of M. Auezov "Abai way". There are not so many works dedicated to literal and linguistic world picture. Mainly authors write about problematic of space and time. Theorists of literature noticed the novelty of usage the concepts "world picture" in philology: "New concepts of philology "world picture", "worldview" connected with modern developments in the science, which proved the existence of different cosmological models of the Universe. "As each century creates its own model, so human-beings of XX century should imagine the universe representation to answerwhat is world and what kind of place has an individual in it. Art could not reflect new world model" $[9,17]$. Works of R. Barthes, K. Levi, E. Volodina, S. Bocharova open the next page in the development of new approaches in development of integrative trends in science. Philosophical categories of space and time, reflected in literature, devolved on philological categories of cognition and understanding of reality. The methodological novelty brought by M. Bakhtin, determined the role of space and time in literature, became literal world picture. The scientist suggested "time-space is a formal literal category, which genre varieties determined by time-space and it contains all narrative knots" [10, 101].

The research in theory and methodology of literal and linguistic world picture is in the infancy stage. Scientific philological tools have been enriched by the concepts "linguistic world picture", "literal world picture", "linguistic literal world picture". Now there is an actual problem to distinguish these concepts in philology.

$\mathrm{N}$. Goncharova, taking into account views of famous linguists, suggested: "linguistic world picture is a mental linguistic knowledge: information about surrounding reality created in individual or collective consciousness and is represented by language means" $[11,396]$.

It is worth to remind that the concepts "linguistic world picture" and "linguistic literal world picture" are not the same, they relate to each other as the general and the particular. Linguistic literal world picture means "syncretical knowledge which became the realization of literal images in speech and became cohesive, complex literal image created by the means of language. The main features of linguistic literal world picture are internationality, possibility to transform literal word and its synthetism, variety of meanings leading to unknowable linguistic literal world picture" [12, 6 p.]. There is no consensus in determination the concept "literal world picture", the evidence of this fact is absence of the completed theory. Scientists agreed that it relates to the secondary systems as linguistic world picture and refers it to author individual world picture. Y. Salnikova tried to understand the structure and sense of literal work, its place in literal process: "we considered that the ratio between objective and subjective in the space-time structure of the text more clearly reflects the classification of P. Zobova and A. Mostepanenko [13, 21], according which a literal work contains the following levels:

1. The real level: physical space and time, the literary text is an ordinary material object, a thing among other things.

2. Conceptual level: "model" reflection of reality, fable, objectified background of literal events. The conceptual space and time show the historic space and time in which actions happened in the book, not the time and space when the book was written.

3 . The perceptual level is directly related to the formation of literal image. In this level the specific uniqueness of this literal text opens which differentiate it from others" [14, 28].

There is variety of "world picture" definitions which connect language with literature but correctly relate the concept to the spacetime continuum. "The problems of linguistic literal world picture only denoted and significant researches are needed in this sphere. Investigation of linguistic literal world picture is possible by means of coordinate systems though which person understands reality and built world view in cognitive space. They are called space-time categories" $[12,6]$.

Thus, the space-time structure of literal text as a basis of literal and linguistic world picture is the link that merges conflicting scientific opinions. Plot is the link for literal world picture in literature science. Linguists are interested in phenomenological peculiarities of world picture and means of language representation, this approach cannot satisfy the theorists of literature, as it does not describe full scientific 
cognition of literal and linguistic world picture. The literal world picture is wider than any science or subject. It is imposed by inner properties of literature such as person and life reflections, variety of life stories and differences of human feelings. This no doubt that paradigm of literal text spreads from grammatical level to philosophically ontological reality. Modern philological science studies image content and language of literal text which are directed to development of special methods and scientific interpretations for meaning recognition of literal text. This fact made scientists research idea of identification meaning of literal word to "archetypes of the culture", which was proposed in the Humboldt concept of literal text perception as system object characterized by specific features and regularities.

G.G. Shpet's theory played great role in cognition and scientific description of the dialectic of creation, functioning and perception literal text. His famous essays on hermeneutics, "Phenomenon and meaning" (1914), "Aesthetic Fragments" (1922) are a major contribution to the development of literary hermeneutics. $\mathrm{He}$ observed "word" and "literature world" in the paradigm of microsystem and macrosystem relations. "Inner form", being medullary element of poetic world structure, forms literal world picture. Main idea of the theory is that the scientist obtained word perception as a structure, which reflects emotionally sensitive and cognitive character. According to G. Shpet supposed that interpretation of image to cognition is a "total emancipation" of poetic form. Character created by literal word cannot be interpreted as "concept" or just like "representation". So during reading process a reader understands character, concept and image of literal text through individual and collective comprehension by interpretation creative literal world picture $[15$, 68 p.]. Thus, reader and literal text each time interact with each other creating dialogue; this created relation is not regulated by the author's idea. The idea of literature perception as an ability to self-regulation is the main feature of an open dissipative system. This idea is accepted as innovative point of view to the wellestablished physical nature regularities.

A Nobel laureate I. Prigogine developed the system theory in the sphere of anthropology and engineering science. The most important aspect in his research was the comparative investigation of open dissipative systems with closed-ordered systems, which have not communicative characteristics. The comparative analysis of these systems has revealed variability, instructiveness, self-regulation of open systems. The fundamental idea is that the "human systems are considered not in terms of equilibrium or as "mechanisms, but as the creative world with incomplete information and changing values, a world in which the future can be represented in many ways. The social problem of values in a wide range can link with the non-linearity. Values are codes that we use to keep the social system in some line of development, which is chosen by history. Value Systems always resist the destabilizing effects of the fluctuations that are generated by this social system, it gives the process the features of irreversibility and unpredictability" $[16,36]$.

So the system theory foregrounds in perception, comprehension, understanding of a literary text. The theory of open systems is related to the category of fractals - a term introduced by B. Mendelbrot, a mathematician and the author of "The Fractal Geometry of Nature" $[17,15]$. Fractal derivates from the Latin word "fractus" and denotes - uneven, broken. B. Mendelbrot used the terms "fractals" and "fractal objects" talking about ability to "selfsimilarity" expressed in the invariance and "irregularities" meaning non-linearity.

Synergetic study jointed in itself traditional approaches of literature study and new concepts based on the system theory and fractal literature, it also jointed humanitarian and basic scientific knowledge. Conceptual paradigm of the synergetic is the meaning self-generation.

It is not sufficient to use traditional scientific approaches for understanding hidden dialectical relations. System-synergetic approach became effective for the detection of multipiece structure of the text, the relationship of its elements, direct and figurative works bonds with reality, meaning polyphony of text's verbal structure. It was restructured the traditional comprehension of gradation - author, text, reader. Subject, idea, author conception, characters system, structure, plot, reader's perception are the elements of literal and linguistic world picture according to system-synergetic approach. These elements are universal and unique at the same time. Historical reality, life and spiritual experience of a text author and a reader, psychology of creativity, the psychology of perception in evaluating the text as an open system are important components in the typology of the functioning of literary text. The works of H. Haken [18], V.S. Stepin [19], E.N. Kniazeva, S.P. Kurdyumov [20], and others are important for development of the synergetic theory.

Academician V.S. Stepin studied the philosophy of science. In his monographs 
"Theoretical knowledge" he explained the properties of self-organization systems as "a process that leads to the formation of new structures" $[21,204]$. The combination of a systematic approach and the synergetic principles in the annex to the humanitarian knowledge, such as literature, gives new possibilities for understanding the plot and the meaning of the literal text. The text perception as the open self-organizing system changes the view on the relationship between the text and the reader, the author and the reader. "Non-equilibrium relations are "sine qua non" condition for selforganization, but self-organization, in its turn, changes the role and meaning of these relations" $[22,135]$. The history of literal compositions functioning has examples when a story is comprehended differently dependently on centuries. The books, which were read with great interest in one historical period, have become uninteresting in another period. But there examples of classic novels which are actual and interesting in each period by variedness of hidden meaning layers.

This factor depends on text autonomy from its author and reader's activeness in meaning understanding. It is appropriate to address to the Einstein's theory of relativity belong to time and space. New time and reality can cause new understanding of the meaning. Scientists V.G. Zinchenko, V.G. Zussman, Z.I. Kirnoze proposed the effectiveness of the system-synergetic approach in studying literary compositions as "an unstable system which are constantly in a state of transition from chaos to order and from order to chaos". They associated quality of nonlinearity with meaning self-creation: "Synergetic approach allows us to investigate the semantic aspect of the "literature" system relationship with the system of numerous contexts and with reality. There are many works in philology titled "Art and synergy", "text synergy" and others [23, 203-204]. Individual reader conception and linguistic world picture recreated by the author enter into complex relation determined by scheme of the system-synergetic method where the main triad is author, composition and reader. This triad is framed by traditions and reality. The direct and reverse associations between structure meanings play deter- minate role. Variety of structural elements is characterized by non-linearity and their openness that ultimately leads to the meaning selfcreation of each individual reader.

\section{References}

1. Hertz G. Principles of Mechanics presented in a new form // Life Science. Anthology of Classical Science Fiction Stories. - M., 1973, P. 246.

2. Planck M. Physical world picture. - M., 1966. - P. 326.

3. Melnikov A.A. Language and national character. The relationship of structure and mentality. - St. Petersburg: Speech--2003. P.256.

4. Gurevich A.Y. Categories of medieval culture. - M., 1972, P.135.

5. Maslov V.A. Cognitive Linguistics. - Minsk, Tetra. Systems, - 2004. - P. 357.

6. Suleimenov E.D. The concept of meaning in modern linguistics. - Alma-Ata, 1989, P.269.

7. Uryson E.V. Problems of linguistic world picture: Anthology in semantics. - M.: Languages of Slavic culture, 2003. P. 304.

8. Fefilov A.E. The nature of the interaction of language, consciousness, reality. // Internet materials - 2004. P. 1-3.

9. Danchinova M.D. Literal world picture in the literature of Buryatia (1960-1990-ies): Spatio-temporal architectonics. Ulan-Ude, P. 138.

10. Bakhtin M.M. Seven Volumes collection. Volume 3 Moscow: -2012 , P.238.

11. Goncharova N.N. Linguistic world picture as an object of linguistic description // Proceedings of the TSU. Humanitarian sciences, 2012, № 2. - P. 396-405.

12. Zobov P.A., Mostepanenko A.M. The rhythm, the space and time in art and literature. - Leningrad, 1974. P. 1125.

13. Salnikov Y.V. Literal world picture in V. Belov prose: Abstract: Kand.filol.nauk. - Voronezh, 2011. P. 28.

14. Aiupova S.B. Categories of space and time in linguistic literal world picture (based on I.S. Turgenev prose). The thesis for participation the degree of Doctor of Philology. - Ufa, 2012. - P. 297.

15. Speth G.G. E.V. Pasternak prose. - M., 1989.

16. Prigogine I. Nature, science and new rationality // Philosophy and Life. - 1991. - № 7. - 36 p.

17. Mendelbrot B. Fractal Geometry of Nature. - M., 2002. $-656 \mathrm{p}$

18. Haken H. Synergetic Computers and Cognition. A. Top-Down Approach to Neural Nets. - Berlin: Heidelberg, 2004. $-256 \mathrm{p}$

19. Stepin V.S. Synergetic and system analysis// synergetic paradigm. Cognitive - communicative strategies of modern scientific comprehension. - M.: Progress-Tradition, 2004. - 560 p.

20. Knyazev E.N., Kurdyumov S.P. Foundations of Synergy: synergistic vision of the world. Izd.3, 2010. - 256 p.

21. Stepin V.S. Theoretical knowledge. - M., 1999. - 237 p.

22. Prigogine I., Stengers I. Time. Chaos. Quantum. - M.: Progress, 1994. - 266 p.

23. Zinchenko V.G., Zussman V.G., Kirnoze Z.I. Literature and methods of its study. System - synergetic approach. - M.: Flint. -2011 . -275 p. 


\title{
UPBRINGING AND EDUCATION: HISTORICAL AND PSYCHOLOGICAL ASPECT
}

\author{
Belova T.A., Britskaya A.L. \\ FGBOUVOOSMU MinzdravaRossii,Omsk, e-mail: belova.t.a@mail.ru,alena_britskaya@mail.ru
}

The article deals with the role of upbringing in the education system. It is considered what kind of educational function the family, a children's preschool institution, a school, an institution of higher education perform in the framework of the formation of a person as a person. The authors note that the educational process is, first of all, the interaction of two personalities - a teacher and a student. The main function of the teacher is the transfer of new knowledge, skills and skills to the student, as well as the education of the future citizen, a specialist in the training. Also, the authors actively use examples from the history of the Russian state, namely, how they brought up future rulers, from the Middle ages to the Romanovs. In conclusion, the authors note that the upbringing of a person is a process that goes on "a red thread" throughout his life. Education of a person, a citizen, a specialist is of great importance in the education system, beginning with the birth of a young child, and then in the framework of preschool, school and vocational education. Parents and teachers help to grow a citizen, patriot, professional. Therefore, the educational process is an important component of the education system in Russia both at the present stage and in its historical past.

Keywords: upbringing, pre-school education, vocational education, child, person, school education, personality

Born on Earth, a person already carries a certain set of spiritual and psychic qualities, which should be developed further during life and revealed in the process of education.

The time of childhood is a period of the formation and development of the person's physical and spiritual-moral positions, the time of acquiring all kinds of knowledge, fixing skills and habits. First of all, a person comes into contact with a new world in the family. Folk wisdom says: "The apple is not far from the apple tree". The living conditions for each child are different. In one family - this is a long-awaited favorite child, and the other child is not needed by anyone in the family. And excessive care, and guardianship, the transformation of a new member of the family into an idol for worship, and the lack of basic care, caress, attention and everything necessary for the development and growth of a child can have an equally lamentable result. The proverb says: "You cann't love a child, you can spoil him". Already in the reign of Alexei Mikhailovich Romanov in Russia, the order of education of the royal heirs is established. Up to five years the child grew and was brought up mainly in the female environment: the queen herself, mothers, nurse, etc. The main task of education was to prioritize the environment by loving and caressing the child. Then the child passed into the sphere of cares of the king-father, gradually joining the mastery of scientific knowledge.

Thus, the atmosphere of the family hearth is what the child faces from the first days of his life. The atmosphere of the spiritual state of the family lays the foundation for the child's future life.

The next stage in the life of a child in the modern world is the life of the child in a pre- school institution. This is a very difficult stage for the baby. The child was always in the family, with his mother and now he finds himself in a completely different situation, with completely unknown people - teachers. Parents in this situation need to prepare the child for new life conditions, to expand his circle of communication. It is very important that the attitude of kindergarten workers to children is warm, but this is rarely found. Therefore, a child very often goes to kindergarten by duty, and not at will. Unfortunately, the work of many educational institutions is largely determined by the tradition, according to which the education system requires the education of an obedient performer, convenient for society. And such "upbringing" begins already with nurseries and kindergartens. The child is fed "by the hour", and not by necessity, accustomed to a rigid regime of the day, etc. As a result, the child experiences a state of "abandonment and non-involvement", but for educators and parents, he becomes quite comfortable "adaptive" child. This situation can then be repeated in schools.

Thus, the process of education and upbringing is a two-way process that includes the pedagogical activity of educators (that is, the performance of the function of organizing, managing and stimulating the child's development) and the child's response to the effects of adults. Especially important is the interaction with adults of those children who are prone to mental disorders. Psychologists recognize the fact that even in the absence of primary defects caused by the disease, the child's mental development can be disrupted by the adverse impact of the microsocial environment. So an unfavorable family atmosphere, lack of necessary communication between an adult and a 
child is dangerous at an early age, as it deprives the child of the necessary impressions, which forms mental deprivation and adversely affects the development of mental functions. The quality of pedagogical influence at early stages depends on the probability of compensation for any defects or, conversely, their aggravation. Therefore, the role of educators is often decisive in the future fate of such children.

The school period in the life of the child is especially important. It is in these years that a system of perception of the world is being developed, the child learns an independent approach to life. By this time the child understands that there are other people on the path of life, except for parents. The school makes new demands on the child, which often becomes an additional factor in the development of deviations in personal development. There is even a special term in the psychology of "didactogeny", which means a violation of the pupil's mental activity with the incorrect educational influence of the teacher.

A striking example of the right relationship between teacher and disciple is St. John of Kronstadt, who taught at the gymnasium. He showed true love towards his students: he did not put "twos", he never asked for lessons on the house, asked those who wished to answer, thanked him for the good answers. It often happened that Father John interceded for a disciple whom they wanted to expel from the gymnasium. He was entrusted with the pupil and actively studied with him. And the positive result did not make me wait long. But this does not mean that he was "kindhearted" towards the students, he saw who needed help and words of support, and who deserved the punishment. And the students felt the sincerity of their teacher and looked forward to the lessons. John of Kronstadt was firmly convinced that many of the problems of an adult were laid down in childhood.

Also responsibly approached the educational process during the training of future heirs of the throne. For example, for the young Emperor Peter II, Andrei Ivanovich Osterman compiled a schedule of studies where the science was based on education that could help the emperor in governing the state: "Namely:

1. A new or civil history ...

2. The general policy ...

3. military art.

... the other parts of knowledge and science can ... then suggest that ... they need to be amused. Prior to that,

1. Ancient history.

2. Arithmetic, Geometry and Trigonometry.

3. Cosmography.
4 Knowledge is natural.

5. General rules of civil architecture.

... especially to watch it, so that the diligence of His Majesty does not bother, and for the sake of no teaching for more than an hour to continue, but always pleasing to the fun after the time allowed for the teaching" [1].

Responsibly approached the educational process during the training of future heirs of the throne. For example, the heir to the throne was educated to behave properly in the society both among compatriots and foreigners (for example, the monarch took the heir to official receptions), maintained a good physical form, actively included physical labor in the order of the heir's day (Paul I loved to grind the details on the machine, and his son, the future Emperor Alexander I, was digging up beds, mowing, plowing, chopping wood). In the future heir to the throne teachers brought up feelings of compassion, civic duty. At the same time, the education and upbringing of the heir did not go in a closed space, actively attracted peers in order for the future sovereign to grow up in the right environment (Metropolitan Makarii formed around the future Tsar Ivan the Terrible circle of persons who later formed the basis of the government of Tsar Ivan - the "Izbrannaya rada").

After graduation, when a person goes into an independent life, his attitude towards others is formed taking into account the acquired life experience, including through education throughout his life from the moment of birth. So if a child in a family or school establishment has a sense of insecurity, a state of anxiety, then this could become a trigger for aggression as a natural way of protection. Hence the negative attitude towards the teaching both among schoolchildren and students, even among those who know the disciplines themselves well. And if a person studies, feeling disgust for knowledge, then we psychologically oppress him. As a result, the result of coercion is either the rejection of imposed acts, or those who impose these actions [2].

An important contribution to the process of the further development of a person is played by his professional path, which originates in a higher educational institution. The teacher of any discipline performs not only educational, but also educational functions. Education of the future specialist has several features in comparison with the education of the schoolboy. So for a student, as a person of a certain age, the greatest plasticity in the formation of complex psychomotor skills is characteristic, the achievement of "peak" results in solving 
verbal and logical problems, etc. But, it is quite obvious that all these achievements are based on the previous processes of biological, psychological, and social development.

Psychologists note that the student's age is a period not only of character stabilization, but also of the greatest development of moral and aesthetic feelings, of mastering the full range of social roles of an adult (civil, professional, labor). An important feature of moral development at this age is the intensification of conscious motives for behavior. Strengthened and those qualities that were lacking in the school period: purposefulness, initiative, determination, independence, self-control and others. Young people begin to show interest in moral problems, such as the purpose of life, duty, love, etc. However, during this period, there may be a differentiation between opportunities and their actual implementation. Researchers in the field of age psychology note that the student's ability to consciously regulate his behavior is not yet fully developed. Therefore, possible manifestations of unmotivated risk, inability to foresee the consequences of their actions and so on.

Higher education has a huge impact on the development of the individual. Under favorable conditions young people develop all levels of the psyche during the student's period. Obviously, for a successful study at the university, a fairly high intellectual level of development is necessary. With a slight decrease in this level, compensation is possible due to increased efficiency or increased motivation. An important role is played by the ability to social adaptation. It is a condition for active and effective activity. The process of adaptation is different for young people and young people, for young people with work experience, for example, adaptation to the conditions of student life is easier, recent students are more easily adapting to academic work. Thus, the task of teachers and especially the student group is not to find a certain average option, but to create conditions for the overall most optimal activity.

An important educational function in higher education is played by humanitarian disciplines. The study of humanitarian disciplines in higher professional education began in fact from its inception. Already in the Middle ages, the teaching of humanities was compulsory and pursued a specific goal - improving the moral and intellectual level of the student. Within the framework of humanitarian disciplines, various moral and ethical problems of man and society have been raised and are being raised, which makes it possible for future professionals to de- velop such qualities as humanism, patriotism, disinterestedness and others [3]. One of the effective ways of implementing the educational task in the classes on humanitarian disciplines is the method of small groups, which allows a group of 4-5 students to solve the task assigned to it, and in the course of its implementation learn how to cooperate with each other, respect the opinion of another person. Also, within the framework of the discussions at the seminar sessions, the student realizes that the rightness may not be on his side, and that the exchange of opinions is more important than personal authority [4]. The success of the work of the group largely depends on the form of organization of its activities. So the collectivecooperative group is organized on the basis of close interaction of all group members. Individual - is based on the independent work of each member of the group. The coordinated group assumes the independent work of each member, but with the correlation of the process and the results of work with the other members of the group. Most often, with the exception of some types of complex creative work, the collective-cooperative form of organization of the group is preferred.

In the process of working with students, the teacher should take into account not only the mental potential of young people, but also the level of motivation and life circumstances. It is necessary to teach the student the most optimal organization of labor. Do not forget about the realization of the most important need for communication, as in communication students learn not only others but themselves, they master the experience of social life. Thus, the psychological development of a person's personality is a dialectical process of the emergence and resolution of contradictions, active work on oneself.

The teacher should raise in the student and the desire for continuous education throughout life. This principle is fundamental in the framework of the competence approach of the modern system of higher education in Russia. Accordingly, the main task of the teacher is to create an atmosphere of interest for each student in the learning process, as well as to organize joint activities of students to solve a complex educational problem. The teacher should awaken in the student the desire to solve complex problem situations, while helping each other. In order for the educational work to have the desired result, the teacher should try to provide positive feedback to students, encourage them to assess themselves and their actions, and in the future also to make corrective 
actions. As the organizer of academic work, the teacher should not forget about the encouragement of students (for example, praise, approval, support and others).

One of the best ways to have an educational effect on students is dialogue. It is very important for the teacher to establish a dialogue both in the "teacher-student" mode and in the "student-student" mode. During the dialogue, students can solve complex problems, critically think, communicate, debate. It is also the dialogical form of communication, unlike monologic, that affects the emotional sphere of a person. And it is important here that the teacher's ability not only listen attentively to the opinions of the students, even if they are erroneous, encourage them, but also be the most capable of tolerance and mutual understanding [5]. The method of group discussion for making optimal decisions is especially effective when discussing ambiguous questions on which there is no unanimous opinion among researchers (which is typical for humanitarian disciplines). The point of collective discussion of such issues is not to inevitably come to an unambiguous answer, but in understanding the essence of the problem and in the possibility to evaluate possible solutions and points of view. The main thing in such discussions is that the members of the group learn to reason logically, convince, defend their position, accurately formulate their thoughts and listen and understand other people. Work in the discussion group should be based on mutual trust, openness and an atmosphere of benevolence, in which even seemingly strange opinions do not cause negative reaction from the members of the group.

Thus, the role of the teacher in educating the future professional is significant and im- portant, despite the fact that sometimes you have to deal with fully formed personalities. Only through direct communication and personal contact, some people pass on their life experience to others, which includes almost everything human that exists in modern man: from elementary skills and use of speech to abilities for various activities and moral values.

To summarize, we note that the upbringing of a person is a process that goes on "a red thread" throughout his life. Education of a person, a citizen, a specialist is of great importance in the education system, beginning with the birth of a young child, and then in the framework of preschool, school and vocational education. Parents and teachers help to grow a citizen, patriot, professional. Therefore, the educational process is an important component of the education system in Russia both at the present stage and in its historical past.

\section{References}

1. Bilfinger G.B. Location of the teachings of his Imperial Majesty Peter the Second Emperor and autocrat All-Russia, and so on, and so on, and so on. On the establishment of His Excellency the state official-chancellor of the State, is the effective adviser of Baron von Osterman, his Imperial Majesty, the Obergofmeister. - St. Petersburg, B.G. - P. 7-11.

2. Britskaya A.L. On some problems of increasing the effectiveness of education // Omsk Scientific Bulletin. Appendix to the release of the thirtieth. - 2005. - № 3 (30) - P. 64-65.

3. Belova T.A., Britskaya A.L., Nepsha I.V., Sivirina O.A., Shvin M.V. The patriotic education of modern youth in a medical university: the example of Omsk State Medical University. // Modern science-based technologies. - 2016. - № 4 (part 2). - P. 309-313.

4. Belova T.A. The use of the technology of "small groups" at the seminars on the discipline "History of the Fatherland" in a medical college. // Modern science-based technologies. - № 92015. - P. 96-98.

5. Belova T.A., Britskaya A.L., Emelyanova N.M., Nepsha I.V., Sivirina O.A. The technology of problem training as a tool for the development of independent work of students. // Modern problems of science and education. - 2015. - № 2 (part 2). 


\title{
CLUSTER APPROACH TO THE FORMATION OF CORPORATE CULTURE OF THE UNIVERSITY
}

\author{
Bondarenko V.P., Ponomarenko E.V., Kozybaev E.Sh, Parmankulova P.Zh. \\ M. Auyezov South Kazakhstan State University, Shymkent, e-mail: vbond2011@mail.ru
}

In the modern world of knowledge and an innovation are the main criteria of economic development in the modern world and improvement factors socially - public life of the world community. However transformation of economy can't be initiated only by knowledge. It demands a complex of structures and system actions by means of which knowledge is formed and the personnel study. In this regard the universities are considered as the institutions playing the vital role in social development of the country. They provide professional development of scientific and educational, technical, administrative and cultural elite of the country. Today the world research universities are not just higher educational institutions of quality education, intellectual and cultural development, and pride objects as the countries consider the education status in comparison with others and lean on competitive human assets. The corporate culture of a higher educational institution forms human assets, and her improvement defines economy of knowledge. In article formation of corporate structure of the university on the example of Southern Kazakhstan State University Southern Kazakhstan State University Southern Kazakhstan State University is considered.

Keywords: cluster, corporate culture, innovation, higher education accreditation, benchmarking

Cardinal changes in the modern world require from the knowledge system deeper understanding of topical problems of humanity. With regard to topical problems teachers/professors and students cannot sit idle. It is not a simple task to graduate demanded specialists in the progressive innovative social modernization all the while positively effect on youth through decent ideal approaches. Correctly selected university strategy as well as development of corporate culture is that what help to accomplish the task.

What is university of the future? This question is in concern not only of academic society but whole intellectual social corp. Not by coincidence State Education Development Program of the Republic of Kazakhstan 20152020 strongly emphasizes on establishment of research universities based on corporate management model. Now universities have a specific status entitled them to develop own educational programmers. It has become possible to create partnership with business structures, commercialize innovations and develop state/ private cooperation.

Corporate culture of any organization plays a key role in its management structure and represents a complex of opinions, anticipations, values, relations and staff policy. For example, American universities applied a synthesis of democratic traditions brought by early medieval universities and pragmatism of German university school.

The American approach to higher education initially differed by academic freedom and was oriented to society. Therefore leading American universities in the middle of 20 century turned in powerful educational, research and scientific/production corporations closely connected with business, industry and management systems [1-2].

Nowadays world research universities are not simply higher institutions of quality education, intellectual and cultural development, but subjects of pride as countries consider their own educational status in comparison with others and base on competitive human assets.

Research status of universities is an adequate form of integration of science and education into the current production process; it has been strengthened all over the world thus increasing number of such universities. In USA there are already over 100 research higher institutions and more than 70 in Great Britain and Germany. China has commenced program on establishment of 100 research universities with the annual budget of each in $\$ 1 \mathrm{bln}$. To meet such objective Ministry of Education and Science of the Republic of Kazakhstan initiated democratic manner of management through corporate structuring of higher institutions.

\section{Materials and methods of research}

The study used the following methods: Empirical - the study of formal and normative documents, observation, conversation, the method of expert assessment, questioning, exploring the views of employers, theoretical analysis, synthesis, generalization, classification, formulation of conclusions.

\section{Results of research and their discussion}

It well corresponds with our strategic objectives in higher institutions to prepare demanded graduates. To this extent a number of serious reforms are planned at the Southern Kazakhstan State University after M. Auezov (hereinafter UKGU). Being the largest 
multidisciplinary institution in higher education in the country the university is in the top of national ranking, positioning itself as wellknown brand in sphere of higher education in Kazakhstan. The university has passed institutional accreditation in MoE\&S, RK; 13 educational chemical and technological programs are accredited by ASIIN (Germany). 4 bachelor chemistry and chemical technology specialties of the university is entitled for Euro-bachelor award assigned by ECTNA European Association. The university is 2 nd in the General ranking of Independent Kazakhstan Agency on education quality insurance (NKAOKO). All the above said attracts more students, increasing number of undergraduates and doctoral candidates.

We tend to involve into scientific and educational process top management of large companies, leading scientists and experts thus transferring the university itself into main production process representing this or that scientific field. At present UKGU are proud of those top managers and leaders who graduated from the university and are employed by wellknown national chemical and petrochemical companies

Perspective development of education system depends on integration into the world educational space. UKGU achieved 98 Agreements on international cooperation through international scientific and technical cooperation and foreign economic affairs. The university is the member of such international agencies as European Association of institutions in higher education (EURASHE); International Academy of Education Sciences; TEMPUS Universities Consortium; Eurasian Universities Association ; Board of CIS Network University; European Association of Universities of hospitality (EURHODIP); signatory of the Magna Charta of Universitatum; is the one the Basic higher institution of SCO universities alliance [3-4].

Above said achievements constitute recognizable brand of the university, its acknowledgement in academic field and demonstrate its importance to the society. Annually over 100 people are sent for training abroad under study exchange programmes, i.e. IAESTE, AIREX, DAAD (German academic exchanges unit), British Council, American Board of American Education Council. Participating in different grants and programs, young teachers strengthen image of the university thus leading to Intellectual nation concept.

The university in course of future corporate structure forms its budget not only out of public funds; it attracts finance from different organizations and business structures. The research component of the university is developed at the expense of grant financing. Under NATO Science Program for Peace and Security the university in association with scientists from Norway, Uzbekistan, Tajikistan, Kyrgyzstan commenced international Project ESP.EAP. SFPP 983945 on Assessment of contaminated transboundary water basins in Central Asia.

Today yet there is no uniform comprehensive approach or magic formula for "manufacturing" world-class university. National features and institutional models are highly variable. Among these different development ways each country can choose the strategy which is mostly corresponds to its capability and resources.

For this reason, applying the best practice (benchmarking) UKGU develops principle ways for establishment of corporate culture purposed to create a model of successful organization. In achieving this we have planned new mission, policy and strategy for university development based on partnership with main region authorities and justified the transition of university to innovative business - structure management.

UKGU development strategic plan 20152020 is based on an approach that represents a university as alliance aimed on education, the scale within which its faculty and students share common ideas; work jointly over uniformity of education and research and integrate possessed knowledge into students' secular education. In the light hereof we consider higher institution as an open, fair, orderly alliance adhered cultural traditions; it is the area wherein specific training and worldview are effectively united into holistic philosophy.

We are forming an academic field for development of intellectual, social and physical competence. As the result a student learns how to control emotions, understands its independence, individuality, sense of purpose, to be tolerant. Through early involvement of students into scientific process we knowingly define their interests, intentions and preferences and create conditions for development of personal system of values and encourage their innovative initiatives.

Main vectors of the strategy are oriented to modernization of top management system applying international standards of corporate management, as well as to high quality skills and university's self-dependency. Innovative technologies became usual techniques in everyday training reflected in increased teaching 
in English, academic and scientific mobility of students and faculty.

It is common for ideal agencies to perform comprehensive measurements of their work. To remain valuable for consumers of education services, its clients and society is the main priority in UKGU policy and strategy. The university is oriented to individual way of study process, selectivity of education programs, courses and teachers, and to most transparent educational process. We work making programs unique corresponding to three rules Just in time, Just enough, Just for me [5-6].

By virtue of e-learning students and undergraduates conduct independent work and research using advanced software and IT technologies. Established Institute of distance learning effectively provides with full range of education services in form of on-line interactive information.

Today's training cannot be beyond a focus on a consumer; life-long learning can be achieved by an integral approach. Towards improvement of students' skills we have established partnership with such well-known companies as PetroKazakhstan Oil Products LLP, Kazfosfat LLP, Yuzhpolimetal JSC , SouthWest Scientific Research Institute of plant growing and animal husbandry, Agroinnovatsiya JSC, Ontustik Munay Gaz LLP, Avtobusservice LLP, Kazakhstan Temir Zholy NC etc.

UKGU cooperation with industrial sector / companies indicated that in addition to traditional engineering staff there is a need in multiple-purpose professions, such as engineers managers, experts of innovative projects as well as in international marketing, patent law, risks assessment experts for innovative projects. Taking into such demands educational programs were developed complying with research university status. We have created institutional background for integration into the world education space and for the complete incorporation into Bologna Process.

Programs, projects, ideas and services rendered by UKGU are the components of corporate structure and oriented to needs of the region. Scientists of the university fulfilled a complex analysis of social and economic development of the Southern Kazakhstan area for the last 10 years. It has allowed to define not only priorities of scientific and technical development but also to assess level of competitiveness of the region, to arrange partnership of those have been involved into innovative process, to develop targets for manufacturing of products taking into account both internal and external market demands.
UKGU performed monitoring to assess current condition within the region. Future development was viewed from different sides and defined sectors of priority such as agroindustrial complex for food security; industrial economy sector and its numerous advanced technologies applied to make a breakthrough in innovation-technological field; tourist cluster and its obligatory adherence of cultural traditions and natural specifics of the region.

During the meeting held by Oblast Akim jointly with all managerial sectorial agencies it was noted that the extent and intensity of innovative targets within the region depend on close relations open by state, business, education, science and industry. It has been concluded to amend South Kazakhstan Development Programme 2015-2020.

UKGU have created innovative infrastructure to involve entirely scientists into modernization of national economy. We are cofounding South Kazakhstan regional science park where new laboratory devices are centered and a basis for trial industrial tests is established, business incubator, design and planning divisions are functioning. The science park is the solely one center within South Kazakhstan where a technological transfer is arranged.

\section{Conclusion}

Corporate culture of higher institution forms human assets and improvement hereof defines knowledge economy. Corporate university must have high-ranking officials and donors in the name of known businessmen, companies' top management who are ready to support university in implementation of its mission. We have established a Trust Board entered by top management of leading national and transnational companies, businessmen and South Kazakhstan Oblast administration.

We have been worked over establishment of an endowment using outsourcing and fundraising. Meantime the main management resources are not represented by finance and other traditional means but intelligence of professors/teachers and young scientists who are business-tenanted and possess leadership practices are attracted.

This article was prepared for grant of the Ministry of Education and Science of the Republic of Kazakhstan to conduct research work on "Building the qualification structure in the system of higher education in Kazakhstan competency-based approach and innovative training, result-oriented".

This research is carried out within the framework of the project AP05131906 
"development of transition of system of continuous pedagogical education in cluster model of development".

\section{References}

1. Vodichev Y.G. "Research" universities of USA and Russian university system, experience in comparative analysis, Novosibirsk, 21.03.2001. http://www.prof.msu.ru/PC/omsk/2_02. htm.

2. Shared 'Dublin' descriptors for Short Cycle, First Cycle, Second Cycle and Third Cycle Awards. - Http://www.jointquality. com/content/descriptors/CompletesetDublinDescriptors.doc.

3. Criteria for Academic Bachelor's and Master's Curricula. - http://www.jointquality.com/content/descriptors/AC English_Gweb.pdf.
4. European Association for Quality Assurance in Higher Education. - Http://www/.enqa.eu.

5. Standards and Guidelines for Quality Assurance in the European Higher Education Area. http:// www.enqa.eu/files/ Report.pdf.

6. EUR'ACE (European Accredited Engineer. Http://www. feani.org/EUR_ACE/EUR_ACE_Main_Page.htm.

7. The Conference of European Schools for Advanced Engineering Education and Research. - http://www.cesaer.org.

The work is submitted to the International Scientific Conference "Fundamental and applied research. Education, law and Economics", Italy (Rome-Florence), September 9-15, 2018, came to the editorial office on 16.08.2018. 


\title{
DYNAMICS OF CHANGES IN THE CONFESSIONAL CONSCIOUSNESS OF THE STUDENTS IN THE CONDITIONS OF EXPERIMENT
}

\author{
${ }^{1}$ Naumenko O.N., ${ }^{2}$ Naumenko E.A. \\ ${ }^{1}$ Ugra State University, Khanty-Mansiisk, e-mail: oolgann@mail.ru; \\ ${ }^{2}$ Tyumen State University, Tyumen, e-mail: hea2004@mail.ru
}

\begin{abstract}
This article deals with the impact of forms and methodical possibilities on the correction of inter-ethnic and inter-religious interaction of students, their normal behavior in different social situations. To appreciate the realization of this purpose, the authors developed a course on "Religions of the region under study". He emphasized the requirements of the educational standard which determines the necessity to study history, culture and religion of the region under study for the specialty "Regional studies" in the sphere of religious and interfaith relations. The experiment was conducted in 2009-2013, followed by the observation of students in 2014-2018.
\end{abstract}

Keywords: multiculturalism, tolerance, teaching experiment; multi-religious education, Christianity, Islam

The problem of Islamic extremism in the modern world has determined the necessity to find ways to counteract this phenomenon. In our opinion, the most productive mechanism of counteraction to ethno-cultural and religious extremism can be considered as preventive measures, aimed to establish a multinational, but a single nation with common cultural and historical roots. Fostering of religious and national tolerance is the first step of this process, the basis to strengthen interfaith relations and create common world-view.

In Russia the modern confessional education (schools and universities) is focused on the formation of the youth's system of moral values reflected in its "own" religion, but it does not involve deep knowledge of the aliens' culture and outlook. Such disciplines as "Fundamentals of Orthodox Culture" and "Fundamentals of Islamic culture" are optionally taught in secondary schools. Attending both disciplines is impractical. Thus, the course strengthens the students' sense of exclusivity, belonging to only one culture. This practice does not unite children or integrate and harmonize their ethno-cultural community, but only puts emphasis on the confessional differences and enhances the form of relations "your / someone's else". The formation of a sense of civic unity is necessary to overcome this barrier. This problem can be solved if the "alien's" religion and culture will be integrated into the cultural space of the today's youth personality and will be well known and understood by members of other faiths.

The object of the study is students; the subject of the study is confessional tolerance and elements of multiculturalism. Tolerance has been diagnosed in the contents of personal qualities, attitudes, values, behaviour and outlook.

\section{Materials and methods of research}

The methodological research has been focused on the principle of molding of the personality in society as a part of personal and cultural approaches. The research included the use of such methods as: observation, survey, teaching modelling, analysis of documents and expert assessment.

The experimental sample included students, male and female, 17-20 years of age; the total number is 73 people. In addition to the experimental group, the tolerance parameters had been studied in the control group, where the work on the formation of tolerance was not carried out. The structure of the experimental and control groups included Muslims and Orthodox Christians. The study consisted of various manifestations of ethno-cultural and religious characteristics within an individual. The structure of the experimental group is presented in Table 1.

In the control groups students of other specialty there was no course "Religions of the region under Study". The groups consisted of students with identical age, sex, educational characteristics. As the first year of the experiment was a period of technical, content, organizational revision of the course and was in the process of regulation, there was no control group. It appeared only in the second year.

The level of tolerant and multicultural orientation of students in the experimental and control groups was defined at the beginning and the end of the pedagogical experiment. The means of such assessment was special, individual-oriented questionnaire with data interesting for a researcher. There were 50 both open and close questions, reflected personal students' attitudes towards the problems of confessional and social interaction, multicultural tolerance. Among them, there were, for example, such questions which dealt with students' complete 
readiness to cross marriages, visits of cultic institutions of "alien" religion, preferences in friend relations, knowledge of basic religious holidays in different confessional groups, etc.

It is necessary to outline the conditions of the experiment.

It is necessary to outline the conditions of the experiment. The South of Tyumen Region is a unique region where multicultural phenomena are historically formed. The level of national and religious tolerance and "friendly feelings" here is exceeds $90 \%$ in some years, according to the information of the Committee on nationalities of the Tyumen region. Sociologists from other regions of Russia confirm the high level of tolerance in Tyumen [10]. In the youth community the tolerance level is lower (Tabl. 3, 4) because of psychologic-age features, of an individual, and the fact that in the groups there were students from other regions that are not characterized by interconfessional concord (for example, Ugra and Yamal). Basically the experimental and control groups consisted (80-90\%) of local students who were brought up in auspicious multicultural environment. Thus, the students expressed appropriate readiness, and the experiment was to finish the process of formation of their tolerant and multicultural consciousness with help of purposeful influence.

Expert assessment was carried out on the informative certain procedure that reflected peculiarities of social behaviour and mentality of a student. There were created two expert groups (independent of one another) for estimates of characteristics of tolerance. Profes- sors who know students for a long period of time, give classes and have an opportunity to compare their personal attitude, values, outlook and behavior have become members of expert groups. They evaluated displays of personal qualities of students on the proposed scale (on a 10 point-based system).

\section{Results of research and their discussion}

This topic as experimental experience is not discussed in the pedagogical science. The authors have considered the theoretical aspects of education religious tolerance [4, 6 et ol.], multiculturalism [3, 8 et ol.] and new teaching technologies [7 et ol.]. Some authors describe the experience of raising religious tolerance, but without multi-religious learning [2, 5 et ol.]. The previous author's articles consider the historical experience of formation of Muslim tolerance [1]. Analysis of the Russian experience of confessional tolerance education through a special training discipline has not yet become a scientific research subject. Experimental research on the formation of multiculturalism is currently no.

As part of the experiment, at the premises of the Tyumen State Academy of International Economics, Management and Law, there was introduced a specialized course on "Religions of the region under study" for students enrolled in Regional studies. The duration of the discipline was 292 hours, 144 of which were class hours. The form of assessment was final test and exam. Thus, student was immersed in the content of the course for quite a long time.

\begin{tabular}{|c|c|c|c|}
\hline \multicolumn{4}{|c|}{ Experimental group members } \\
\hline $\begin{array}{c}\text { Academic } \\
\text { year }\end{array}$ & $\begin{array}{l}\text { The number of } \\
\text { students in the group } \\
\text { (persons) }\end{array}$ & $\begin{array}{l}\text { The number of students who } \\
\text { consider themselves as Mus- } \\
\text { lims (persons, \%) }\end{array}$ & $\begin{array}{c}\text { The number of students who } \\
\text { consider themselves as Orthodox } \\
\text { Christians (persons, \%) }\end{array}$ \\
\hline $2009-2010$ & 26 & $7(27 \%)$ & $19(73 \%)$ \\
\hline $2010-2011$ & 21 & $6(28,5 \%)$ & $15(71,5 \%)$ \\
\hline $2011-2012$ & 15 & $5(30 \%)$ & $10(70 \%)$ \\
\hline $2012-2013$ & 11 & $4(36 \%)$ & $7(64 \%)$ \\
\hline
\end{tabular}

Control group members

Table 2

\begin{tabular}{|c|c|c|c|}
\hline $\begin{array}{c}\text { Academic } \\
\text { year }\end{array}$ & $\begin{array}{c}\text { The number of } \\
\text { students in the group } \\
\text { (persons) }\end{array}$ & $\begin{array}{c}\text { The number of students who } \\
\text { consider themselves as Mus- } \\
\text { lims (persons, } \%)\end{array}$ & $\begin{array}{c}\text { The number of students who } \\
\text { consider themselves as Orthodox } \\
\text { Christians (persons, } \%)\end{array}$ \\
\hline $2010-2011$ & 30 & $10(33,3 \%)$ & $20(66,6 \%)$ \\
\hline $2011-2012$ & 31 & $12(37,2 \%)$ & $19(62,8 \%)$ \\
\hline $2012-2013$ & 29 & $11(31,9 \%)$ & $18(68,1 \%)$ \\
\hline
\end{tabular}


The teacher offered the subject of compulsory implementation. The students had to examine primary religious sources, visit different religious places. Unsubscribing from this course was impossible due to the obligatory nature of the discipline. In addition, the necessity for studying the subject was determined with the bond "fail the test - fail the exam expulsion". In case of disagreement with the content of the discipline the student were able to exchange into a different specialty. Thus, the students of "Regional Studies" were actually imposed to study this course.

Perhaps, from a legal point of view, this approach meant a restriction of religious students' rights and their academic and religious freedom. As a compensatory measure, teacher and the Academy administration did not interfere in the commission of some cult, ritual actions. Students were allowed, for example, to wear religious clothes elements (such as a headscarf), to pray, to use specialized library, an exhibition of confessional religious values. Moreover, such a religious demonstration was used to achieve the purpose of the experiment: the students were given the opportunity to freely talk about their prayers and rituals, their history, purpose, values, and most importantly, their emotions and religious feelings (for example, between life before and after the emergence of confessional self-consciousness).

This pedagogical approach contributed to a better understanding for the Orthodox part of the group values of Islam. It also emphasized respect for Islam and at the same time it urged Muslims to treat Orthodox Christians in the same way. Muslims had to search for analogues in Christianity (e.g. the role of women's headscarf in Orthodox culture).

The program involved the studying not only the history of religions, their features in the Tyumen region and current status, but also a deeper exploration: the direct study of the Quran, the Torah and the Bible in various interpretations of theologians. The most important methodological element can be considered a reference to the following mandatory accents:

- To the common historical roots of different religions, protagonist in the Torah, the Bible, the Quran, as well as the similarity of the spiritual and moral values system;

- To discrepancies in religious primary sources: the students had to understand the historical, political, cultural, linguistic and other reasons for the differences in the interpretation of texts.

Thus, there was an assignment, as part of experiment, to form students' creative ap- proach to understanding the religious sources and distrust of pseudo-missionaries thinking.

Students had to visit places of religious purpose: the mosque, an Orthodox church, a Catholic church, a synagogue, as well as the study of museum collections with exhibits of religious cultures. The teacher encouraged students, who wanted to acquaint the group with family ceremonial objects: icons, Shamail (wall panels with prayers from the Quran), amulets, charms, and others. Besides that all students made multimedia presentations on ethnoconfessional trend which were the foundation for further discussions.

In the educational process the teacher, as mandatory didactic components, had used the following points:

1. Putting emphasis on the evaluation categories and concepts, such as "totalitarian sect is bad and orthodoxy is good", "Islamic fundamentalism is bad and traditional Islam is good", etc. However, at the same time, each class started with a positive assessment for world religions, for example: "Islam is one of the greatest and most tolerant of religions, and the Quran is also one the world's oldest holy books". This assurance made Muslim student trust their teacher and the provided assignments, which at the same time helped the students of other faiths foster appreciation for Islam.

In Germany, the practice of the confessional education was not valued and usually waived evaluation categories for studied religions [9], believing that the religion is of any self-worth. This approach left the learning process unfinished and prone to confuse its students instead of providing basis for the formation of their minds.

2. Not putting stress on any version of Islam (Christianity). Postulations of the largest schools of thought were studied in a comparative context with their mandatory assessment and identifying the causes of deformation of the original dogmas. There was proposed the idea that all religions have common roots and they originated from the same conceptual background.

The analysis of evaluates of two independent expert groups and testing data has shown that educational and methodical and upbringing process in the studying of subject has caused change in the terms of confessional tolerance. This change has affected the scope of scientific, practical, social and cultural knowledge of religious issues. In the next three years, the formation of confessional tolerance consistently confirmed. 
The level of tolerance and multicultural consciousness of students in the experimental control group

\begin{tabular}{|c|c|c|}
\hline Academic year & Before the experiment & After the experiment \\
\hline $2009-2010$ & $75,6 \%$ & $89,0 \%$ \\
\hline $2010-2011$ & $76,3 \%$ & $98,2 \%$ \\
\hline $2011-2012$ & $79,0 \%$ & $99,1 \%$ \\
\hline $2012-2013$ & $80,1 \%$ & $99,6 \%$ \\
\hline Average data & $78,0 \%$ & $96,5 \%$ \\
\hline
\end{tabular}

Table 4

The level of tolerance and multicultural consciousness of students in the control group

\begin{tabular}{|c|c|c|}
\hline Academic year & Beginning of the academic year & End of the academic year \\
\hline $2010-2011$ & $75,6 \%$ & $72,9 \%$ \\
\hline $2011-2012$ & $68,9 \%$ & $70,3 \%$ \\
\hline $2012-2013$ & $76,0 \%$ & $78,2 \%$ \\
\hline Average data & 73,5 & 73,8 \\
\hline
\end{tabular}

Expert evaluations testified the positive dynamics of the process also.

The estimate of students' tolerance degree was made from measurements of average tolerance ranking of a student before the experiment and after it. For this purpose the method of expert survey was used. Statistical data manipulation was made to verify the results. To verify the results the concordance coefficient of expert commentary was calculated (concordance coefficient $\mathrm{W}$ ) and was tested its statistical significance on the base of $\mathrm{X}^{*}$ Pearson (Table 5, Table 6).

Quantitative analysis of the data in the tables 5 and 6 clearly shows increase in the level of tolerant consciousness of students who took part in the experiment of the method of tolerant and multicultural consciousness formation. An average change in the development of tolerant component in consciousness in the academic year was defined by quantitative measures $18,5 \%$. The measures of changing tolerance and multicultural components in consciousness of the control group students changed within a statistical margin of error $-0,3 \%$.

The results of surveys of students of different confessions and cultures indicate that they have begun to understand each other better. "... If I had known then what I know now, I would not say this to him [Muslim] ...”, “... now I know why he [Muslim] did that ...", "I had despised the Russian, but now understand that they have such a religion" - the most characteristic statements of the students.

This approach can be used as a preventive measure to the majority of students. But, unfor- tunately, it is not very effective in teaching students with a high level of religious addiction. There is an interesting example to illustrate this statement. There were two people who accepted a radical version of Islam in the groups: a college boy of Russian nationality and college girl of Kazakh nationality. Religious consciousness of the college boy was managed to overcome only in two years, with the support of the mullahs and devout Muslim who offered help. At the same time he rejected any conversations with teachers, and the impact on him had to be carried out by the aide-Muslim under a false name, through contacts on the Internet. As a result, the student has agreed to meet with Mullah, who had previously been acquainted with the problem. The authority of the mullahs allowed for a positive ethno-confessional correctional work. The religious consciousness of the college girl managed to mitigate only partially in terms of attitude to her neighbors in the dormitory (for example, not to put a loud alarm clock at 5 am to perform the namaz, etc.), however, it failed to change her views and to overcome religious aggressiveness of behavior.

In 2013 the Institute was closed as financially inefficient, and the experiment was stopped.

The problem of tolerant and multicultural consciousness formation of students is much broader than its solving within the specialized course. With the purpose of diversification of major didactical methods of formation such characteristics of consciousness the attempts of using elements of confessional education and multicultural analysis of the contents of 
other disciplines were made. We studied the effectiveness of the methods in the group of students at other higher institution while studying human sciences in which there were no confessional and ethno-cultural aspects.

In 2014-2018, an example is the experience of tolerance education in the subject "Fundamentals of law" in the third year of "Economy" specialization. There was selected a mixed ethno-confessional group, where Muslims number reached up to $50 \%$, while the group in general consisted of 30 people. The methodology was used during the study of the content of the subject. The study of law took place in the comparative aspect of law doctrines in the various confessional systems (For example, Sharia and the Russian system of law). The methodology proved to be insufficiently effective. There was no quality improvement of knowledge of law, let alone confessional and ethno-cultural preparedness. The private space of Muslim students (aged from 20 years) was dominated by the grouping effect that increased their ethno-cultural domination greatly and information had been rejected. They were sure that "they know more about Islam and Sharia than the Russian professor", although experimental work in the group was carried out by the same specialist. Also there was a significant rejection of knowledge and negativism in the confessional and ethno-cultural sphere of interaction of students under incidental study of bases ethnic and confessional issues.

\section{Conclusion}

Results can be achieved under certain pedagogical conditions and particularly using the effect of immersion of students in the content of a special "Religions of the region under study" course. Besides, it is necessary:

1. The number of Muslim students in the group should be significantly less than $50 \%$ of its composition (preferably up to $25-30 \%$ ). When there are more there works out the social and psychological setting of dominance in conditions of which there is a certain non-individuation of the consciousness of the majority of students. The material under discussion is reinforced by the collective archetypal value of the confessional image. This effect produces a strong group opposition to the logic of tolerant comparison of dogmatic, ritual and other confessional constructions. In addition to the effect of dominance, there are other social and psychological effects of the group in the practice of the educational process which realize cleanly in the numerical superiority of the Muslim students.

Table 5

Summarized results of formation measures of tolerant and multicultural consciousness of students in the experimental groups

\begin{tabular}{|c|c|c|c|c|c|c|}
\hline $\begin{array}{c}\text { Academic } \\
\text { year }\end{array}$ & \multicolumn{2}{|c|}{$\begin{array}{c}\text { The average grade of tolerance } \\
\text { of student before the experiment }\end{array}$} & $\begin{array}{c}\text { The average grade of tolerance } \\
\text { of student after the experiment }\end{array}$ & \multicolumn{2}{|c|}{ The concordance coefficient W } \\
\cline { 2 - 7 } & $\begin{array}{c}\text { The expert group } \\
\text { № 1 }\end{array}$ & $\begin{array}{c}\text { The expert } \\
\text { group } \\
\text { № 2 }\end{array}$ & $\begin{array}{c}\text { The expert group } \\
\text { № 1 }\end{array}$ & $\begin{array}{c}\text { The expert } \\
\text { group } \\
\text { № 2 }\end{array}$ & $\begin{array}{c}\text { The expert } \\
\text { group № 1 } \\
\text { before / after }\end{array}$ & $\begin{array}{c}\text { The expert } \\
\text { group № 2 } \\
\text { before / after }\end{array}$ \\
\hline $2009-2010$ & 7,1 & 7,3 & 8,7 & 7,9 & $0,54 / 0,61$ & $0,71 / 0,68$ \\
\hline $2010-2011$ & 6,8 & 7,4 & 9,2 & 9,1 & $0,66 / 0,65$ & $0,61 / 0,74$ \\
\hline $2011-2012$ & 7,4 & 8,9 & 9,0 & 9,4 & $0,88 / 0,72$ & $0,68 / 0,63$ \\
\hline $2012-2013$ & 7,5 & 7,1 & 9,7 & 9,3 & $0,70 / 0,78$ & $0,69 / 0,85$ \\
\hline
\end{tabular}

Table 6

Summarized results of indicators of a tolerant and multicultural consciousness of students in the control groups

\begin{tabular}{|c|c|c|c|c|c|c|}
\hline $\begin{array}{c}\text { Academic } \\
\text { year }\end{array}$ & $\begin{array}{c}\text { The average grade of toler- } \\
\text { ance of student at the begin- } \\
\text { ning of the academic year }\end{array}$ & $\begin{array}{c}\text { The average grade of toler- } \\
\text { ance of student at the end } \\
\text { of the academic year }\end{array}$ & \multicolumn{2}{|c|}{ The concordance coefficient W } \\
\cline { 2 - 7 } & $\begin{array}{c}\text { The expert group } \\
\text { № 1 }\end{array}$ & $\begin{array}{c}\text { The expert } \\
\text { group } \\
\text { № 2 }\end{array}$ & $\begin{array}{c}\text { The expert group } \\
\text { № 1 }\end{array}$ & $\begin{array}{c}\text { The expert } \\
\text { group } \\
\text { № 2 }\end{array}$ & $\begin{array}{c}\text { The expert group } \\
\text { № 1 before / } \\
\text { after }\end{array}$ & $\begin{array}{c}\text { The expert group } \\
\text { № 2 } \\
\text { before / after }\end{array}$ \\
\hline $2010-2011$ & 7,2 & 7,4 & 7,0 & 7,6 & $0,50 / 0,58$ & $0,73 / 0,61$ \\
\hline $2011-2012$ & 7,7 & 7,1 & 7,0 & 7,8 & $0,65 / 0,55$ & $0,68 / 0,61$ \\
\hline $2012-2013$ & 7,9 & 7,3 & 7,8 & 7,1 & $0,73 / 0,74$ & $0,59 / 080$ \\
\hline
\end{tabular}


The effect of "infection" defines the dominant influence on the minds of group of most orthodox confessional and associated with them behavioral positions of individual students, whose views and actions are beginning to uncritically be supported by all members of the group. In addition, the group effect of social settings of being "oneness and chosenness" is very noticeable and it can be changed by the professor, harmonizing ethnic and confessional relations between students in their social, professional and everyday reality.

An extremely important effect of group dynamics should not go unnoticed. It is important in the effective confessional harmonization of students and is achieved by means of specialized training - confessional conformity. The greater the numerical superiority of the representatives of Islam in the same study group, the greater the effect of conformal reactions would be observed in it. Therefore, the vast number of students of the confessional orientation will support manifestation of extreme types of their confessions dogmas. Overcoming social and psychological effect by pedagogical influence is extremely difficult. It is especially difficult to correct Islamic confessional dogmatism.

Methodically correct, psychologically adjusted formation of academic study group is a fundamental principle of productive and, ultimately, an effective measure of the success of the confessional education and the harmonization of social relations of undergraduates.

2. Data of a questionnaire survey of students, which are held at the beginning and at the end of the course, indicate a significant shift of indicators confessional tolerance in the direction of increasing its capacity. Students begin to perceive the problems of ethnic and confessional disputes and situations, leading to conflicts, more tolerant, and subjectively less critical.

3. The most susceptible age of students for the formation of confessional tolerance in our experiment proved to be the age of 17-19 years. Therefore, subjects of ethno-confessional cycle are advisable to plan for $1-2$ year of college or senior year of vocational or secondary school.

4. The number of members of the academic groups, studying the subject of ethno-confessional cycle is very important. A group of 8-15 people is seen the best possible (which in the social and psychological dimension corresponds to the characteristics of a small group)

5. The amount of curricular and extracurricular classes must conform to the configuration of ethnic and confessional harmonization, be sufficiently informative in terms of cognitive interest of students. Classes should cover quite a long period of time (annual cycle) be regular and obligatory. Teaching process should be carried out in an active form by using didactically activating and educational elements.

6 . There are requirements for professors of confessional subjects which are obligatory: they must be of high qualification and a certain authority. The teacher should not be a deeply religious man - this fact would not allow him to not give preference to any religion. That is why it should not be allowed to invite a clergyman of any confessional orientation for teaching subjects of confessional cycle.

7. Inclusion in the curriculum of subjects of confessional cycle in the extent and form that was present in the experiment seems to be cost-consuming. However, the necessity for such practices in higher education is dictated by the necessity for building reliable confessional peace, prosperity and harmonization, so the cost of such work has a reasonable basis.

The experiment on the formation of religious tolerance among students through the teaching work in the study of a specialized course has been effective. In 2014-2018, as a result of its realization there were identified positive developments in the process of formation of confessional tolerance among students. Further observation of the students showed that they have weakened the barriers to entry into an interfaith marriage. They feel equally comfortable in a Mosque, Church and Synagogue, and sometimes visit its together friends of other nationalities and religions.

Positive developments appeared in substantive characteristics of personality of students. First of all, these changes have affected the sphere of social relations, expanding the limits of its legal relationships, by changing sequence of actions in situations of conflict related to the influence of ethno-confessional conflictogenics. These changes in the personality determined in the content of personal values, ideology and behavioral assessments. This experience of formation of confessional tolerance can be regarded as a positive. The results presented in this article are based on expert judgment of specialists. Further research in this sphere will enable to build statistically significant evaluation of their results and draw conclusions on the level of the quantitative data analysis.

This experience can be used in the process of developing of state programs of preventive resolution of ethnic and confessional contradictions. It can be used in the development of 
measures focused on preventing conflict and manifestations of extremism in combination with other measures of law, political and educational nature.

\section{References}

1. Bortnikova Yu.A., O.N. Naumenko, E.A. Naumenko. The state education as system of fight against Islamic extremism // The Bulletin of the Kemerovo State University. 2015. No 3-1. P. 9-10.

2. Vilkhovskaya N.I., Dergachev A.Yu. Level of tolerance of students of Novosibirsk higher education institutions: applied aspects of monitoring and a way of formation of bases of tolerance means of a foreign language // The Humanities and education in Siberia. 2014. No 4 (16). P. 38-44.

3. Zhukova T.A., Schrenk M. Multiculturalism and education: problems and prospects // Young scientist. 2016. No. 5-6 (109). P. 41-44.

4. Zenovich D.V. Education of tolerance and interethnic tolerance at teenagers - an important problem of modern education // Collections of conferences of Research Center Sotsiosfera. 2013. No 37. P. 25-27.
5. Kiselyova E.S., Karavanskaya L.N., Romanova M.L., Shaposhnikova T.L. The relationship between tolerance and personal and professional development of students// Scientific Notes of University of P.F. Lesgaft. 2013. № No 9 (103). P. 63-66.

6. Naumenko E.A. Multimedia course "Religions of the studied region" as a means of education of students " religious tolerance // Educational technologies and society. 2016. Vol. 19. No. 4. P. $277-297.2016$

7. Tyunnikov Yu.S. Interrelation of Evaluation and SelfEvaluation in the Diagnostic Procedures to Assess Teachers' Readiness for Innovation // European Journal of Contemporary Education. 2016. No 2 (16). P. 248-256.

8. Fedyunina S.M. Multiculturalism in the higher education: integration contexts // Scientific notes of the Russian state social university. 2017. No 3 (55). P. 20-23.

9. Shcherbanev D.Yu. Alternative model of development of religious education in Germany // News of the Southern Federal University. 2009. No 2. P. 9-64.

10. Yashin V.B. Tolerance in polyconfessional the region: a modern situation in the sphere of the public and religious relations in the Tyumen region (on materials of sociological monitoring) // Tolerance in modern society: experience of interdisciplinary researches. Yaroslavl, 2011: Pub.YaGPU. P. 205-207. 


\title{
WETTABILITY OF SOLID NICKEL BY MELTED CHLORIDES OF ALKALINE AND ALKALINEARTH METALS AND THEIR INTERFACIAL CHARACTERISTICS
}

\author{
Dokhov M.P.
}

Federal State Budget Educational Institution of Higher Education Kabardino-Balkarian state agrarian university named after V.M. Kokov, Nalchik, e-mail: vdokhova@yandex.ru

\begin{abstract}
The purpose of this paper is to calculate interfacial energy between salt melting and solid nickel. The interfacial energy of nickel in contact with various salt melting were evaluated at the various temperatures. We previously developed the thermodynamic theory which allows to calculate the interfacial energy at the boundary between proper melting with the solid body. Based on this theory we determined the interfacial characteristics of many organic and inorganic compounds and several metals. But this theory gives good results only with low-energy surfaces, since there is problem of accounting for the temperature factor. It is necessary to bring the surface energy of a solid body in accordance with the temperature at which the measured contact angle. This theory allows of determine the magnitude of the surface energy of a solid body at the melting temperature. Data of surface liquid energy and contact angles are taken from the literature. In the conclusion, it should be noted that our method of calculation can be also adaptable to the investigation of other solid-melt systems.
\end{abstract}

Keywords: wettability, contact angle, nickel, interfacial energy

The interphase energy between a solid and melts has a significant effect on the transport of matter across the electrode-electrolyte phases boundary. In metallurgy, the dependence of wetting on the droplet size obtained by the electrolysis of melts of liquid metals, the destruction of the lining of electrolysis baths, the appearance of an anode effect, etc. is known.

However, despite the significant role played by the interfacial energy at the solid-liquid interface (melt) in various fields of science and technology, so far there is no direct method for measuring this quantity. Therefore, unfortunately, we have to resort to semi-empirical methods for its determination. Moreover, it is seldom in the literature that in the same work a complex measurement of all the necessary quantities is carried out simultaneously to find the interfacial energy at the solid-melt (liquid) boundary of another substance.

To write this article, we were able to find in the literature the necessary quantities for calculating the interfacial energy of solid nickel at the boundary with the chlorides of alkali and alkaline-earth metal chlorides in various environments [7].

\section{Method of calculations}

In the present paper we used thermodynamical formulas obtained by us earlier to determine the temperature coefficient of the nickel surface energy $\Delta \sigma_{\mathrm{SV}} / \Delta \mathrm{T}[4]$ :

$$
\begin{gathered}
\left.\sigma_{\mathrm{SL}}=\sigma_{\mathrm{LV}}\left(2-3 \cos \theta+\cos ^{3} \theta\right) / 4\right)^{1 / 3} ; \\
\sigma_{\mathrm{SV}}=\sigma_{\mathrm{LV}}\left[\left(\left(2-3 \cos \theta+\cos ^{3} \theta\right) / 4\right)^{1 / 3}+\cos \theta\right] .
\end{gathered}
$$

In the formulas (1) and (2) $\Delta \sigma_{\mathrm{SL}}$ - the interphase energy of the solid-body boundary - is the intrinsic melt, $\sigma_{\mathrm{LV}}$ is surface energy of the vapor melt, $\sigma_{\mathrm{SV}}$ is surface energy of the solid, is the proper vapor, and $\theta$ is the contact angle formed by the proper melt on the surface of the solid.

From the known values of $\sigma_{\mathrm{LV}}$ and $\theta$, formulas (1) and (2) make it possible to determine $\sigma_{\mathrm{Sv}}$ at the melting temperature of the metal.

First, from the literature we find one experimental value of $\sigma_{\mathrm{SV}}$ of nickel, measured at a temperature different from the melting point, then we calculate the $\sigma_{\mathrm{SV}}$ of nickel by the formula (2). The difference between the surface energy calculated and measured by the values of $\Delta \sigma_{\mathrm{sv}}$, related to the temperature difference at which the surface energy of nickel is determined, made it possible to determine $\Delta \sigma_{\mathrm{sV}} / \Delta \mathrm{T}$.

Due to the fact that the nickel wetting angles with alkali and alkaline-earth metals were measured at temperatures much lower than the melting point of nickel, the surface energy of solid nickel was recalculated by us for the temperature at which $\theta_{1}$ was measured.

As it is mentioned above, in the work [4] we developed a thermodynamic theory and obtained formulas that enabled us to calculate the surface energy of a solid body with its vapor $\sigma_{\mathrm{SV}}$ and the interfacial energy of a solid - its own melt $\sigma_{\mathrm{SL}}$. From the known values of the surface energy of the melt, $\sigma_{\mathrm{LV}}$, and the wetting angle $\theta$ at the equilibrium temperature of a onecomponent three-phase system.

In [2], a table of relative values of $\sigma_{\mathrm{SV}} / \sigma_{\mathrm{LV}}$ and $\sigma_{\mathrm{SL}} / \sigma_{\mathrm{LV}}$ for all possible changes in the angle $\theta$ from $0^{\circ}$ to $180^{\circ}$ was compiled.

Direct measurement of the edge angles of solid metals by intrinsic melts with high melting points is a difficult task. With this 
circumstance, apparently, the absence in the literature of the experimental data $\theta 1$ is connected. Earlier, we calculated the edge angles of solid metals with our own melts, including for nickel, which turned out to be equal to $\theta_{1}=21^{\circ}$ [3]. It was found that the calculated values of $\sigma_{\mathrm{SL}}$ for single-component systems correspond to the criteria for wetting low-energy surfaces by low-temperature liquids under equilibrium conditions. As is well known, the interphase energy in equilibrium systems depends on the difference and structure of the contacting phases and decreases when their properties approach. For example, for two phases of different polarity, the interphase energy will be the lower the lower the polarity difference of these phases (P.A. Rebinder's polarity rule).

Eremenko V.N. expressed the principle according to which similar wetting is similar, the meaning of which, in the opinion of some researchers, is that the interphase energy between such substances is low (V.N. Eremenko's principle of similarity).

Indeed, studies, including ours, show that for the one-component systems and for dissimilar low-energy surfaces, when they are wetted with low-temperature liquids, the "like-so-solike" principle is valid.

For the contact of high-energy surfaces with low-temperature liquids, good wetting does not guarantee a strong decrease in the interfacial energy. At the same time, in systems where simple contact is the only source of interfacial energy reduction, the establishment of a connection between a solid and a wetting liquid can be disturbed by the presence of contamination films that interfere with perfect contact. Such a metal-film-melt system remains stable, since there is no tendency to transition and to the exchange of atoms between phases, since their chemical potentials are equal.

A different situation is observed in interacting nonequilibrium systems. For such systems, in addition to a purely contact process, the interfacial energy can decrease as a result of the interfacial interaction-the diffusion of one of the components of the wetting liquid from the surface layer into the volume, the dissolution of the metal in the liquid, etc., i.e. from the flow of irreversible processes of chemical interaction at the interphase boundary [5].

The authors, whose values of the boundary angles are used by us, for their calculations note that the measured wetting angles on nickel in the chlorine atmosphere may not correspond to the thermodynamic equilibrium state of their surface, since during the experiment a continuous process of their oxidation with chlorine occurred to form chlorides that did not accumulate on the their surfaces, but dissolved in salt melts, diffusing from the surface layer to the volume. In calculations such angles were used by us, considering them as contact angles, as is customary in terminology.

As the surface energy of molten nickel at the crystallization temperature, when calculating the interfacial energy and the surface energy of solid nickel at the melting temperature $\sigma_{\mathrm{SV}}$, we used the averaged value $\sigma_{\mathrm{LV}}=1770 \mathrm{~mJ} /$ $\mathrm{m}^{2}$ taken from [6]. Substituting the last value of $\sigma_{\mathrm{LV}}$ together with the boundary angle given above, using the indicated table, we calculate $\sigma_{\mathrm{SL}}$ and $\sigma_{\mathrm{SV}}$ of nickel at the melting point.

$$
\sigma_{\mathrm{SL}}(\mathrm{Ni})=261 \mathrm{~mJ} / \mathrm{m}^{2}, \sigma_{\mathrm{SV}}=1914 \mathrm{~mJ} / \mathrm{m}^{2} \text {. }
$$

The value of $\sigma_{\mathrm{SL}}$ of nickel obtained by us is in agreement with the experimental data given in the review paper [8], found by the method of supercooling small drops.

The calculated $\sigma_{\mathrm{SV}}$ of nickel also agrees with the experimental value of $\sigma_{\mathrm{SV}}$ measured by the zero-creep compensation method [1]. The value of the surface energy of solid nickel $\sigma_{\mathrm{SV}}(\mathrm{Ni})=1940 \mathrm{~mJ} / \mathrm{m}^{2}$ obtained by the authors at a temperature $\mathrm{T}=1670 \mathrm{~K}$, which is below the melting point by $58 \mathrm{~K}$.

From the two found values of $\sigma_{\mathrm{SV}}$ of nickel, we calculate the temperature coefficient of the surface energy of solid nickel

$$
\begin{gathered}
\Delta \sigma_{\mathrm{SV}} / \Delta \mathrm{T}=(1914-1940) /(1728-1670)= \\
=-26 / 58=-0.4483 \mathrm{~mJ} / \mathrm{m}^{2} .
\end{gathered}
$$

In the literature, instead of $\Delta \sigma / \Delta \mathrm{T}, \mathrm{d} \sigma / \mathrm{dT}$ is usually written, which, in our opinion, is not correct.

The values of the temperature coefficients are small, but finite. Their recording in a differential form a priori means that they are infinitesimal. Therefore, the differentiation of the surface energy with respect to temperature must be done by replacing the dots of the differential d, the $\Delta$ (delta) and the final result in terms of $\Delta$.

In a one-component condensed system, as a rule, the temperature coefficient should be negative, i.e. increasing the temperature reduces the surface energy.

In double and multicomponent liquids and solids positive, negative and even zero temperature coefficients (so-called temperature buffering) are possible.

Table shows the angles of wetting of solid nickel by molten salts and their interfacial characteristics at different temperatures. 
From Table it follows that as the temperature increases, $\sigma_{\mathrm{LV}}$ and $\mathrm{W}_{\mathrm{A}}$ of all compositions of salt melts decrease linearly. The $\sigma_{\mathrm{SV}}$ and $\sigma_{\mathrm{SL}}$ are also decreased in a given temperature range. Salt melts well wet the nickel, but a sharp decrease in the interfacial energy is not observed.

In the absence of a similarity between the wettable solid and the wetting liquid, good wetting is possible only under the condition $\sigma_{\mathrm{SV}}>\sigma_{\mathrm{LV}}$. In this case, $\theta<\pi / 2$, and in the case $\sigma_{\mathrm{SV}}<\sigma_{\mathrm{LV}}, \theta>\pi / 2$.

In calculating the phase-to-phase characteristics, we used the surface energy values of the molten chlorides of alkali and alkaline-earth metals, measured by the maximum pressure method in a gas bubble (argon or chlorine) [7]. The authors presented the results of the temperature dependence of $\sigma_{\mathrm{LV}}$ as an empirical equation with the help of which we gave the values of $\sigma_{\mathrm{IV}}$ to the temperatures at which the angles of salt melts on solid nickel were measured. The edge angles presented in Table are rounded to the whole. The calculated values of interphase characteristics are also rounded up to integers of measure unit.
Calculations of the adhesion of salt melts to nickel were carried out by two formulas

$$
\begin{aligned}
& \mathrm{WA}=\sigma_{\mathrm{LV}}+\sigma_{\mathrm{SV}}-\sigma_{\mathrm{SL}}, \\
& \mathrm{WA}=\sigma_{\mathrm{LV}} \times(1+\cos \theta),
\end{aligned}
$$

for self-testing and to avoid possible errors

It should be noted that the ratio (4), called the Dupre equation,expresses the fact that the change in the free energy of the system during its transition from one state to another as a result of the reversible isothermal process is equal to the difference in the free energy of the system in these two states. It directly follows that the increase in the binding energy of a liquid and a solid causes a decrease in the interfacial energy between the solid and the liguid. In particularly, the latter position is confirmed by our calculations.

On the same basis described above, the energy release during the reaction between the solid and the liquid can be equated with the work of adhesion. This position was also taken into account in the calculations of interfacial energy in systems in which the contact angles were measured under the atmosphere of chlorine.

The angle of wetting of solid nickel by molten salts and their interphase energies

\begin{tabular}{|c|c|c|c|c|c|c|c|}
\hline $\begin{array}{c}\text { Molten } \\
\text { salt }\end{array}$ & $\begin{array}{c}\text { Environ- } \\
\text { ment }\end{array}$ & $\mathrm{T}, \mathrm{K}$ & $\begin{array}{c}\sigma_{\mathrm{ll}} \\
\mathrm{mJ} / \mathrm{m}^{2}\end{array}$ & $\theta,^{\circ}$ & $\begin{array}{c}\sigma_{\mathrm{ss}} \\
\mathrm{mJ} / \mathrm{m}^{2}\end{array}$ & $\begin{array}{c}\sigma_{\mathrm{s}}, \\
\mathrm{mJ} / \mathrm{m}^{2}\end{array}$ & $\begin{array}{c}\mathrm{W}_{\mathrm{A}}, \\
\mathrm{mJ} / \mathrm{m}^{2}\end{array}$ \\
\hline \multirow[t]{6}{*}{$\mathrm{LiCl}$} & \multirow[t]{4}{*}{$\mathrm{Ar}$} & 932 & 138 & 12 & 2271 & 2136 & 273 \\
\hline & & 953 & 136 & 11 & 2261 & 2128 & 269 \\
\hline & & 983 & 134 & 10 & 2248 & 2116 & 266 \\
\hline & & 1022 & 130 & 10 & 2230 & 2102 & 258 \\
\hline & \multirow[t]{2}{*}{$\mathrm{Cl}_{2}$} & 929 & 135 & 10 & 2272 & 2139 & 268 \\
\hline & & 968 & 131 & 9 & 2255 & 2126 & 260 \\
\hline \multirow{10}{*}{$\begin{array}{c}\text { LiCl-KCl } \\
(0,58-0,42)\end{array}$} & \multirow[t]{6}{*}{$\mathrm{Ar}$} & 704 & 139 & 10 & 2373 & 2236 & 276 \\
\hline & & 752 & 135 & 9 & 2352 & 2219 & 268 \\
\hline & & 805 & 130 & 9 & 2328 & 2200 & 258 \\
\hline & & 849 & 127 & 8 & 2308 & 2182 & 253 \\
\hline & & 926 & 120 & 7 & 2274 & 2155 & 239 \\
\hline & & 1031 & 112 & 7 & 2226 & 2115 & 223 \\
\hline & \multirow{4}{*}{$\mathrm{Cl}_{2}$} & 703 & 136 & 10 & 2374 & 2240 & 270 \\
\hline & & 773 & 130 & 9 & 2342 & 2214 & 258 \\
\hline & & 863 & 122 & 8 & 2302 & 2181 & 243 \\
\hline & & 1013 & 109 & 7 & 2234 & 2126 & 217 \\
\hline \multirow{8}{*}{$\begin{array}{c}\text { LiCl-KCl } \\
(0,62-0,38)\end{array}$} & \multirow[t]{5}{*}{$\mathrm{Ar}$} & 798 & 162 & 13 & 2331 & 2173 & 320 \\
\hline & & 861 & 157 & 14 & 2303 & 2151 & 309 \\
\hline & & 921 & 153 & 12 & 2276 & 2126 & 303 \\
\hline & & 972 & 149 & 13 & 2253 & 2108 & 294 \\
\hline & & 1036 & 145 & - & 2224 & - & - \\
\hline & \multirow{3}{*}{$\mathrm{Cl}_{2}$} & 800 & 159 & 13 & 2330 & 2175 & 314 \\
\hline & & 853 & 156 & 12 & 2306 & 2153 & 309 \\
\hline & & 1041 & 142 & 11 & 2222 & 2083 & 281 \\
\hline
\end{tabular}
at different temperatures 
As an example, we will perform a procedure for calculating the surface energy of solid nickel at a temperature at which the contact angle formed by the molten salt of $\mathrm{LiCl}$ on the surface of solid nickel is measured.

According to the data of the authors of [7], this angle at $932 \mathrm{~K}$ is equal to $\theta=12^{\circ}$. Using formula (1) and the value of $\sigma_{\mathrm{sV}}$ of nickel at the melting temperature found above, we obtain

$$
\begin{gathered}
\sigma_{\mathrm{SV}}=1914+0,4483(1728-932)= \\
=2271 \mathrm{~mJ} / \mathrm{m}^{2}
\end{gathered}
$$

(recall that with decreasing temperature, $\sigma_{\mathrm{sV}}$ increases). Similarly, at a temperature of 932 $\mathrm{K}$, it is necessary to bring the surface energy of the $\mathrm{LiCl}$ melt. For this purpose, we use the empirical equation obtained by the authors of [7].

$$
\sigma_{\mathrm{LV}}=\sigma_{0}-\beta \mathrm{T},
$$

where $\sigma_{0}=215 \mathrm{~mJ} / \mathrm{m}^{2}, \beta=0,0829 \mathrm{~mJ} /\left(\mathrm{m}^{2} \times \mathrm{K}\right)$ in $\operatorname{argon}$ and $\sigma_{0}=212 \mathrm{~mJ} / \mathrm{m}^{2}, \beta=0,0836 \mathrm{~mJ} /$ $\left(\mathrm{m}^{2} \times \mathrm{K}\right)$ in the atmosphere of chlorine.

Substituting these values in (7), respectively, we obtain:

$$
\sigma_{\mathrm{LV}}=138 ; 135 \mathrm{~mJ} / \mathrm{m}^{2} \text {. }
$$

Now we find the interfacial energy at the interface of the $\mathrm{LiCl}$ - nickel melt.

$$
\begin{gathered}
\sigma_{\mathrm{SL}}=\sigma_{\mathrm{SV}}-\sigma_{\mathrm{LV}} \times \cos \theta=2271-138 \times \\
\quad \times 0.9781=2136 \mathrm{~mJ} / \mathrm{m}^{2} \text { in argon. }
\end{gathered}
$$

Similarly, we find $\sigma_{\mathrm{SL}}$ in a chlorine atmosphere

$$
\begin{aligned}
\sigma_{\mathrm{SL}}= & \sigma_{\mathrm{SV}}-\sigma_{\mathrm{LV}} \times \cos \theta=2272-135 \times \\
& \times 0,9848=2139 \mathrm{~mJ} / \mathrm{m}^{2} .
\end{aligned}
$$

Calculations for other salt systems are carried out according to the same scheme.

In conclusion, we note that the calculation method presented here is applicable to the evaluation of interphase characteristics and other solid-liquid systems.

\section{Conclusions}

1 . The interphase energy $\sigma_{\mathrm{SL}}$ and the surface energy of solid nickel $\sigma_{\mathrm{SV}}$ at the melting point are determined.

2 . The surface energy of solid nickel is reduced to the temperatures at which the edge angles of salt melts on nickel are measured.

3 . Interfacial energies and work of adhesion of molten chlorides of alkali and alkalineearth metals to nickel were calculated.

4. It is shown that, in the absence of similarity between the wettable solid and the wetting liquid, a low value of the contact angle is not a prerequisite for a sharp decrease in the interfacial energy at the solid-melt interface of another substance.

\section{References}

1. Digilov R.M. Measurement of the surface tension of refractory metals in the solid state / R.M. Digilov, S.N. Zadumkin, V.K. Kumykov, Kh.B. Khokonov // Physics of Metals and Metallography. - 1976. - T.41. - №5. - P. 979-982.

2. Dokhov M.P. Changes in the interfacial energy of the solid body-melt and solid body-pairs, depending on the edge angle. Ed. Journal of Izv. Vuzov. Physics. - Tomsk: VINITI, 1985. $-12 \mathrm{p}$.

3. Dokhov M.P. On the relative values of the surface energies of metals at the triple point. // Metals. - 1994. - No. 2 P. 16-21.

4. Dokhov M.P. Calculation of the interphase energy of some organic compounds at the interface of a single crystalmelt // ZHF. - 1981. - 55. - No. 5. - P.1324-1327.

5. Naidich Yu.V. Contact phenomena in metallic melts. Kiev: Naukova Dumka, 1972. - 196 p.

6. Nizhenko V.N. Surface tension of liquid metals and alloys (one- and two-component systems)/ V. N. Nizhenko, L.I. Floka. Directory. - M.: Metallurgy, 1981. - 208 p.

7. Smirnov M.V. Wetability of solid materials by molten chlorides of alkali and alkaline earth metals in an atmosphere of argon and chlorine. / M.V. Smirnov, V.P. Stepanov, A.I. Rodionov, A.A. Aleksandrov, A.Ya. Korkin. Research methods and properties of interfaces of contacting phases. - Kiev: Naukova Dumka, 1977. - P.121-124.

8. Chadwik G.A. Solid-liquid interfacial energy // Interfaces conference, Melburne. The Australian institute of metals. Butterworths, 1969. - P.101-113. 


\title{
COMPARATIVE ANALYSIS OF DEVELOPING SYSTEM AND FINITE AUTOMAT MODELS
}

\author{
Girlin S.K., Ferenchuk I.I. \\ V.I. Vernadsky Crimean Federal University in Yalta, e-mail: sk.girlin@gmail.com
}

\begin{abstract}
Many real objects of modeling can be considered as two-product, multi - or continuous - product developing systems. There are two branches of industry (as two-product developing system): one is called a subsystem A of developing system in which developing system creates new working places, and the second is called a subsystem $\mathrm{B}$ in which it creates or produces goods and services that are external with respect to this system. The distribution of working places in two-product developing system by some control function between the subsystems A and B is very important. The problem of this optimal distribution was formulated by academician V.M. Glushkov. Based on developing system resource sharing into internal and external (arriving at the system from the outside) ones, Girlin S.K. and Ivanov V.V. proposed and detailed the equations of systems', which in contrast to Glushkov's equations use functions of a wider class, additionally take into account the direct effect of external factors on the developing system, allow investigating problems without the part history of the system till the moment of the beginning of its modeling and allow a more efficient control of the system due to allocating not only internal but also external resources among subsystems. In this paper we dwell on the comparisons between Glushkov and Girlin mathematical models of developing system and the classical model of finite automat. It is shown that the concept of developing system originally introduced by academician Glushkov is not an open dynamic system. The proposed by Girlin S.K. concept of developing system is more general and allows us to define and solve new math problems.
\end{abstract}

Keywords: integral model, open developing system, finite automat, mathematics of development

There are two basic classes of developing systems (DS) (or evolutionary systems): 1) DS that are already have been created and have initial prehistory, 2) DS that are not have been created and have not initial prehistory. The second class is named originating DS [3]. Each of these classes divides, in turn, on three classes: Artificial DS (ADS) that are have been created by human beings and are functioning with their participation; Natural DS (NDS), in particular, the cell and cell associated objects [45]; and Joined DS (JDS): ADS and NDS as a whole [11]. Some examples of ADS are: industry, science, any educational center, including school, college, university, and education as a whole, art, health services, etc. The examples of NDS are the cell and cell associated objects, a separate plant, a separate organism, a population of animals, the biosphere, etc. We can consider the neosphere (in the sense by academician V.I. Vernadsky) as JDS that is the combination of two DS, one of which is human activity as ADS and another of which is the other part of our planet as NDS [11, p. 10]. The main elements of ADS are work places (WP). A work place is usually localized in the time and space aggregate of labor functions of the respective ware: material, energy, and information, which should be fulfilled by a respective specialist. The results of WP functioning in industry are various goods and services or products. The main characteristics or indices of the WP functioning are efficiency (the quantities of products produced per unit expenditure and per unit time). There are three important classes of WP: one that enters the DS from external environment or from other DS, the second reproduces or creates new more effective WP for the DS itself, and the third reproduces external goods with respect to DS. There are two branches of industry: one is called a subsystem A of DS in which DS creates new WP, and the second is called a subsystem B of DS in which DS creates or produces goods and services that are external with respect to DS. The distribution of WP by some control function $y$ between the subsystems A and B is very important. The problem of this optimal distribution was investigated by V.M. Glushkov and V.V. Ivanov [9]. The main result is for small-term period of the time the desired $y$ is minimally possible, but for large-term period of the time the desired $y$ may differ from the minimally possible on the larger initial part of the time segment.

Modeling macroeconomic system academician V.M. Glushkov used a set of nonlinear integral Volterra type equations containing unknown functions not only in sub-integral expressions but in the lower limits of integrals. Introduction of function to the lower limits of integrals had important economic sense: this function was interpreted as a time boundary for the elimination of obsolete technologies for manufacturing system's products. The proposed mathematical apparatus was applied later for modeling many other systems: ecological, biological, biophysical, medical, scientific enterprises, computing centers, populations, etc. Theoretical investigations and numerous applications have led to the creation of the theory of DS. Further development and generalization of DS Glushkov models [3, 5] (in particular, DS interaction with external environment, the 
latter being another DS) led to the creation by Glushkov V.M., Ivanov V.V. and S.K. Girlin of a new science that was named "Mathematics of Development" (on February 12, 2018, it was included in the "Register of new scientific directions", № 0008). Within the framework of this science Girlin S.K. opened three fundamental laws of development [7, P. 77-79] (based on analysis of a number of theorems proven by Glushkov, Ivanov and Girlin). These laws can be set forth as follows.

First law of optimal development ("law of altruism"). If the size of planning time is small enough, the sought optimum of functional is arrived at the maximally possible (by virtue of limitations of task) use in the subsystem $\mathrm{B}$ of internal and external resources for implementation of basic function of the system.

Second law of optimal development ("law of reasonable egoism"). If the size of planning time is great enough, the sought optimum of functional is arrived at the substantial stakes of internal and external resources, using the subsystem of self-perfection on the internal necessities of the system on greater initial part of cutting-off of planning time and maximally possible use in the subsystem $B$ of internal and external resources for implementation of basic function of the system at the end of it. This law was shown out of the theorems at general enough suppositions.

Third law of optimal development ("law of hierarchy of priorities"). If the size of planning time is great enough, the sought optimum of functional is arrived at the following priorities of allocation of internal and external resources between the subsystems of DS: first of all at the larger initial size of planning time the subsystem $A_{1}$ ("science") has priority ( $A_{1}$ is the subsystem, in which new technologies of system products creation functions of $\alpha$ and $\beta$ kinds), then at the long time size has priority the subsystem of self-development $A_{2}$ (the subsystem, in which new products of the first kind are produced, providing the fulfillment of the internal function of the system - its existence and development itself), and at the end of the planning time $\left[t_{0}, T\right]$ the subsystem $\mathrm{B}$ has priority, in which products of the second kind are produced, providing the fulfillment of the main system function to the system).

We'd like to notice that the law of "reasonable egoism" of the system can be considered as clarification of basic principle of communism: "to each - on necessities, from each - to abilities".

Let us conduct a comparative analysis of models of V.M. Glushkov [9], models [3, 5] and a finite automat. A typical mathematical diagram of a finite automat is often used in modeling real processes. Following [2], let's use the following definition of "a finite automat". A finite automat is defined at discrete moments of time $t_{0}, t_{1}, t_{2}, \ldots$. If the unit of time period is defined as $\Delta t=t_{i}-t_{i-1}$, then $t=0,1,2, \ldots$. A finite automat is characterized by finite sets of states $z$, input signals $x$ and output signals $y$. At every moment of the automat time (except $t_{0}$ ) an input signal $x(t)$ is received in automat, under the influence of which the automat moves to a new state, in accordance with the transition function $z(t)=\varphi(z(t-1), x(t))$ and produces an output signal which is defined by the output function $y(t)=\psi(z(t-1), x(t))$. If characteristics of $z_{i}, i=1,2, \ldots$, are numbers, then the state $z$ is regarded as the vector with coordinates $z_{1}, z_{2}, \ldots, z_{n}$. In general, when $z_{i}$ are not numbers (for example, they are vectors, matrices, or objects of more complex nature), the state $z$ is interpreted as "generalized" vector, and the features of $z_{i}$ are interpreted as its "coordinates". The same can be said about the signals. The input signal appears as $x=\left(x_{1}, x_{2}, \ldots, x_{m}\right)$, and the output signal as $y=\left(y_{1}, y_{2}, \ldots, y_{r}\right)$.

An object of modeling can be seen as an evolutionary or a developing system (DS) [5, 9] if it contains at least two subsystems: subsystem A of self-improvement in which part of products of the first kind (which support the internal function of the modeled object by material, energy and information, i.e., its existence and development) create a new, more efficient (i.e., more productive) products of the first kind, and subsystem B in which another part of products of the first kind perform the main (external) function of the modeled object, i.e., the creation of some of the products of the second kind (executing the external function of the modeled object materially, energy and information-wise in interaction between the modeled object and its external environment). For example, in economic system products of the first kind are working places and products of the second kind are the products of a system created for an external "customer" (these products are goods and services that are external with respect to DS). The internal resources of DS will take only products of the first kind, which are sources of themselves and products of the second kind. Let's call the external resources of DS the products of both the first and the second kind entering the DS from the external environment (however, some external resources become internal resources of the DS). 
Using the above notations, the equations of the simplest two-product DS can be written as follows:

$$
\begin{gathered}
z(t)=\int_{a(t)}^{t} \alpha(t, \tau) u(\tau) z(\tau) d \tau+v(t) x(t), \\
y(t)=\int_{a(t)}^{t} \beta(t, \tau)(1-u(\tau)) z(\tau) d \tau+(1-v(t)) x(t), \\
P(t)=\int_{a(t)}^{t} z(\tau) d \tau, \\
0 \leq v(\tau), u(\tau) \leq 1, \quad 0 \leq a(t) \leq \tau \leq t, a\left(t_{0}\right)=0,0 \leq t_{0} \leq t \leq T<+\infty .
\end{gathered}
$$

Here $z(t)$ and $y(t)$ are the rates of appearance in DS of the new products of respectively first and second kinds at the time $t ; x(t)-$ is the rate of entering of external resource in DS at the time instant $t(x, z$ and $y$ are assumed to be of one dimension); $v(t) x(t)$ and $(1-v(t)) x(t)-$ are the rates of entering in the subsystems $\mathrm{A}$ and $\mathrm{B}$ of the products of respectively first and second kinds at the time instant $t, 0 \leq v \leq 1$; $u(\tau) z(\tau)$ and $(1-u(\tau)) z(\tau)$ - are the shares of $z(\tau)$ used for the manufacturing of $z(t)$ (in subsystem A) and $y(t)$ (in subsystem B) respectively, $0 \leq u \leq 1 ; a(t)$ - is a time boundary for liquidation of obsolete technologies for manufacturing first and second kinds products, which means that the product created before the threshold $a(t), a(t) \leq t$, is never used at time $t$, but the product created after the threshold $a(t)$ is used entirely, $0 \leq a(t) \leq \tau \leq t ; \alpha(t, \tau)$ and are efficiency indexes of effectiveness of creation of the first (in the subsystem A) and the second (in the subsystem B) kind of new products at time $t$ respectively, i.e., the number of units of $z(t)$ and $y(t)$ created in the unit of time starting from time $t$ per one unit of $u(\tau) z(\tau)$ and $(1-u(\tau)) z(\tau)$ respectively, $0 \leq a(t) \leq \tau \leq t$; $t_{0}$ - is a starting point for modeling; for the segment $\left[0, t_{0}\right]$ we use prehistory of DS for which all the functions are given (their values will be noted by the same symbols but with the index " 0 ", e.g. $u(\tau) \equiv u_{0}(\tau)$ and $z(\tau) \equiv z_{0}(\tau)$, $\tau \in\left[0, t_{0}\right], \quad a\left(t_{0}\right)=0 ; t_{0}$ and $\mathrm{T}$ is respectively the starting and ending point for DS modeling.

This two-product model can be easily generalized for multi-product and continuous models. External similarity between the twoproduct and the continuum models allows us to easily generalize the two-product model results concerning the existence and the uniqueness of a solution for two-product model $[4,7]$ to the continual and thereby multiproduct models.
If we put in the above system of equations and inequalities $x(t) \equiv 0, \quad t \in\left[t_{0}, T\right]$, we obtain as a special case of the DS model, originally proposed by academician V.M. Glushkov [8]. In this model [8] he assumed some predetermined nonzero initial prehistory (or initial condition) during the initial time interval $\left[0, t_{0}\right]$. Let's assume the given functions are such that the system of equations is completely determined. In this case, we get the problem of determining the dynamics of DS, in other words we need to solve the corresponding system of Volterra integral equations of the second kind with delay (typically nonlinear). From the theory of Volterra integral equations of the second kind it is well known that if on $\left[t_{0}, T\right]$ a free member is $x(t)=0$, then the solution $z(t)$ on $\left[t_{0}, T\right]$ of such an integral equation is zero. However, if we assume the function $P(t)$ is positive and defined on the interval $\left[t_{0}, T\right]$, then, dividing the region $[a(t), t]$ of integration into sections $\left[a(t), t_{0}\right]$ and $\left[t_{0}, t\right], t \in\left[t_{0}, t_{1}\right]$, $t_{1}=\min \left\{t^{*}: t^{*} \in\left[t_{0}, T\right], a\left(t^{*}\right)=t_{0}\right\}$, it can take as a free member non-zero term in the first equation of the above system

$$
\int_{a(t)}^{t_{0}} \alpha(t, \tau) u_{0}(\tau) z_{0}(\tau) d \tau, t \in\left[t_{0}, t_{1}\right], a\left(t_{1}\right)=t_{0} .
$$

Clearly, the solution, which can be obtained, for example by means of the resolvent, will no longer be zero. Thus, in the case of setting positive function $P(t)$ it is implicitly assumed that the non-zero state $z(t)$ of the system is implicitly changed depending on some unknown input signal. If the initial prehistory is absent $\left(0=a\left(t_{0}\right)=t_{0}\right)$ or it is zero $\left(z_{0}(\tau)=0\right.$ or $\left.u_{0}(\tau)=0, \tau \in\left[a\left(t_{0}\right), t_{0}\right], 0=a\left(t_{0}\right)<t_{0}\right)$, then for the existence of a nonzero integral equation solution $z(t)$ we need a non-trivial function $v(t)$ $x(t)$, which is interpreted as input signal of the 
system. These considerations have led to the introduction of the concept of "originating developing system" [3].

Following [3], let's call the originating DS such a DS, for which the initial prehistory (or initial conditions) is absent (in this case $\left.0=a\left(t_{0}\right)=t_{0}, z\left(t_{0}\right)=z\left(t_{0}+0\right)=v\left(t_{0}\right) x\left(t_{0}\right)\right)$ or where initial conditions are equal zero: $z_{0}(\tau)=0$ or $u_{0}(\tau)=0, \quad \tau \in\left[a\left(t_{0}\right), t_{0}\right], \quad 0=a\left(t_{0}\right)<t_{0}$, $z\left(t_{0}\right)=z\left(t_{0}+0\right)=v\left(t_{0}\right) x\left(t_{0}\right)$.

Interestingly, if the function $a(t)$ is increasing strictly on $[0, T]$ (this case can be interpreted as a permanent removal of obsolete technologies as a result of scientific and technical progress), and continuous functions $P(t), x(t)$ are set on $[0, T]$ then the solution $z(t), t \in[0, T]$, depends on the resolvent of the first integral equation of the above system, functions $P(t), x(t)$, and does not depend on the initial condition $z(0)[4, \mathrm{p} .108-112]$. Note that the introduction of a non-zero free terms $v(t)$ $x(t)$ and $(1-v(t)) x(t)$ into the equations allowed us to study not only a new class of the originating developing systems, but also to look for solutions in a more general class of piecewise continuous functions $z(t)$ and $y(t)$ (in the Glushkov equations $z(t)$ and $y(t)$ are sought in the class of continuous functions).

In addition, introduction of a piecewise continuous function $v(t), 0 \leq v(t) \leq 1$, allowed to expand the ability to manage the DS dynamics: in particular, in solving problems of optimal control we can use not only the controlling piecewise continuous function $u(t)$, $0 \leq u(t) \leq 1$, which distributes internal resources between subsystems of the system to ensure the very existence and development of the system, but also the controlling piecewise continuous function $v(t), 0 \leq v(t) \leq 1$, which distributes external resources between the subsystems of the system to ensure the existence and development of the system and the execution of the main functions of the system.

\section{Conclusions}

A comparative analysis of models of developing systems and a finite automat is conducted. It is shown that a developing system originally introduced by Glushkov is not an open dynamical system (for example, for the case of missing or zero initial prehistory). To resolve this substantial deficiency Ivanov V.V. [10] attempted to introduce the input influence in the notations of the present work function $f(t)=z(t)+y(t)$ (which can be interpreted as the predetermined potential ability of the system to produce products of the first and second kind in the time unit). However, from our point of view it is much more convenient (especially for the purpose of managing the dynamics of DS) to introduce as inputs functions $x(t)$ and $v(t)$. In addition, the introduction of such functions allows to formulate and solve new mathematical problems that are highly important for practical use (e.g., a problem of cooperative interaction of developing systems [1], a problem of modeling optimal import substitution in economic system [9]).

The authors are grateful to Oleg Polischuk for language assistance and useful remarks.

\section{References}

1. Bugerko N.V., Girlin S.K. On one problem of cooperative interaction of two-product developing systems // Sovremennyi naukoemkie technologii. - 2013. - № 6. - P. 49-53 (in Russian).

2. Buslenko N.P. Modeling of complex systems. M.:Nauka, 1078. - 400 pp. (in Russian).

3. Girlin S.K. Modeling originating developing systems // DAN Ukr. SSR, Ser. A. - 1987. - № 10. - P. 65-67 (in Russian).

4. Girlin S.K. Lectures on integral equations. - Yalta: RIO KGU, 2012. - 168 pp. (in Russian).

5. Girlin S.K., Ivanov V.V. Modeling of developing systems interaction // DAN Ukr. SSR, Ser. A. - 1986. - № 1. - P. 58-60 (in Russian).

6. Girlin S.K. Mathematical Theory of Development. A Course of Lectures/ Girlin S.K., Ivanov V.V. - Simferopol: PP "ARIAL", 2014. - $140 \mathrm{p}$

7. Girlin S.K., Scherbina K.P. Modeling of optimal interaction of continuum developing systems // Uspechi sovremennogo estestvoznania - 2012. - № 4. - P. 32-37.

8. Girlin S.K., Scherbina K.P. Modeling of optimal interaction of continuum developing systems // Uspechi sovremennogo estestvoznania - 2012. - № 4. - P. 32-37.

9. Glushkov V.M., Ivanov V.V., Yanenko V.M. Developing Systems Modeling. - M.: Nauka, 1983, 352 p. (in Russian).

10. Ladyka L.A., Girlin S.K. Modeling of import substitution in a two-product economic system // Mat-ly IX Mejdunarodnoy elektronnoy studencheskoy nauchnoy konferencii "Studencheskiy nauchnyi forum - 2017" / http://www.scienceforum. ru/2017/2321/27645_(in Russian).

11. Ivanov V.V. Model development and optimization / V.V. Ivanov - Dordrecht / Boston / London: Kluwer Academic Publishers, 1999. -249 p. 


\title{
MULTIFUNCTIONAL MEMORY CIRCUITS OF MARAKHOVSKY
}

\author{
Marakhovsky L.F. \\ State University of Infrastructure and Technology,Kiev,e-mail: marachovsky@ukr.net
}

\begin{abstract}
The article gives the limitations of the element base with memory on the flip-flops, the devices of which are described in automatic discrete time and the formulation is made to develop the extension of the properties of the element base due to memory on multifunctional circuits described in automatic continuous time. In the article a new definition of a multifunctional elementary automaton is given, a method of microstructural synthesis of such automata of two classes is considered, formulas are presented for establishing and preserving functions in automatic continuous time, and formulas are given that determine the basic parameters of elementary memory circuits. At the end of the article, examples of functional schemes of two classes of multifunctional memory circuits are given. In conclusion, the advantages of multifunction schemes over triggers are given.
\end{abstract}

Keywords: triggers, multifunctional memory circuits, automatic continuous time

Throughout the world, the search for new circuit-based solutions of elementary memory circuits with qualitatively new properties continues [1-5]. Unfortunately, all the works on the tunable memory scheme under consideration were carried out due to tunable excitation functions and outputs based on the RS trigger, which have fundamental limitations [6]:

1 . They all work in the automaton discrete time $t_{i}(i=1,2 . \ldots, n, \ldots)$;

2 . The basic memory scheme ( $R S$-trigger) for known triggers does not allow you to rebuild the work of memorized states;

3. All these devices are described by the Mealy and Moore automata, which determine the sequential nature of the operation of the devices;

4. The transition in memory circuits occurs in one variable $x(t)$;

5 . The principle of program management proposed by Charles Bebbage does not allow the simultaneous processing of general and local information and determines the division of information into only two parts.

In connection with these fundamental limitations of the class of monofunctional memory circuits (triggers), multifunctional memory schemes are proposed based on new principles and methods of structural organization.

The principle of the structured organization of multifunctional memory circuits (MFIS) is that $n$ logical elements OR-NOT (AND-NOT) are used, which are divided into $m(m<n)$ groups. The outputs of the elements of one group are not associated with the inputs of their group of logical elements. They are connected to the inputs of the elements of other groups of the memory scheme according to one of the defined laws (for example, with the inputs of all other logical elements or the inputs of only elements of two, three, etc. of $\mathrm{m}$ groups of elements). One of the free inputs of each $i$-th element is connected to the inputs of the setting input bus, and the second of the free inputs of each $i$-th element is connected to the inputs of the memory bus that stores the input bus. The introduction of an additional saving input bus in the memory scheme and the creation of groups of logical elements in a group of more than one was a fundamentally new phenomenon in the development of multifunctional memory circuits.

The principle of memorizing states in an MFIS is that the input signals that establish $x_{i}(t)$ that arrive at the nodes of the setting input bus uniquely determine the output active values of at least one logical element of the $i$-th group.

The output active values of the installed element through their output structural bonds keep the output values of other elements of the memory circuit inverted, which in turn through the inverse structural connections confirm the established output values of the logic elements when one of the conserved sets of input signals supplied by the conserving input bus. These set values of the state of the memory circuit $a(\Delta)$ are stored due to the state preservation functions $\delta_{e}$ until the next input $x_{i}(t)$ input signal arrives [7].

The use of state conservation functions $\delta \mathrm{e}$ in monofunctional Miley and Moore automata (also in memory circuits (triggers)) was not considered, because all triggers kept their states only with one passive input signal $e(\Delta)$, which was called an "empty word of zero length" although this function physically existed. In automatic discrete time, there was no length (interval $\Delta$ ) for it, and under its influence no single transition from one state to another was realized. But this input signal $e(\Delta)$ has always been taken into account by the developers of memory circuits.

Definition 1. The MFIS will be called a single-level multifunctional elementary automaton (MEA) with a complete transition system and a complete output system for each of the $r_{e}$ $\left(r_{e}>1\right)$ state conservation functions $\delta_{e}$. 
MEAs can be functionally represented as re single-level elementary automata, each of which remembers all its states only with one of the various corresponding sets of input signals that preserve $e_{j}(\Delta)\left(j=\overline{1, r_{e}}\right)$ [7].

Method of microstructural synthesis of elementary multifunctional memory circuits

Consider a method of microstructural synthesis, which allows us to construct an asynchronous MFIS class $L$ from the logical elements of a functionally complete system.

We use the combination scheme OR-NOT, which realizes this function:

$$
y=\overline{f(a) \vee f(x) \vee f(e)},
$$

where $f(a)$ - is a function of an arbitrary input signal coming from the output of an element of another group for storing the state in the MFIS; $f(x)$ - is a function of an arbitrary set of input signal $x_{i}(t)$

$f(e)$ - is a function of an arbitrary saving $e_{j}(\Delta)$ set of the input signal.

The combination scheme (1) is called a basic automaton with one state or simpler than a basic automaton (BA). The simplest BA are logical elements of the AND-OR-NOT, ORNOT or NAND type.

The method of microstructural synthesis of asynchronous MFIS of class $L$ consists of the following algorithm. We take $n$ BA and divide them into $m(m<n)$ groups. The $\mathrm{BA}$ in each $i$-th group $(i=1,2, \ldots, m)$ has no feedback, because their output nodes do not join the input nodes of the BA of this $i$-th group. The outputs of the BA of the i-th group are respectively connected directly or through the OR (AND) separation scheme or directly to the inputs $f(a)$ of all BAs of the other groups.

One of the free inputs $z_{\text {i }}$ of each $i$-th BA is connected to the inputs of the setting input bus ШX, and the second of the free inputs $u_{i}$ of each $i$-th $\mathrm{BA}$ is connected to the inputs storing the input bus WE of the memory circuit. Input nodes $z_{i}$ can receive input $x_{i}(t)$ input signals, and input $e_{i}(\Delta)$ inputs can be input sequentially one by one for one clock cycle $T_{i}\left(T_{i}=t_{i}+\Delta_{i}\right)$. Stable output signals at the output nodes yj of the BA correspond to the shifted states $a_{i}(T)$ of the MFIS, where $a_{i}(T)=a_{i}(\mathrm{t})+a_{i}(\Delta)$. The shift of the output signal $y_{i}(T)$ is equal to the delay of two logic elements, which is necessary to establish a stable output state in the memory circuit.

The $x(t)$ input signals of the MFIS unambiguously establish a certain state aj(t) of the memory circuit. The excitation function $\delta$ in an elementary automaton can be described in vector form:

$$
a_{i}(t)=\delta_{x}[x(t)] .
$$

The value of the binary set at the input nodes $z$ of the multifunctional memory scheme, under the action of the input signal setting $x(t)$, is characterized by the fact that only at the input nodes of the logical elements $\left(\mathrm{BA}_{j}\right)$ of one $i$-th group, the input signal can have a value equal to the passive signal 0 (1) On at least one logical element (BA) of this $i$-th group. At the input nodes of logic elements (BA) of other groups, the values of the input signal must be equal to the active signal $1(0)$. The MFIS stored signal $e_{j}(\Delta)$ can memorize one of the states $a_{j}(\Delta)$ defined by the state block $\pi$, predetermined by the setting input signal $x_{i}(\mathrm{t})$. The function $\delta_{e}$ of conservation of a state in an elementary automaton can be described in vector form:

$$
a(T)=\delta_{e}[a(T), e(\Delta)], a(t)=a(\Delta) .
$$

The value of the binary set at the input nodes uj of the MFIS under the action of the saving $e(\Delta)$ input signal is characterized by the fact that at least two MFIS groups at the input nodes of the BA have input signals whose value is equal to the passive signal $0(1)$. The number $K$ of storage states for a given $e(\Delta)$ input signal is equal to the number of groups in the MFIS, at the inputs of which the value of the input signal at node $u_{j}$ is equal to the passive signal 0 (1). Thus, the value of the number $K$ can vary depending on the input signals $e(\Delta)$ saving from 2 to $m$. The state $a_{i}$ of the MFIS is identified with the state of the values of the output signals $y_{j} \mathrm{BA}_{j}$ of only one group if at least one of the output signals $y_{j}$ of this group is equal to the active signal $1(0)$. The unit value of the output signal $y_{j}$ in this group is called the MFIS, because this output signal $y_{j}$ acts on the $\mathrm{BA}_{j}$ of other groups, setting on them output signals $y_{j}$ equal to the logical zero. The characteristic number $K_{\text {o }}$ of the storage states of the $i$-th group is calculated by the formula:

$$
K_{i}=2^{R}-1,
$$

where $R$ is the BA number in the $i$-th group of the MFIS.

The number $K_{i}$ of the storage states of the $i$-th group of the MFIS is a block of $\mu_{i}$ states. The transition from the state $a$ to the state $a_{s}$ in the block of $\mu_{i}$ states is possible with a change in the $e(\Delta)$ input signal. Such a transition is called enlarged. The function $\delta$, of the coarse transition can be represented in vector form:

$$
\begin{gathered}
a(\Delta)=\delta_{y}[a(t), e(\Delta)] ; \\
a(t) \neq a(\Delta) ; a(t), a(\Delta) \in \mu_{i} .
\end{gathered}
$$


Setting the block $n$ states of monofunctional memory circuits

Table 1

\begin{tabular}{|l|l|l|l|l|}
\hline $\boldsymbol{e}^{-}$ & $\boldsymbol{x}_{l}$ & $\boldsymbol{x}_{2}$ & $\cdots$ & $\boldsymbol{x}_{K}$ \\
\hline $\boldsymbol{e}_{0}$ & $A_{l}$ & $A_{2}$ & $\cdots$ & $A_{K}$ \\
\hline
\end{tabular}

Table 2

Specifying the state matrix of multifunctional memory circuits

\begin{tabular}{|c|c|c|c|c|}
\hline $\begin{array}{l}\theta_{j} \\
x_{i}\end{array}$ & $x_{I}$ & $x_{2}$ & $\ldots$ & $x_{K}$ \\
\hline$e_{I}$ & $A_{l I}$ & $A_{2 I}$ & $\ldots$ & $A_{K I}$ \\
\hline$e_{2}$ & $A_{12}$ & $A_{22}$ & $\cdots$ & $A_{k 2}$ \\
\hline$\cdots$ & $\cdots$ & $\cdots$ & $\cdots$ & $\ldots$ \\
\hline$e_{m}$ & $A_{I m}$ & $A_{2 \mathrm{~m}}$ & $\cdots$ & $A_{k n}$ \\
\hline
\end{tabular}

Thus, the number of memory states of an MFIS can be represented in a matrix form, where the rows of the matrix determine the blocks of $\pi_{\text {s }}$ states that are remembered for the corresponding input signals retaining $e_{i}(\Delta)$, and the matrix columns are the states $\mu_{i}$ blocks that are set by the corresponding setting $x_{i}(t)$ input signals. A single-valued transition from the state $a_{i}$ in the state $a_{\text {r }}$ of the $\pi_{\text {s }}$ state block (in the matrix row) is performed under the influence of the input signals establishing the $x_{i}(t)$ and the enlarged transition to the new state in the $\mu \mathrm{i}$ state block - under the influence of the preserving $e(\Delta)$ Input signals trigger circuits and SMEs have only one block of $\pi$ states. This characteristic indicates that monofunctional memory circuits (triggers and SMEs) is a particular case of the MFIS. Consider tables of tasks for monofunctional (Table 1) and multifunctional (Table 2) memory schemes, which supports this conclusion.

The function $\varphi$ of the outputs in the MFIS depends on the setting input word $p=x, e$, which establishes and stores the states $a$. In this case, two cases are possible: when the function $\delta_{0}$ of conservation of state (3) or the function $\delta$ of the coarse transition (5) is realized.

The function $\varphi_{1}$ of the outputs, which depends on the state of the automaton $a(\Delta-1)$ and sets the input signal $x(t)$, characterizes the first-order automaton and in the vector form has the form:

$$
y(t)=\varphi_{1}[a(\Delta-1), x(t)] .
$$

The function $\varphi_{2}$ of the outputs depends on the state $a(t)$ of the state and on the stored $a(\Delta)$ state, which characterizes the automaton of the second kind and in the vector form has the form:

$$
y(T)=\varphi_{2}[a(t), a(\Delta)] ; a(t)=a(\Delta),
$$

or

$$
y(T)=\varphi_{2}[a(T)], a(T)=a(t) \mathrm{U} a(\Delta) .
$$

The function $\varphi_{2}$ outputs ensures that the set state $a(T)$ is maintained for a continuous cycle time $T$.

The function $\varphi_{3}$ of the outputs in the MFIS depends on the set $a(\mathrm{t})$ state and on the stored input signal $e(\Delta)$ and which can be represented in vector form as follows:

$$
y(\Delta)=\varphi_{3}[a(t), e(\Delta)] .
$$

The function $\varphi_{3}$ outputs characterizes automata of the third kind, which determines the direction of the output signal $y(\Delta)$ as a function of the saving signal $e(\Delta)$.

\section{Description of elementary multifunctional memory circuits}

The most famous binary elementary memory circuits are triggers based on the $R S$ trigger [4-6], which is a particular case of the MFIS [2]. Such schemes are characterized by three main parameters: $M$ - the number of stable states a, each of which corresponds to a certain output signal of the memory circuit $y_{2}(T) ; r_{x}-$ is the number of setting input signals $x(t)$ and $r$ is the number of conserved input signals $e(\stackrel{e}{\Delta})$, 
which are formally associated with the MFIS structure. The basic MFIS structures created on NAND or NOR logical elements are called basic automata (BA), and their parameters are determined by the proposed formulas.

Memory circuits consist of groups BA(elements), the groups of which are interconnected by feedback circuits, and the characteristic number of memory states $K_{i}$ in the $i$-th group is determined by the formula (4). Thus, the number $M$ of stable states $a(\Delta)$ of the MFIS stored under the influence of the input signals retaining $e(\Delta)$ is determined by the formula:

$$
M=\sum_{i=1}^{m} K_{i}
$$

where $K_{i}-$ is the characteristic number of states in the ith group of the MFIS.
The total number $r_{x}$ of different sets of $x(t)$ input signals set by the MFIS is given by:

$$
r_{x}=M+1,
$$

where $M-$ is the number of stable states of the MFIS, which are conserved;

1 - is an additional set of the input signal that sets $x_{p}(\mathrm{t})$, which uniquely establishes the state $a(\mathrm{t})$, which is not conserved for any set of the MFIS stored $e(\Delta)$ input signal. Such a set of $x_{p}(\mathrm{t})$ input signal in deterministic devices is forbidden [5].

The total number $r$ of different sets of $\mathrm{e}$ $(\Delta)$ inputs that are stored in the MFIS can be defined by the formula

$$
r_{e}=\prod_{i=1}^{m} K_{i}
$$

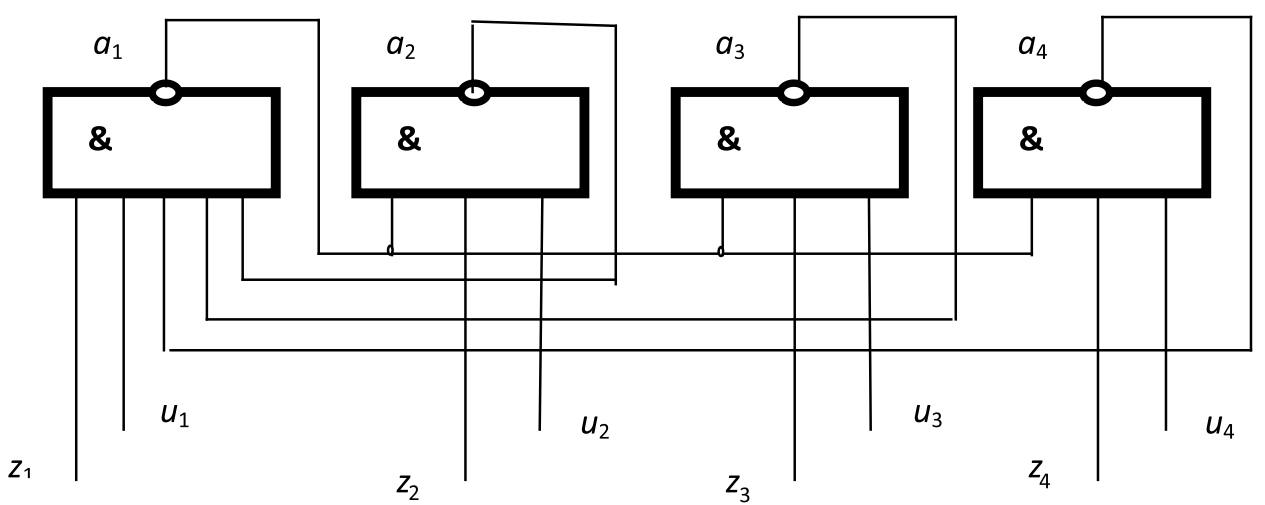

Fig. 1. MFIS class L on the elements of the AND-NOT

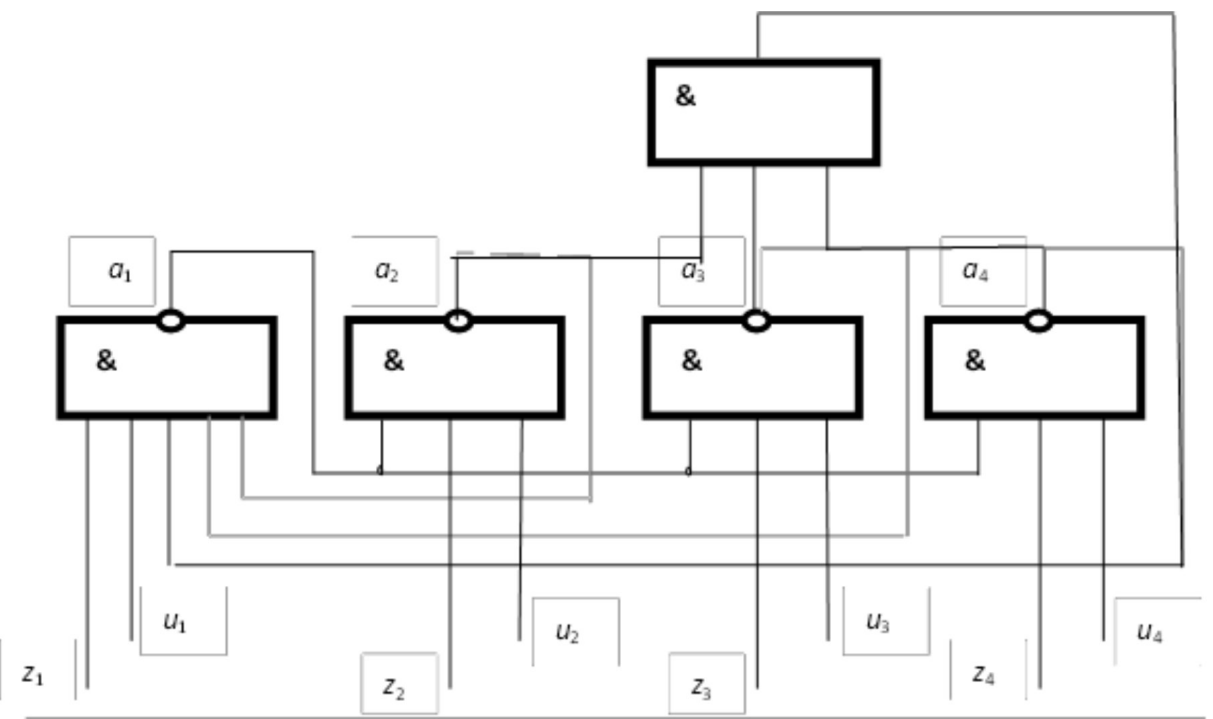

Fig. 2. MFIS class LM on the elements of the AND-NOT 
Thus, it becomes clear that two sets of input signals are required for the operation of multifunctional circuits: setting and saving $e(\Delta)$, which enter one clock cycle of $T(T=t+\Delta)$. A feature of these two sets of input signals is that the setting xi $(\mathrm{t})$ absorbs the preserving $e_{j}(\Delta)$ if they arrive at the same hour.

$$
x_{i}(t)=x_{i}(t) \bigcup e_{j}(t) .
$$

Logical elements of one group are connected by their output nodes to the input nodes of all logical elements of other groups. Other inputs of logic elements (at least two) that connect to the corresponding input MFIS buses are used for setting and storing input signals. The output nodes of the logic elements are connected to the output line of the MFIS.

Let us consider an example of the synthesis of the functional scheme of an MPSE on the elements AND-NOT of two classes $L$ and $L^{M}$.

An important functional advantage of MFIS over flip-flops and SMBs is the possibility of reconstructing the structure of the memory states during operation for one machine clock $T$, otherwise it can be said that an increase in the degree of freedom from 1 to re is determined.

\section{Conclusion}

Multifunctional memory circuits have the advantage over the basic binary memory scheme of the $R S$-flip-flop. MISPs reduce the hardware costs per stored state; increase the functionality by realigning the structure of state storage and simultaneously processing the levels of hierarchical information represented as sets of input-preserving signals $e(\Delta)$ as general and local information represented as sets of input signals $x(t)$ in one machine clock cycle $T$.

\section{References}

1. Cassidy A.S., P. Merolla, J.V. Arthur, S. Esser, B. Jackson, R. Alvarez-Icaza, P. Datta, J. Sawada, T.M. Wong, V. Feldman, A. Amir, D. Rubin, F. Akopyan, E. McQuinn, W. Risk, and D.S. Modha, "Cognitive computing building block: A versatile and efficient digital neuron model for neurosynaptic cores," in International Joint Conference on Neural Networks (IJCNN). IEEE, 2013.

2. Nikitin A.V. A little about the memristor .. // "Academy of Trinitarianism”, M., El No. 77-6567, publ.19539, 12.09.2014.

3. IBM is working on the creation of a "computer brain" http: // www. cybersecurity.ru/it/82336.html.

4. Towards the creation of a cognitive computer http:// itc.ua/ articles / na_puti_k_ sozdaniyu_kognitivnogo_kompyutera 43475? Page $=1$ Paul Merolla1, John Arthur1, Filipp Akopyan1;2, Nabil Imam2, Rajit Manohar2, Dharmendra S. Modha1. A Digital Neurosynaptic Core Using Embedded Crossbar Memory with $45 \mathrm{pJ}$ per Spike in $45 \mathrm{~nm}$. -1IBM Research Almaden, 2Cornell University, 2014

5. IBM Research: Neurosynaptic chips. Watson.ibm.com. Retrieved May 11, 2014, from http://researchweb.watson.ibm. com/cognitive-computing/ neurosynaptic-chips.shtml.

6. Marakhovsky L.F. Expansion of the fundamentals of the modern element base of computer systems // "Academy of Trinitarianism", Moscow, El. No. 77-6567, publ.

7. Marakhovsky L.F. Multifunctional memory circuits. Kiev: USiM - № 6. - 1996. - P. 59-69. 


\title{
MULTICRITERIA OPTIMIZATION AND SIMULATION FOR THE DESIGN OF MACHINES
}

\author{
Matusov L.B.
}

Russia Academy of Science, Institute of Machines Science named after A.A. Blagonravov, Moscow, e-mail: matusoff.l@yandex.ru

\begin{abstract}
The construction a feasible solution set with a given accuracy is a main problem in engineering optimization and simulation. In order to construct the feasible solution set, a method called the Parameter Space Investigation (PSI) has been created and successfully integrated into various fields of industry, science, and technology. The methods of approximation of the feasible solution set on the basis of the PSI method are considered in our paper The issues of the estimation of the PSI method convergence rate, the approximation of the feasible solution set are described. These results is applied here for solving the multicriteria simulation (identification) problems of machines design.
\end{abstract}

Keywords: feasible solution set, Pareto optimal set, approximation, identification, adequate vectors, identified vectors

\section{The Main Definitions}

Let us consider a artificial intelligence or mechanical system, whose opera

tion is described by a system of equations or whose performance criteria may be directly calculated. We assume that the system depends on $r$ design variables $\alpha \alpha_{1}, \ldots, \alpha_{r}$ representing a point $\alpha=\left(\alpha_{1}, \ldots, \alpha_{r}\right)$ of an $r$-dimensional space . In the general case, one has to take into account the design variable constraints, the functional constraints, and the criteria constraints [1]. There also exist particular performance criteria, such as productivity, materials consumption, efficiency and so on. It is desired that, with other things being equal, these criteria, denoted by $\Phi_{v}(\alpha), v=1, \ldots, k$, would have the extreme values. For simplicity, we assume that $\Phi_{v}(\alpha)$, are to be minimized.

In order to avoid situations in which the expert regards the values of some criteria as unacceptable, we introduce the criteria constraints

$$
\Phi_{v}(\alpha) \leq \Phi_{v}^{* *}, v=1, \ldots, k
$$

where $\Phi_{v}^{* *}$ is the worst value of criterion $\Phi_{v}(\alpha)$ to which the expert may agree.

The criteria constraints differ from the functional constraints in that the former are determined when solving a problem and, as a rule, are repeatedly revised. Hence, reasonable values of $\Phi_{v}^{* *}$ cannot be chosen before solving the problem.

The design variable constraints, the functional constraints and the criteria constraints define the feasible solution set $D[1]$.

Let us formulate one of the basic problems of multicriteria optimization.

Definition 1. A point $\alpha^{0} \in D$, is called the Pareto optimal point if there exists no point $\alpha \in D$ such that $\Phi_{v}(\alpha) \leq \Phi_{v}\left(\alpha^{0}\right)$ for all $v=1, \ldots, k$, and $\Phi_{v_{0}}(\alpha)<\Phi_{v_{0}}\left(\alpha^{0}\right)$ for at least one $v_{0} \in\{1, \ldots, k\}$.

A set $P \subset D$ is called the Pareto optimal set if it consists of Pareto optimal points. When solving the problem, one has to determine a design variable vector point $\alpha^{0} \in P$, which is most preferable among the vectors belonging to set $P$.

The Pareto optimal set plays an important role in vector optimization problems because it can be analyzed more easily than the feasible solution set and because the optimal vector always belongs to the Pareto optimal set, irrespective of the system of preferences used by the expert for comparing vectors belonging to the feasible solution set.

\section{Construction of the Feasible Solution Set With Prescribed Accuracy \\ The Estimation of the Convergence Rate}

The algorithm discussed in [1] allows simple and efficient identification and selection of feasible points from the design variable space. However, the following question arises: How can one use the algorithm to construct a feasible solution set $D$ with a given accuracy? The latter is constructed by singling out a subset of $D$ that approaches any value of each criterion in region $\Phi(D)$ with a predetermined accuracy. Let $\varepsilon$, be an admissible (in the expert's opinion) error in criterion $\Phi$. By $\varepsilon$ we denote the error set $\left\{\varepsilon_{v}\right\}, v=1, \ldots, k$. We will say that region $\Phi(D)$ is approximated by a finite set $\Phi\left(D_{\varepsilon}\right)$ with an accuracy up to the set $\varepsilon$, if for any vector $\alpha \in D$, there can be found a vector $\beta \in D_{\varepsilon}$ such that

$$
\left|\Phi_{v}(\alpha)-\Phi_{v}(\beta)\right| \leq \varepsilon_{v}, v=1, \ldots, k .
$$

We assume that the functions we shall be operating with are continuous and satisfy the 
Lipschitz condition $(L)$ formulated as follows: For all vectors $\alpha$ and $\beta$ belonging to the domain of definition of the criterion $\Phi_{v}(\alpha)$, there exists a number $L_{v}$ such that

$$
\left|\Phi_{v}(\alpha)-\Phi_{v}(\beta)\right| \leq L_{v} \max _{j}\left|\alpha_{j}-\beta_{j}\right| .
$$

In other words, there exists $L_{v}^{\prime}$ such that

$$
\left|\Phi_{v}(\alpha)-\Phi_{v}(\beta)\right| \leq L_{v}^{\prime} \sum_{j=1}^{r}\left|\alpha_{j}-\beta_{j}\right| .
$$

We will say that a function $\Phi(\alpha)$ satisfies the special Lipschitz condition $(S L)$ if for all vectors $\alpha$ and $\beta$ there exist numbers $L_{v}^{j}$, $j=1, \ldots, r$ such that

$$
\left|\Phi_{v}(\alpha)-\Phi_{v}(\beta)\right| \leq \sum_{j=1}^{r} L_{v}^{j}\left|\alpha_{j}-\beta_{j}\right|
$$

where at least some of the $L_{\mathrm{v}}^{j}$ are different.

Let $\left[L_{v}\right]$ (or $\left[\sum_{j=1}^{r} L_{\mathrm{v}}^{j}\right]$ ) be a dyadic rational number exceeding $L_{v}$ (or $\sum_{j=1}^{r} L_{v}^{j}$ ) and sufficiently close to the latter, and let $\left[\varepsilon_{v}\right]$ be the maximum dyadic rational number that is less than or equal to $\varepsilon_{v}$ and whose numerator is the same as that of $\left[L_{v}\right]$ (or $\left.\left[\sum_{j=1}^{r} L_{v}^{j}\right]\right)$. A dyadic number is a number of the form $p / 2^{m}$, where $p$ and $m$ are natural numbers.

Theorem 1. If criteria $\Phi_{v}(\alpha)$ are continuous and satisfy either the Lipschitz condition or the special Lipschitz condition, then to approximate $\Phi(D)$ to within an accuracy of $\varepsilon$ it is sufficient to have

$$
\max _{v} 2^{\tau}\left(\frac{\left[L_{v}\right]}{\left[\varepsilon_{v}\right]}\right)^{r} \text { or } \max _{v} 2^{\tau}\left(\frac{\left[\sum_{j=1}^{r} L_{v}^{j}\right]}{\left[\varepsilon_{v}\right]}\right)^{r}
$$

points of the $P_{\tau}$ net [2]. (For details on $\tau$ and the $P_{\tau}$ net, see [1].)

The number of points needed to calculate the performance criteria in this estimate may be so large that the speed of computers may prove to be inadequate. This difficulty may be overcome by developing "fast" algorithms dealing not with an entire class of functions but instead taking into account the features of the functions of each concrete problem. Let the Lipschitz constants $L v=1, \ldots, k$, be specified, and let $N_{1}$ be the subset of the points of $D$ that are either the Pareto optimal points or lie with- in the $\varepsilon$-neighborhood of a Pareto optimal point with respect to at least one criterion. In other words, $\quad \Phi_{v}\left(\alpha^{0}\right) \leq \Phi_{v}(\alpha) \leq \Phi_{v}\left(\alpha^{0}\right)+\varepsilon_{v}$, where $\alpha^{0} \in P$, and $P$ is the Pareto optimal set. Also, let $N_{2}=D \backslash N_{1}$ and $\bar{\varepsilon}_{\mathrm{v}}>\varepsilon_{\mathrm{v}}$.

Definition 2. A feasible solution set $\Phi(D)$ is said to be normally approximated if any point of set $N_{1}$ is approximated to within an accuracy of $\varepsilon$, and any point of set $N_{2}$ to within an accuracy of $\bar{\varepsilon}$.

In next theorem the algorithm of approximation is given [3].

Theorem 2. If criteria $\Phi_{v}(\alpha)$ are continuous and satisfy either the Lipschitz condition or the special Lipschitz condition, then there exists a normal approximation $\Phi\left(D_{\varepsilon}\right)$ of a feasible solution set $\Phi(D)$.

\section{Multicriteria Simulation}

In this section we will describe applying above mention results to solving a multicriteria identification problems of artificial intelligence, medical engineering and mechanical systems. As a rule these applied identification problems have been treated as single-criterion problems. In the majority of conventional problems, the system is tacitly assumed to be in full agreement with its mathematical model. However, for complex engineering systems we generally cannot assert a sufficient correspondence between the model and the object. This does not permit us to use a single criterion to evaluate the adequacy. In multicriteria identification problems there is no necessity of artificially introducing a single criterion to the detriment of the physical essence of the problem.

Parametric identification is reduced to finding numerical values of the equation coefficients, based on the realization of the input and output processes. In doing so, frequency responses, transfer functions, and unit step functions are often used. A number of problems require preliminary experimental determination of the basic characteristics of a system (e.g., the frequencies, shapes, and decrements of natural oscillations). In identification problems we will deal with particular adequacy (proximity) criteria. By adequacy (proximity) criteria we mean the discrepancies between the experimental and computed data, the latter being determined on the basis of the mathematical model. For example, when identifying the parameters of the dynamical model of an automobile it is necessary to take into account such important indices (particular criteria) as vibration accelerations at all characteristic points of the driver's seat, driver's cab, frame, and engine; vertical dynamical reactions at contact 
areas between the wheels and the road; relative (with respect to the frame) displacements of the cab, wheels, engine, etc.

In all basic units of the structure under study we experimentally measure the values of the characteristic quantities of interest (e.g., displacements, velocities, accelerations, etc.). At the same time we calculate the corresponding quantities by using the mathematical model. As a result, particular adequacy (proximity) criteria are formed as functions of the difference between the experimental and computed data. Thus we arrive at a multicriteria problem. The multicriteria consideration makes it possible to extend the application area of the identification theory substantially.

\section{Defining the Feasible Solution Set and the Adequate Vectors}

We denote by $\Phi_{v}^{c}(\alpha), v=\overline{1, k}$ the indices (criteria) resulting from the analysis of the mathematical model that describes a physical system, where $\alpha=\left(\alpha_{1}, \ldots, \alpha_{r}\right)$ is the vector of the parameters of the model. Let $\Phi_{v}^{\exp }$ be the experimental value of the criterion measured directly on the prototype. The experiment is assumed to be sufficiently accurate and complete. Suppose there exists a mathematical model or a hierarchical set of models describing the system behavior. Let $\Phi=\left(\left\|\Phi_{1}^{c}-\Phi_{1}^{\exp }\right\|, \ldots,\left\|\Phi_{k}^{c}-\Phi_{k}^{\exp }\right\|\right)$, where $\|$.$\| is a particular adequacy (closeness,$ proximity) criterion[4]. This criterion, as has already been mentioned, is a function of the difference (error) $\Phi_{v}^{c}-\Phi_{v}^{\text {exp }}$. Very often it is given by $\left(\Phi_{v}^{c}-\Phi_{v}^{\exp }\right)^{2}$ or $\left|\Phi_{v}^{c}-\Phi_{v}^{\exp }\right|$. If the experimental values $\Phi_{v}^{\exp }, v=\overline{1, k}$ are measured with considerable error, then the quantity $\Phi_{v}^{\exp }$ can be treated as a random variable. If this random variable is normally distributed, the corresponding adequacy criterion is expressed by $M\left\{\left\|\Phi_{v}^{c}-\Phi_{v}^{\exp }\right\|\right\}$, where $M\{\|\cdot\|\}$ denotes the mathematical expectation of the random variable $\|\cdot\|$. For other distribution functions, more complicated methods of estimation are used, for example, the maximum likelihood method.

We formulate the following problem by comparing the experimental and calculation data, determining to what extent the model corresponds to the physical system, and finding the variables of the model. In other words, it is necessary to find the vectors $\alpha^{i}$ satisfying the design variable constraints, the functional constraints, and the next criteria constraints

$$
\left\|\Phi_{v}^{c}\left(\alpha^{i}\right)-\Phi_{v}^{\exp }\right\| \leq \Phi_{v}^{* *} .
$$

These constraints define the feasible solution set $D_{a}$. Here, $\Phi_{v}^{* *}$ are criteria constraints that are determined in the dialogue between the researcher and a computer. To a considerable extent, these constraints depend on the accuracy of the experiment and the physical sense of the criteria.The formulation and solution of the identification problem are based on the parameter space investigation method. We specify the values $\Phi_{v}^{* *}$ and find vectors meeting the design variable constraints, the functional constraints, and the criteria constraints. The vectors $\alpha_{i}^{i}$ belonging to the feasible solution set $D_{\alpha}$ will be called adequate vectors. The restoration of the parameters of a specific model is the main purpose and essence of multicriteria parametric identification. Having performed this procedure for all structures (mathematical models), we thus carry out multicriteria structural identification.

The vectors $\alpha_{i d}^{i}$ that belong to the set of adequate vectors and have been chosen by using a special decision making rule will be called identified vectors.

The role of the decision making rule is often played by nonformal analysis of the set of adequate vectors. If this analysis separates several equally acceptable vectors $\alpha_{i d}^{i}$, the solution of the identification problem is nonunique.

The identified vectors $\alpha_{i d}^{i}$ form the identification domain $D_{i d}=\bigcup \alpha_{i d}^{i}$. Sometimes, by carrying out additional physical experiments, revising constraints $\Phi_{v}^{* *}$ etc., one can reduce the domain $D_{i d}$ and even achieve the result that this domain contains only one vector. Unfortunately, this is far from usual. Nonunique restoration of variables is a recompense for the discrepancy between the physical object and its mathematical model, incompleteness of physical experiments, etc.

If a mathematical model is sufficiently good (i.e., it correctly describes the behavior of the physical system), then multicriteria parametric identification leads to a nonempty set $D_{\alpha}$. The most important factors that can

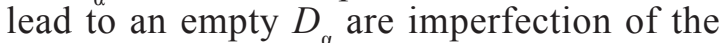
mathematical model and lack of information about the domain in which the desired solutions should be searched for.

The search for the set $D_{\alpha}$ is very important, even in the case where the results are not promising. It enables the researcher to judge the mathematical model objectively (not only intuitively), to analyze its advantages and drawbacks on the basis of all proximity criteria. 


\section{The Search For Identified Solutions With Prescribed Accuracy}

Let $\varepsilon_{v}(v=\overline{1, k)}$ characterize the desired accuracy of the correspondence between the physical system and its mathematical model with respect to the criterion $\Phi_{v}^{c}$ (i.e., the inequality $\left\|\Phi_{v}^{c}-\Phi_{v}^{\exp }\right\|<\varepsilon_{v}$ must hold). Then the values of all criteria restoring the experimental characteristics with a prescribed accuracy can be found through the approximation of the adequacy criteria range.

In multicriteria identification, we are interested not only in values of adequacy criteria, but also in values of variables. For example, let $\alpha$ and $\beta$ be vectors giving "good" values to adequacy criteria, i.e., $\Phi(\alpha) \approx \Phi(\beta)$, while at the same time the vectors $\alpha$ and $\beta$ are significantly different. In this case, if there is no additional information available for making the choice between the vectors $\alpha$ and $\beta$, we can regard $\Phi(\alpha), \Phi(\beta)$ as being equally adequate to the physical experiment. However, the researcher must keep in mind all vectors corresponding to good values of adequacy criteria. This is explained by the following considerations. In practice, it is usually impossible to formalize all requirements imposed on a physical or engineering system. If we take into account only one of two vectors corresponding to approximately the same values of adequacy criteria, we may possibly lose the better vector with respect to nonformalized criteria. Suppose we have succeeded in meeting all the demands of the system. In this case, we should consider all the aforementioned vectors when working with the mathematical model after completing the identification. Suppose we are to optimize the parameters of the model with respect to some criteria. If we have eliminated one of two equally adequate vectors, the dropped vector can turn out to be the preferred one with regard to the performance criteria. Taking into account these considerations, we can modify the definition of the solution of the multicriteria identification problem.

We denote by $V \Phi(P)$ an $\varepsilon$-neighborhood of the Pareto optimal set $\Phi(P)$ in the space of adequacy criteria. It is reasonable to define the solution of the multicriteria identification problem as a set $W$ of all variable vectors $\alpha$ belonging to the feasible solution set $D_{\alpha}$ and satisfying the inclusion $\Phi(\alpha) \in V_{\varepsilon}(\Phi(P))$.

As a result of nonformal analysis of the set $W_{\varepsilon}$, the researcher can choose the most preferred vectors.

Let us show how one can solve the problem by using the parameter space investigation method.

The solution algorithm is based not only on the approximation of the criteria space, but also on the approximation of the variable space. Let $\Phi_{k+j}(\alpha)=\alpha_{j}$, and $\delta_{k+j}$ be the admissible error for the variable $\alpha_{i}$, where $k$ is the number of adequacy criteria. By using the algorithm of Theorem 2, let us construct the approximation of the set $D_{\alpha}$ to the accuracy $\delta=\left\{\delta_{k+j}\right\}, j=\overline{1, r}$, and the approximation of its image $\Phi(D)$, to the accuracy $\varepsilon=\left\{\varepsilon_{v}\right\}, v=\overline{1, k}$. The fact that we have declared the variables $\alpha_{i}$ as criteria $\Phi_{k+j}$, enables us to approximate $\Phi\left(\dot{D}_{\alpha}\right)$ and $D_{\alpha}$ simultaneously. In this case, the $\operatorname{set}^{\alpha} V \Phi(P)^{\alpha}$ can be approximated to the accuracy $\varepsilon$, and any vector of $D_{a}$ can be determined to the accuracy $\delta$ Using the approximations of $D_{\alpha}$, and $\Phi\left(D_{\alpha}\right)$ we can find the set $W_{\varepsilon}$, and thus obtain the solution of the multicriteria identification problem.

Let us call the set $W_{\varepsilon}$ the set of $\varepsilon$-adequate vectors. The vectors $\alpha_{\text {id }}$ that belong to the set of $\varepsilon$-adequate vectors and are determined with the help of a decision-making rule will be called identified vectors. The set $D_{i d}$ of all identified vectors is called the identification set.

\section{References}

1. Sobol' I., Statnikov R. Selecting Optimal Parameters in Multicriteria Problems. 2nd edn. Znanie, Moscow, (2006).

2. Statnikov R., Matusov J. Multicriteria Optimization and Engineering.Chapman and Hall, New York, 1995.

3. Statnikov R., Matusov J. Use of P- nets for the approximation of the Edgeworth-Pareto set in multicriteria optimization. JOTA, V. 91, (3), pp. 543-560(1996).

4. Statnikov R, Matusov J. Multicriteria Analysis in Engineering. Cluever, Dordrecht, 2002.

The work is submitted to the International Scientific Conference "Computer simulation in science and technology", UAE (Dubai), 4-10 March 2018, came to the editorial office on 10.10.2018. 